A Journal of Agricultural Science Published by the California Agricultural Experiment Station

\title{
THE RED SCALE AND ITS INSECT ENEMIES
}

\author{
HAROLD COMPERE
}

UNIVERSITY OF CALIFORNIA - BERKELEY, CALIFORNIA 
The red scale, Aonidiella aurantii (Mask.), was first noted in California in 1877. Two years later, introduction of its natural enemies was first suggested, and since 1891 nearly all the citrus-growing regions of the world have been searched for parasites or predators that would control it. At various times and in various countries claims have been made that parasites or predators or a combination of the two controlled red scale. True, there are countries, particularly China, where red scale seldom injures citrus seriously, or even rarely infests this host. This has been attributed sometimes to one, sometimes to another, or to a combination, of its insect enemies; but the evidence is not sufficiently convincing that its innocuousness in such regions is due solely to these enemies. All the factors need to be weighed, especially host-plant relations of red scale, which are complex and often contradictory from one country to another. The red scale is not a serious citrus pest in Florida, where insect enemies are not considered to be a factor, except by the most partisan adherents of biological control.

All or nearly all of the insects claimed to control red scale anywhere have been imported into California, and some of them have become established; yet the red scale continues to rate as the most important scale pest of citrus in this state. In some seasons and in some limited areas a high percentage of the scales may be destroyed by parasites or predators, but at least up to 1948 the growers usually found it necessary to resume chemical means of control to protect the fruits and save the trees from injury. It is too early to appraise the results of some work done since 1948.

Red scale was known as a pest of citrus in Australia much earlier than in California, and it may have been in South Africa even by 1857. It is a serious citrus pest in both countries, and attempts to find a biological control for it have followed a course similar to that in California. The consensus of Australian workers is that the scale is not controlled by its insect enemies there. Recently, on the other hand, South African workers have claimed that it is controlled in that country by a combination of parasites and predators if chemical control is omitted.

In the long search for enemies of red scale, much effort has been wasted because of inadequate systematics. Up to 1937 a misleading classification of red scale and a failure to find any structural difference between it and two of its close relatives caused confusion. Further confusion and repetitious effort has been caused by similar trouble in the systematics of its insect enemies.

In assaying the chances of finding a natural enemy to control red scale in citrus groves, it must be borne in mind that horticultural varieties of citrus differ radically from the original wild species and are grown commercially under conditions different from the humid tropics where the wild species are native. 


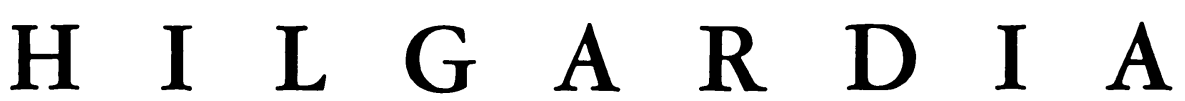 \\ A Journal of Agricultural Science Published by \\ the California Agricultural Experiment Station}

\begin{tabular}{lll}
\hline VoL. 31 & NOVEMBER, 1961 & No. 7 \\
\hline
\end{tabular}

\section{THE RED SCALE AND ITS INSECT ENEMIES \\ HAROLD COMPERE ${ }^{2}$}

The Red scale, Aonidiella aurantii (Maskell), has proved to be the most injurious and costly insect infesting citrus in parts of California, Australia, and South Africa. Its control by the introduction of insect enemies has been the most sought goal in applied biological control for more than 70 years. This is an account of the attempts to control red scale biologically from 1879 to 1948. From the vantage point of today, it is possible to appraise rather accurately the work done prior to 1948; but only time and perspective will make possible an accurate appraisal of the work done since then. The history of the yellow scale is included because it is almost inextricably interwoven with that of the red scale.

This paper expresses a pessimistic view of the possibilities for biological control of the red scale. For other views the reader is referred to papers cited in the second paragraph of the Summary and Conclusions and to other papers on red scale and its parasites by the same authors.

Conflicting and often contradictory reports have been made concerning the red scale and its enemies, beginning with its first appearance in California as a pest of citrus. Today, as in the past, there is a diversity of opinions concerning it, and especially with respect to the role of insect parasites and predators in its control. This article will not settle the issues; but it can be of value if a knowledge of the past helps to prevent repetitious work and mistakes in the future. Probably no insect demonstrates better than the red scale the importance of sound classifications and exact identifications, the unreliability of prophecies which on the basis of findings in one area attempt to foretell what will be found in another area, the consequences of unrestrained enthusiasm for the biological method of control, and last but not least, the importance of evaluating all the factors that affect the plants and insects as living organisms.

\section{EARLY REFERENCES TO RED SCALE}

It has been generally believed that the red scale, Aonidiella aurantii, was introduced into California first in 1879 on six lemon trees brought from Australia by Matthew Keller and planted in one of the orange groves in the city

\footnotetext{
${ }^{1}$ University of California Citrus Research Center Paper No. 1315. Submitted for publication February 21, 1957.

${ }^{2} \mathrm{Mr}$. Compere is Specialist in Biological Control in the Citrus Experiment Station, Riverside.
} 
of Los Angeles. This is the account given by Coquillett (1892). But there is evidence to show that the red scale was well established in southern California and had earned a reputation as a killer of citrus trees as early as 1877 . It was mentioned in January 1878 in the report of a committee of the Southern California Horticultural Society. This report was issued to counteract publicity that was considered unfavorable to the citrus industry. The unfavorable publicity was an editorial article by L. M. Holt (fig. 1) published in October 1877 in the journal of the same society. Holt's editorial follows:

The year 1877 has been prolific in the development of enemies to the culture of citrus trees in southern California. Heretofore it has been the tendency to suppress the actual existence of diseased trees or anything else having a tendency to come in conflict with the successful cultivation of orange groves and lemon and lime orchards. The reasons for this, of course, have been of a pecuniary nature, but at present the enemies to the orange are too apparent to be hidden from view.

It is not our intention at present to discuss causes and propose remedies, hut simply to call attention to a few items that will bear a close investigation and careful study by all those who would successfully cultivate the orange.

The scale bug is everywhere and is known to all men conversant at all with the citrus family of trees. Some localities are more free from the scale bug than others, but none are entirely free. It is generally conceded that trees near the coast suffer more from this pest than those localities in the inland valleys, but even in the most favored localities many trees are affected....

... It is the duty of the Horticultural Society to investigate these diseases, and it is the duty of every orange grower in the state to watch carefully his trees and give the public any information he may have in regard to the cause and cure of any ailments he may find in his orchard. (Holt, 1877.)

The Society's committee was reassuring. They reported that the brown scale was not a serious enemy of oranges and was decreasing, and continued:

The committee found no other enemy of the orange tree worthy of note, except in one case where they came across an orchard in which a few trees were affected with the red scale bug. [Italies are the present writer's.] This bug is more serious in its work than the brown scale bug, and if let alone it eventually kills the trees attacked. It spreads slowly, however, and is easily exterminated, and hence is not to be feared. The committee found one case where the red scale bug had attacked a few trees in a young orchard. (Southern California Horticultural Society, 1878.)

Although the yellow scale, Aonidiella citrina (Coquillett), was present in the San Gabriel district of southern California as early as 1872, there can be little question about the identity of the "red scale bug" of the committee's report since it killed young trees, and the yellow scale never does this.

History shows that there was good cause for the growers to be alarmed and that the red scale reproduced and spread at an explosive rate. For an explanation of the committee's attempt to quiet the alarm raised by Holt, it is necessary to examine briefly the background of its members.

Holt was a member of the committee that issued this report. There are reasons to suspect that he wrote impulsively and published the alarm without first consulting his associates, and that he was not prepared to withstand their opposition. In 1875 he managed the company that founded Pomona, and in this venture was associated with Thomas A. Garey.

The other members of the committee were DeBarth Shorb, Garey, and Milton Thomas. Shorb was the president of the society and the owner of a 


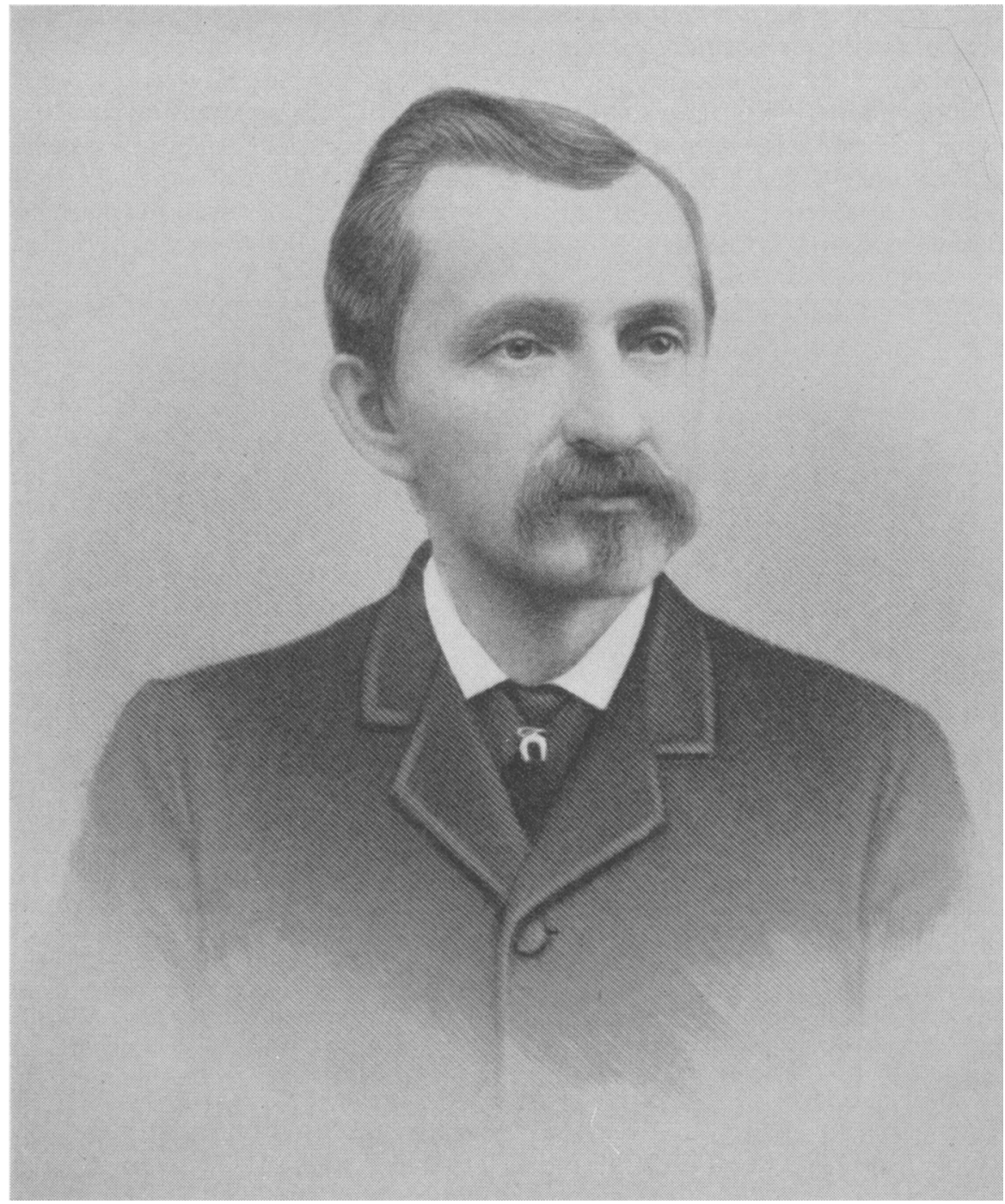

Fig. 1.-L.M. Holt (1840-8), school teacher, journalist, promoter, and manager of citrus properties, who in 1877 publicly alerted orchardists to the seriousness of citrus-infesting scale insects in southern California.

large tract of land where the eity of Alhambra is now located. This land was then being subdivided and offered to prospective orange growers in ten-acre plots. Garey was known as the "orange king." He owned and operated the largest nursery in southern California. Thomas was a nurservman with property adjoining that of Garey. According to an unpublished article written by my father, George Compere, the first infestation of cottonycushion scale, Icerya purchasi Maskell, found in southern California was on a few plants in Garey's nursery; and when it was called to Garey's attention 
he became alarmed for the possible damage that a knowledge of this infestation might do his business rather than for any injury the insects might do the plants. ${ }^{3}$

The committee report was not the end of attempts to prevent alarms about citrus pests. It seems apparent that information about the early infestations was withheld from J. Henry Comstock when he visited California in 1880 and from Daniel W. Coquillett, a U. S. Department of Agriculture entomologist who worked in California from 1882 to 1893.

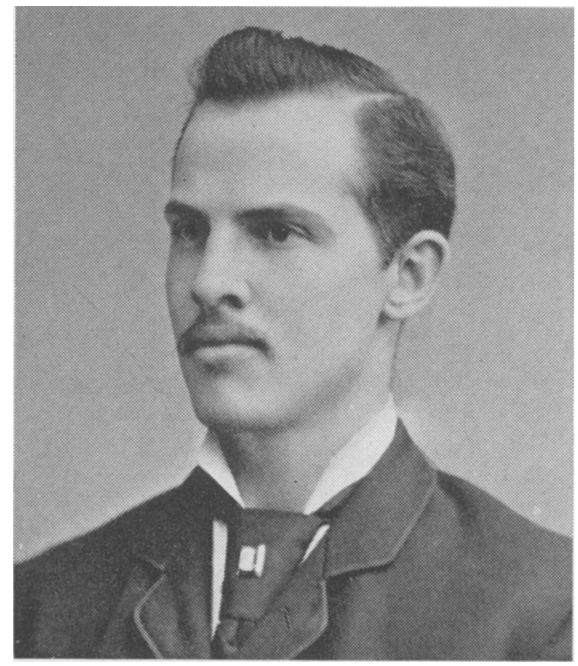

Fig. 2.-William Harris Ashmead (18551907 ), world-renowned hymenopterist, who studied citrus-infesting insects in Florida and in 1879 called attention to the importance of natural enemies in controlling them. (Copy of photograph taken about 1890 - from the National Archives).

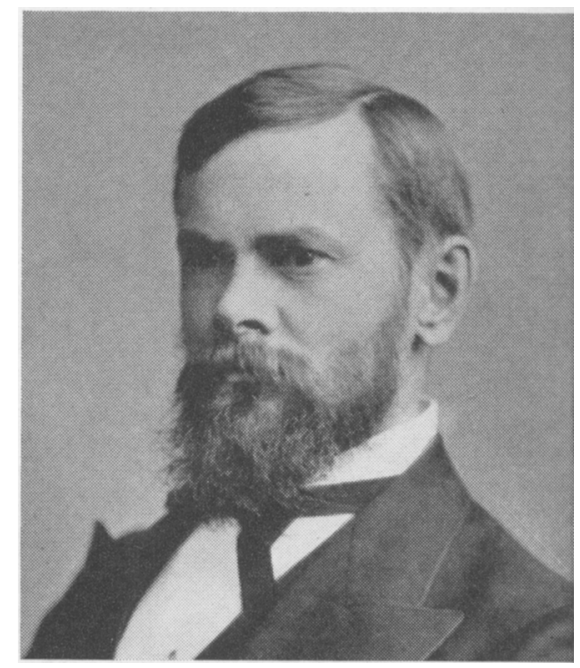

Fig. 3.-John Henry Comstock (18491931), famous pioneer entomologist who made a scientific study of the scale insects in California in the summer of 1880, and reported that the red scale was more to be feared than any other citrus pest. (From a photograph taken about 1881-from the National Archives).

Attempts to identify the red scale began in 1879, when an editor of the Pacific Rural Press sent a sample of the insect to William H. Ashmead (fig. 2) in Florida and another to Comstock in Washington for identification. Comstock (1880) reported that in all probability it was an undescribed species, closely related to Aspidiotus ficus [=Chrysomphalus aonidum (Linn.)], which had lately become extremely common in Florida; and in the same article Ashmead reported it to be the same as that prevalent in Florida. Believing the two species to be the same. Ashmead (1880a) expressed a wish to learn its geographic distribution and habitat, and wanted to know whether

${ }^{3}$ A typescript entitled "George Compere's Reminiscence of the White Cottony Cushion Scale, Icerya purchasi Maskell, in California and Observations of Same in Other Countries," together with other letters and unpublished reports referred to in this paper, which have been in my possession, have been placed in the archives of the Department of Biological Control, Citrus Experiment Station, University of California, Riverside. Similar material that has been in the Department files has also been placed in these archives. 
it had been imported into California from some foreign country, or vice versa. In response to Ashmead's request, the editor published an appeal to readers of the Pacific Rural Press for information concerning the source of red scale in California. This brought a reply from L. M. Holt (1880, p. 67). He gave an excellent account of the introduction of yellow scale into San Gabriel by L. J. Rose in 1872, its spread there, and the methods used to combat it, and stated, "The red scale has also made its appearance in Los Angeles, in one locality spreading from Lisbon lemon trees imported from Australia." He commented that when in San Francisco in the summer of 1879 his attention was called to lemons imported from Australia that were covered with red scale.

The year 1880 stands as a milestone in the history of seale insects in California. J. Henry Comstock (fig. 3) spent three months in California and Utah in the summer of this year investigatinng scale insects, and a year later published his classical report on the scale insects (Comstock, 1881b). Leland O. Howard (1881) published on the parasites of the scale insects that same year. Before the comprehensive report was published, Comstock (1881a) had described the red scale as new under the name Aspidiotus citri. Shortly after his description was published, Comstock received a copy of William $\mathrm{H}$. Maskell's (1879) paper containing the description of Aspidiotus aurantii Maskell. He immediately wrote Maskell requesting specimens of $A$. aurantii. After comparing the specimens from Maskell with those from California, Comstock (1881b) concluded that his species citri was a synonym of Maskell's species aurantii. Comstock failed to find morphological characters for distinguishing between the yellow scale of San Gabriel and the red scale of Los Angeles and included both under the name aurantii. Referring to both scales as one species, Comstock (1881b) wrote: “. . . and from what I have seen of it, I believe it is more to be feared than any other scale insect infesting citrus trees in this country."

\section{OTHER EARLY CITRUS SCALES}

Prior to about 1877, when the red scale first came to notice as a citrus pest in southern California, orchardists were fighting scale insects over a rather wide front in southern California.

The soft (brown) scale, Coccus hesperidum Linn., was the first scale insect that came into prominence as a pest of citrus in southern California. It was referred to by its scientific name by J. Strentzel in 1877. Although there is no documentary proof, the subsidence of the soft (brown) scale prior to 1880 probably resulted from the accidental introduction of the same species of parasites that control it in California today.

Possibly as early as $1876 \mathrm{~L}$. J. Rose and his neighbors were fighting the yellow scale in the San Gabriel district.

In 1878, George Compere was fighting the black scale, Saissetia oleae (Bern.), that infested the orange trees in the old Vejar orchard on Washington Street, Los Angeles, which was under his care.

In 1878 the cottony-cushion scale in Los Angeles was confined to the Garey nursery. Comstock (1881b) records having found cottony-cushion seale in 
the Stowe grove at Santa Barbara in 1880, but does not mention having seen it farther south. It seems evident that information concerning the early infestation in the Garey nursery was withheld from Comstock.

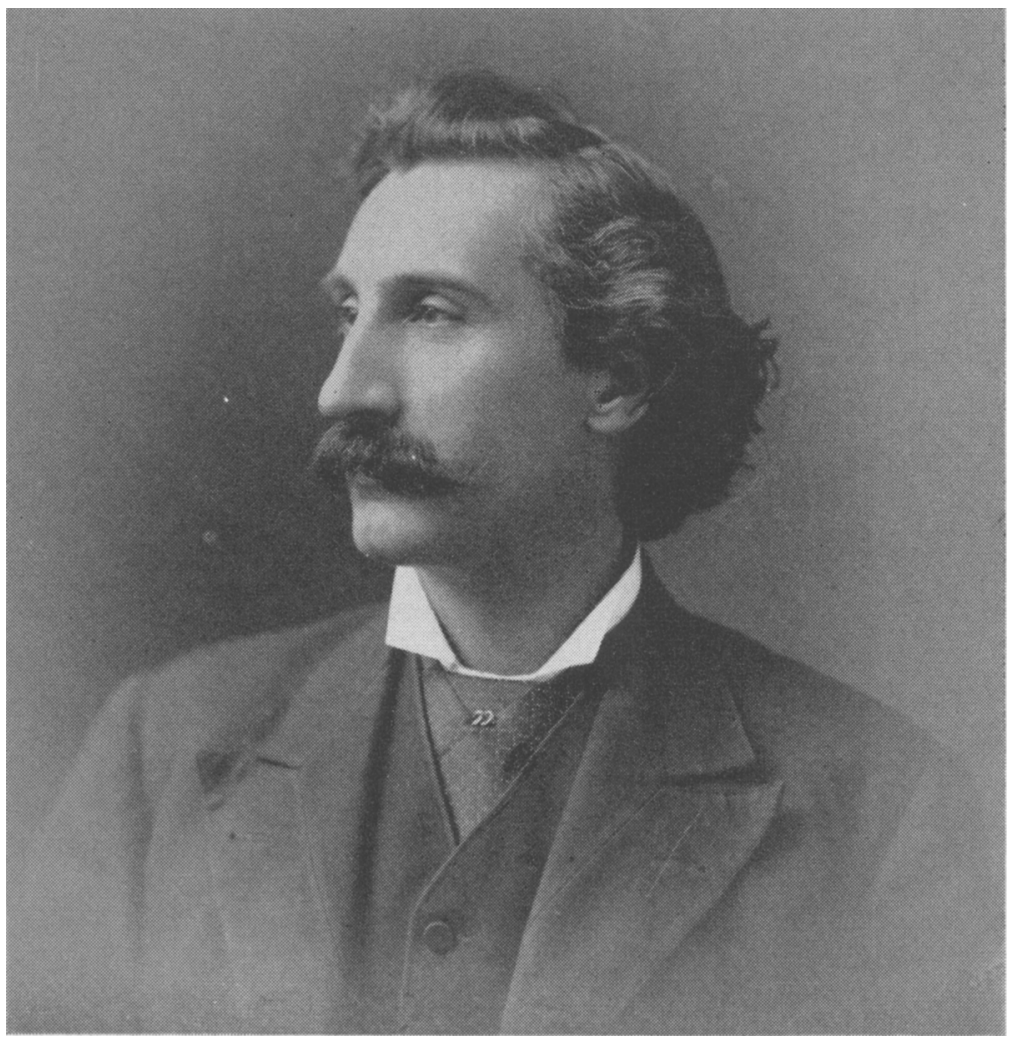

Fig. 4.-Charles Valentine Riley (1843-1895), one of the most talented and capable entomologists of all time, who became concerned with red scale in 1887, but opposed those advocating that a search be made in Australia for enemies to control red seale in California. (From an original portrait in the Brunner Collection taken about 1883.)

\section{EARLY ADVOCATES OF BIOLOGICAL CONTROL}

Thoughtful entomologists early recognized the value of parasitic and predaceous insects in the control of plant-feeding insects. But perhaps the first to recommend, in print, the importation of insect enemies from a pest's native home was Asa Fitch. In 1855 Fitch wrote to the President of the Royal Entomological Society in London to request that the latter try to arrange for someone to ship the European parasites of the wheat midge, Contarinia tritici Kby., to this country (Fitch, 1861).

Somewhat later, entomologists singled out scale insects as being particularly promising pests to control biologically. C. V. Riley (1869) (fig. 4) reported that the predaceous mite Hemisarcoptes malus (Schimer) probably 
more than anything else was preventing the oystershell scale, Lepidosaphes ulmi (Linn.) from ruining apple orchards in some states. William LeBaron (1870) transferred Aphytis mytilaspidis (LeBaron), the hymenopterous parasite of the oystershell scale, from one part of Illinois to another in an attempt to control this pest. Ashmead (1880b) was impressed with the great amount of damage that scale insects and mites were doing to citrus in Florida and reported on the importance of natural enemies in controlling them. He expressed the opinion that owing to "an immutable law of the Universe" all pests have their enemies to prey on them and keep them "under."

An editor of the Pacific Rural Press, writing anonymously in 1879, first recommended that an attempt be made to control red scale in California with its enemies. After discussing an earlier article by Ashmead in the Florida Agriculturist, in which the importance of parasites and predators in the control of citrus-infesting scales was emphasized, this editor wrote:

It is certainly the teaching of general experience with ruinous insects that they are often reduced by their natural enemies to such an extent that their evil work is restrained and sometimes arrested. It would seem wise to take measures to introduce these foes of the scale insects in the places where the pest has full sway. (Wickson, 1879.)

Although the red scale is not mentioned specifically in this quotation, the editor was concerned with red scale in particular, and the generalized recommendation was made in connection with this insect. If my interpretation is correct, this recommendation reflects an opinion that natural enemies may not always be the deciding factor that makes for the scarcity of a pest in one locality and excessive abundance in another. This presents in basic form an issue which has been contended in technical terms and at higher scientific levels for more than 70 years.

The anonymous editor of the Pacific Rural Press who was concerned with red scale was almost certainly Edward James Wickson (fig. 5). Wickson joined the staff of the Pacific Rural Press in 1875 and the faculty of the University of California in 1879. From 1905 to 1912 he served as Dean of the College of Agriculture. In later years Wickson came to be regarded as an arch enemy of biological control by the leaders of the biological-control movement in California. In all probability Wickson was not antagonistic to biological control but only to what he considered unsound thinking, dogmas, slogans, and questionable practices.

L. O. Howard (fig. 6) probably had red scale in mind when strongly recommending that attempts be made to control scale pests with their hymenopterous parasites (Howard, 1881). At this date it was realized that the introduced plant-feeding species, which multiplied explosively and quickly attained plaguelike proportions far exceeding the infestations known in other countries, offered particular promise of being controlled by the introduction of their enemies. It was generally accepted that the relative scarcity of a pest in its country of origin and an excessive abundance in its country of introduction was evidence that in all probability it was introduced without the natural enemies that often check excessive multiplication and hold populations at relatively low levels. 
Riley, then Entomologist, Division of Entomology, U. S. Department of Agriculture, singled out the cottony-cushion scale and the red scale as promising subjects for attempts at control by the introduction of their enemies:

The general importance of the introduction of parasites which affect a species in its native land, and which have not accompanied it into the land of its introduction, [has] been insisted on in our earlier writings and in those of others, and the ease with which this may be done in the case of the more minute parasites of the scale

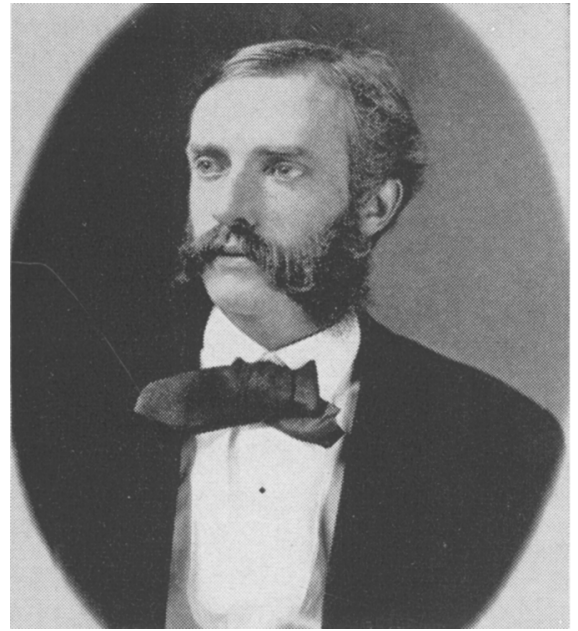

Fig. 5.-Edward J. Wickson (18481923), horticulturist, journalist, educator, who in 1879 first recommended that an attempt be made to control red scale with its enemies. (From a photograph taken in 1872 in the possession of Wickson's daughter. Copy obtained through the courtesy of Knowles A. Ryerson.)

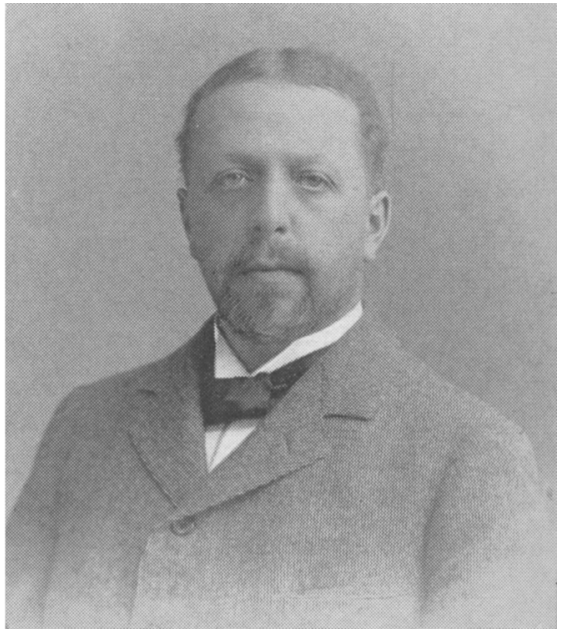

Fig. 6.-Leland Ossian Howard (18571950 ), a specialist on the parasitic Hymenoptera. The world's most honored entomologist, and from about 1896 to 1930 the leading authority on biological control. No man was better qualified, had a better perspective, or was more judicious in matters pertaining to biological control. (From a photograph in the Brunner Collection.)

insects adds to its importance in this connection. Considering the fearful losses already occasioned to citrus growers by two species (the Icerya in question and the California red scale), introduced from Australia, we know of no way in which the department could more advantageously expend a thousand dollars than by sending an expert to Australia to study the parasites of the species there and secure the safe transport of the same to the Pacific Coast.... (Riley, 1886.)

Riley (1889) made the same recommendation a second time, but before it was again published, he must have become aware that the red scale was as serious a pest of citrus in Australia as in California, for at the California State Fruit Growers' Convention held at Riverside in April of 1887 he vigorously opposed those advocating that a search be made in Australia for enemies to control red scale in California. Presumably, prior to 1887 Riley had overlooked the evidence testifying to the seriousness of red scale in Australia. Riley was the featured speaker and gave the principal public address before 
the Convention (Riley, 1887). He recommended that an expert be sent to Australia for enemies of the cottony-cushion scale only. A resolution, the original draft of which was prepared by Riley, was adopted by the Convention. This resolution petitioned the Congress of the United States to apppropriate a fund to finance a search in Australia for enemies of the cottonycushion scale only. An attempt to amend this resolution by inserting the name "red scale" in addition was defeated. The note of discord between Riley and those advocating that a search be made in Australia for enemies of red scale marks the beginning of a quarrel that lasted throughout the lifetime of all those involved.

Attempts to secure Congressional approval and financial support for an expedition were futile. But in 1889 Riley sent Albert Koebele to Australia to search for enemies of the cottony-cushion scale. Koebele sent back several ladybird predators, among them the vedalia, which promptly brought the cottony-cushion scale under control and continued to control it. The honor for this went to Koebele; in California Riley was given little or no credit for the most spectacular and successful control in the history of entomology. True, the idea of controlling the cottony-cushion scale by the introduction of its enemies was not Riley's alone; ${ }^{4}$ the California horticultural officials exerted strong political pressure on Riley to undertake this project. But in my opinion, Riley, more than any other man, deserves the credit for planning and directing the work that resulted in the control of cottony-cushion scale.

\section{POLICIES, POLITICS, AND PERSONALITIES}

After the success of vedalia, the enthusiasm and faith of the citrus growers and officials of the California State Board of Horticulture was unrestrained. In 1890 the Board announced through its Secretary, B. M. Lelong, "It is our policy to introduce all parasites and predaceous insects that may be discovered in other states and countries" (Lelong, 1890b, pp. 13-14). Koebele was proclaimed by Californians as the world's outstanding authority on biological control. Riley's opinions and recommendations were rejected or ignored. The smoldering quarrel between Riley and the state officials burst into flame.

No account of the attempts to control red scale biologically would be complete without telling of the part played by Ellwood Cooper. He was the most influential man of his time in horticultural and entomological matters in California. From 1883 to 1907 he held important official positions, first as a member of the State Board of Horticulture, next as its President, and finally as State Commissioner of Horticulture. He was educated, wealthy, and most successful as a horticulturist. Regarding him, Essig (1931, p. 587) wrote, "If the great fruit interests of this state ever conceive the idea of erecting a monument to the one who has performed the greatest service for those interests, the monument should be to the memory and honor of Ellwood Cooper." At nearly every State Fruit Growers' Convention where Cooper presided,

\footnotetext{
${ }^{4}$ Lelong (1890a, p. 260, footnote) stated that the idea of introducing beneficial insects into California was first conceived in 1881 by the State Board of Horticulture, but that Alexander Craw was the first to call the public's attention to it. The error of these claims is evident from the account in the preceding section.
} 
insect pest control was the principal topic. Long before the introduction of vedalia, Cooper was a staunch believer in the possibilities of this kind of control.

Under Cooper's leadership the Californians requested that an immediate search be made in all foreign countries for enemies to combat all the serious scale pests in California, and in particular the red scale.

In 1891 the California State Legislature appropriated $\$ 5,000$ to send an expert to Australia and adjacent countries to collect beneficial insects and ship them to California. The state officials requested Riley to assign Koebele to this project but Riley refused, wanting no part in it. Cooper then appealed over the head of Riley to J. H. Rusk, Secretary of the United States Department of Agriculture, and succeeded in obtaining the services of Koebele under a coöperative agreement whereby his salary was paid by the federal government and the traveling expenses by the state government.

According to Cooper (1913, p. 10), the Division of Entomology gave Koebele lengthy instructions which were then nullified by Rusk in a personal letter to Koebele instructing him to disregard the Division's instructions. There are good reasons, other than Cooper's testimony, to believe that Koebele worked under Cooper's instructions and not those of Riley. According to Howard, ${ }^{5}$ after Koebele's return from the second trip to Australia, the matters of contention became so acute that Rusk said he would have no more to do with California. Koebele and Daniel W. Coquillett, both agents of the Division of Entomology then stationed in California, were given the choice of moving to Washington, D.C., or resigning from the federal service. Koebele resigned and Coquillett moved to Washington.

The quarrel between Riley and the state officials is reflected in two reports prepared by Koebele after his return from the sceond trip. Koebele's first report (1892) relating to his second trip to Australia was prepared hurriedly for the State Board of Horticulture and was published by the state. The second, more carefully prepared comprehensive report (Koebele, 1893) was for the Secretary of Agriculture, and it was published by the United States Department of Agriculture at the request of the California State Board of Horticulture. These reports do not bear the usual endorsement and letter of transmittal of the Entomologist, Division of Entomology, and the opinions expressed are in opposition to those of Riley, the Entomologist. The seriousness of the quarrel is attested by a footnote appended by Riley and Howard to one of Coquillett's reports. According to this footnote, Coquillett (fig. 7) was denied admittance to Cooper's ranch at Santa Barbara (Coquillett, $1893 b$, p. 26).

After the subsidence of yellow scale in San Gabriel and the black scale, Saissetia oleae, in his olive orchard when Rhizobius ventralis (Er.) was established there in 1892 (see p. 199), Cooper's enthusiasm for biological control knew no bounds and he became a militant crusader. It was his unshakable conviction that scale insects became pests only where they occurred outside of their native home; that in their native home injurious insects are controlled by parasites or predators; that in order to control a pest the problem is to

${ }^{5}$ From unpublished letter from L. O. Howard to George Compere, Washington, D.C., October 25, 1905. 
discover its native home. Then control is easy: go to the native home, find the parasite or predator that holds the pest in check; import the parasite or predator, turn it loose, and let nature do the rest.

Riley expressed his dissenting opinions in simple and positive terms in 1893: he believed that introduced pests might be controlled by the introduc-

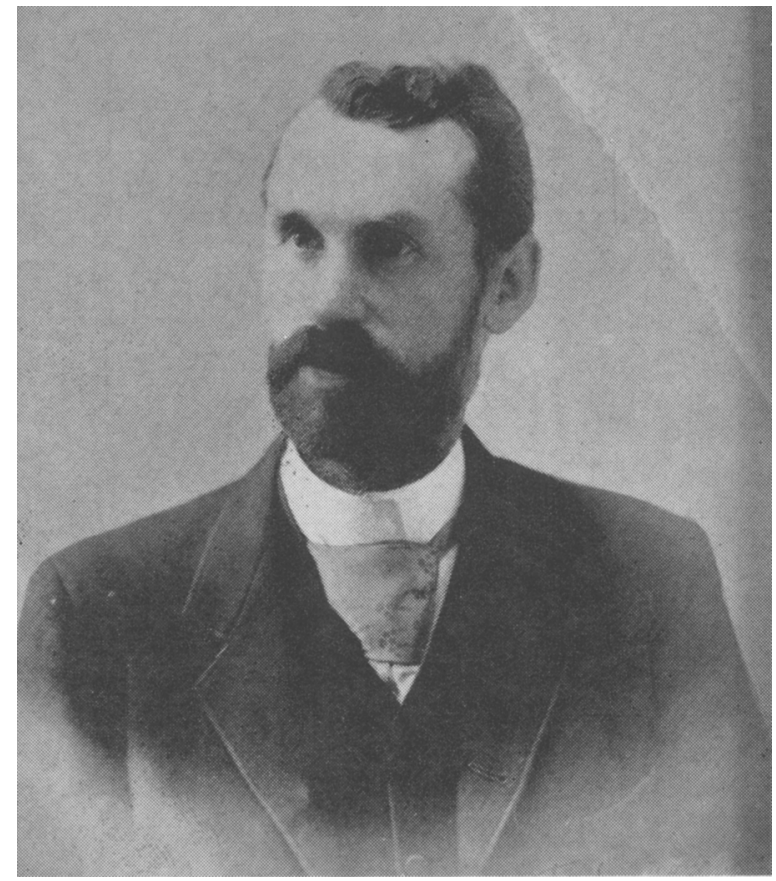

Fig. 7.-Daniel William Coquillett (1856-1911), probably the most conservative and reliable observer of citrus scale insects and their enemies in California from 1882 to 1893. The value of Coquillett's observations and his development of a practical method of killing citrus-infesting insects by fumigation with cyanide gas has never been suitably recognized. (From a copy of a photograph taken about 1894-from the National Archives.)

tion of their enemies in exceptional cases only; that searches should be carefully planned in advance on the evidence of history, systematics, climate, and geography; that the closer the similarities between two countries with respect to climate, flora, and fauna, the better the chances of controlling the pest in the one country by the introduction of its enemies from the other country; and that little or nothing could be hoped for in the introduction of miscellaneous enemies from one country to another, especially when these enemies did not control their hosts in the country where they were found. As a first law of nature Riley wrote:

Year in and year out, with conditions of life unchanged by man's actions, the relations between the plant feeders and the parasitic and predacious species of its 
own class remain substantially the same, whatever the fluctuations between them for any given year....

Corollary to this he wrote:

... while a plant feeder's natural enemies are apt to cause its excessive abundance to be followed by a corresponding decrease, yet this alternation of excessive abundance and excessive scarcity will often be produced irrespective of natural checks. An injurious insect which has been on the destructive march for a period of years will often come to a sudden halt, and a period of relative and sometimes complete immunity from injury will follow. This may result from climatic conditions, but more often it is a consequence of disease, debility, and want of proper nutrition which are necessary corollaries of undue multiplication. Frequently, therefore, it may be inaccurate and misleading to attribute the disappearance of a particular injurious species to some parasite or predacious species which has been let loose upon it, and nothing but the most accurate observation will determine the truth in such cases.... (Riley, 1893a, p. 138.)

Riley's opinions and statements of policy are in sharp contrast with those proclaimed by the California State Board of Horticulture. Today, 70 years later, there are still two schools of thought: one advocating preliminary studies and advance planning; the other, immediate action over a wide front.

The views of the State Board of Horticulture did not go unopposed within the State of California. From about 1891 to 1913 they were challenged by the Department of Entomology of the University of California, particularly when Charles W. Woodworth (fig. 8) was its head. Woodworth disagreed with the Board even more sharply than did Riley. One extreme seems to provoke its opposite, and Woodworth went so far as to express the opinion that parasites and predators never controlled their hosts and that the cottonycushion scale was not controlled by vedalia. He theorized (Woodworth, 1908) that the elimination of one cause of death or the addition of an entirely new natural enemy will usually have but a slight effect or none at all on the rate of the pest's survival. This is just about the antithesis of the recognized principles of biological control and the teachings of Darwin (1859, p. 67), who wrote, "Lighten any check, mitigate the destruction ever so little, and the number of the species will almost instantaneously increase to any amount."

Woodworth (1908) also theorized that in order for a balance to exist there must be a reciprocal action between opposing forces; and he distinguished between the mode of action of biotic factors such as parasites and predators, and that of abiotic factors such as climate. In this respect his opinions were in accord with the principles of biological control as generally recognized today.

Despite Riley and Woodworth, Cooper's zeal for biological control continued unabated. He insisted upon the necessity of not using insecticides where beneficial insects had been released, ${ }^{8}$ and it may have been his insistence on this that gave Howard (1930) grounds for writing, "It is safe to say that

\footnotetext{
${ }^{6}$ For example, in 1901 the Orange County Board of Horticultural Commissioners reported a letter from Cooper "advising people not to spray or fumigate their trees but to protect the Rhizobius and they would finally clean the trees of black scale." (Minutes of the Board of Horticultural Commissioners of Orange County from May 28, 1897 to November, 1909, p. 78, minutes of meeting Santa Ana, California, Aug. 30, 1901.) Although this particular item pertains to black scale, the same recommendation was made with regard to other scales.
} 
a large share of the loss through insects suffered by California from 1888 until, let us say, 1898 was due to this prejudiced and badly based policy."

Cooper proclaimed in speeches and publications that all the worst orchard

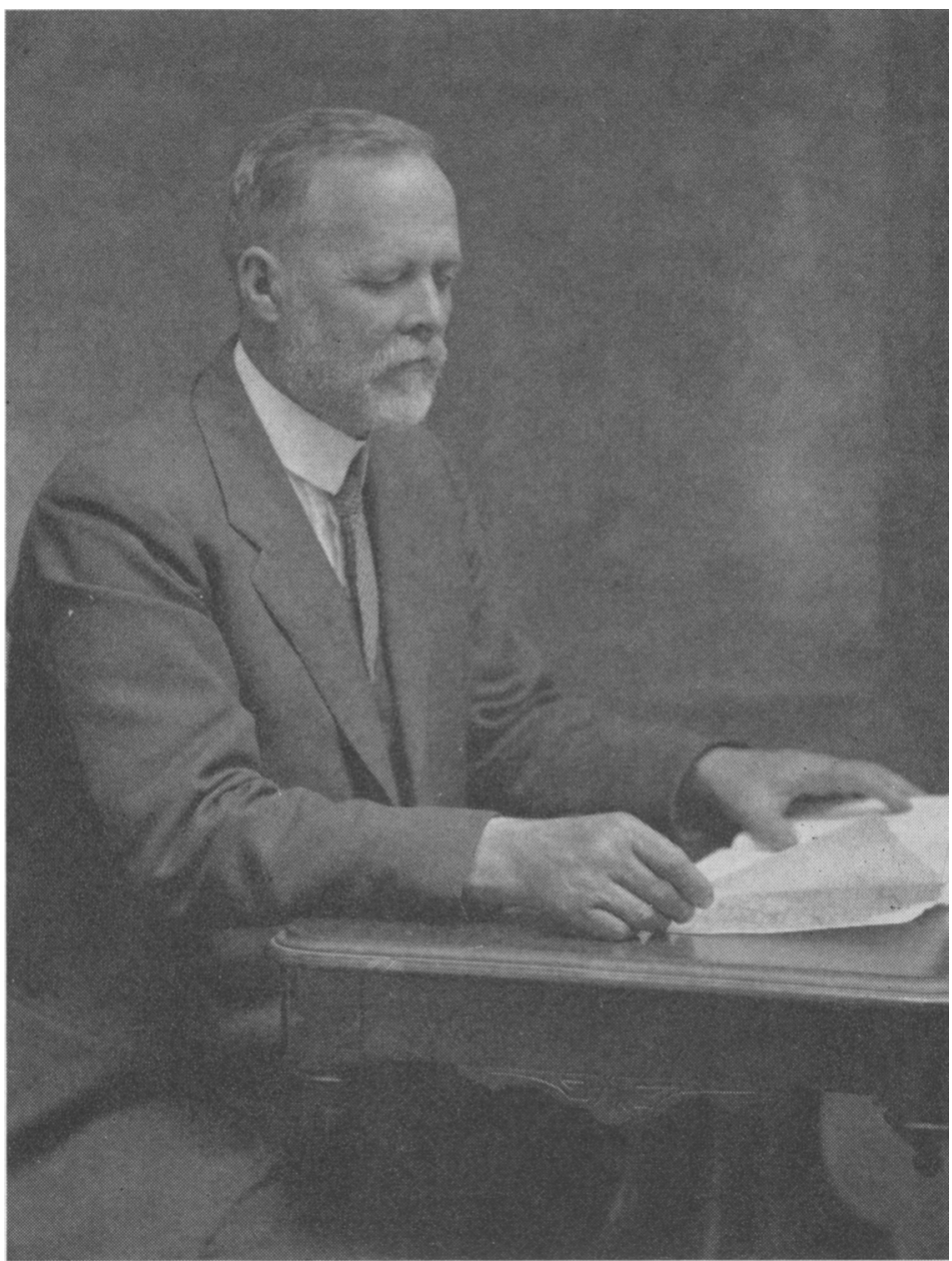

Fig. 8.-Charles W. Woodworth (1865-1940), Professor of Entomology, University of California, Berkeley, Head of the Department from 1913 to 1930 , a critic of biological control.

pests had been, or were about to be controlled in California by beneficial insects, and wrote letters to the heads of the Australian states offering for $£ 1,000$ to supply a parasite to control codling moth.

Unrestrained enthusiasm for biological control led Cooper to interfere in matters outside his jurisdiction, particularly in the control of the gypsy moth in Massachusetts, and the cotton boll weevil in the southern states. This brought him into conflict with Howard, who replaced Riley as Entomologist of the Division of Entomology in 1894. Howard found it necessary to enlist 
the support of many of the world's leading entomologists to prevent Cooper from contracting with Massachusetts to search for a parasite to control the gypsy moth in that state.

If my interpretation is correct, it was Howard's recommendation that resulted in the replacement of Cooper by J. W. Jeffery as State Commissioner of Horticulture in 1907. The "political process" by which Cooper was removed from office is revealed in Cooper's unpublished letters to George Compere, supplemented by Howard's published statements (1930). The movement in California to replace Cooper may not have been initiated by Howard, but it received his most effective support. Cooper's letters show that he failed to win the support of General Harrison Gray Otis. Cooper was told by Harry Chandler, Otis's son-in-law, that Howard had advised the General and that it was useless for him (Cooper) to see the General personally, since he had made up his mind and had endorsed J. W. Jeffery for the position. Otis, the founder and publisher of the Los Angeles Times, was one of the most powerful men of his day in state politics. Cooper's dismissal from office for doing what he considered his duty, and his replacement by Jeffery, was a blow to his pride from which he never recovered. His last years were spent in seclusion on his estate, "Ellwood," at Santa Barbara. With reference to Cooper, Howard wrote:

His name was prominently mentioned for the position of United States Secretary of Agriculture,... and had he been appointed to this position his friends said he would have immediately reorganized the entomological service of the government and discharged everyone who did not hold his extreme views on the subject of biological control. (Howard, 1930.)

Certainly Cooper did not engage or retain in state service men who did not share his views.

\section{THE CONTROVERSY OVER THE DISTINCTION BETWEEN RED AND YELLOW SCALES}

For nearly fifty years, attempts to control red scale biologically were handicapped and confused by the failure to find any morphological distinction between red and yellow scales. At first the leading entomologists insisted, despite evident differences in injuriousness and physiology, that the two were one species.

Numerous articles from 1887 to 1894 concern the controversy over the distinction between red and yellow scales. More informative than the prepared articles is the published transcript of a public debate between Lelong (1887) and Riley (1887) before the California State Fruit Growers' Convention at Riverside, April 1887. Lelong reported his observations that the scale in the San Gabriel Valley attacked only the leaves and fruit and did not cause the limbs to die back, though the tree might turn yellow; whereas the one in the Santa Ana Valley attacked wood as well as leaves and fruit and did cause limbs to die back. He maintained that-despite the opinions of Comstock and Cooke (the State Horticultural Officer) - the two scales were different because their habits were different.

Riley acknowledged that he himself had observed the two forms at Los Angeles and said, "I do not think they are the same species, but until a more 
careful study is made I should not depart from the opinion of Professor Comstock."

In my opinion, Riley was attempting to defend an untenable position and was poorly prepared for the encounter with Lelong. When confronted with the evidence and the logic of Lelong, he gave ground, but only temporarily. He based his ultimate decision on the conventions of systematies and not on the facts of nature and, on the basis of morphological evidence, pronounced the red and yellow scales to be the same. He did not foresee that with improvements in optical equipment and better techniques, species would be recognized at lower and lower levels of morphological distinctness (see fig. 25 , p. 225). In Riley's day the Linnean or morphological concept of a species was regarded as the basic unit in applied biological control. Today, more and more consideration is being given to biological species or units below the level of morphological distinctness. These lesser units, whatever they may be-strains, races, varieties, subspecies, sibling species, or biological speciesscreened as distinct in work with living insects, are not disregarded. In applied biological control, functional or biological characters may prove to be more important than morphological ones.

Riley's insistence on identifying the red scale and the yellow scale as the same species added to the confusion. According to Howard (1894, p. 288), Riley disapproved the technical description of Aspidiotus citrinus prepared by Coquillett and it was never published. In the literature the authority for the name is cited as the page where Coquillett $(1891$, p. 29) wrote, "the orange tree experimented upon was infested with the yellow scale, (Aspidiotus citrinus)...." The bulletin in which this appears bears the date January 3 , 1891, in the letter of submittal from Riley to the Secretary of Agriculture, but the date of issue is not given. As early as February 28, 1891, Craw (1891a) was in print with the name " 'yellow scale,' Aspidiotus citrinus, Coquillett" in an issue of the California Fruit Grower. In that same year this article was issued in pamphlet form by the California State Board of Horticulture (Craw, 1891b). Again this same year Craw (1891c) used the name Aspidiotus citrinus Coquillett and gave a more adequate description of the species and its history. Questions concerning the legality of the name $A$. citrinus Coquillett are outside the scope of this article. When in 1892 Coquillett published an account of the introduction of red scale into California (see p. 174) based on information provided by Alexander Craw, Riley appended a footnote to Coquillett's account indicating that the insect had arrived several years earlier than 1879. But this is misleading: Riley had the introduction of the yellow scale in mind. Presumably in deference to Riley, Howard's (1894) paper on the parasites of the yellow scale appeared under the title "The Hymenopterous Parasites of the California Red Scale."

Craw (1890) was probably correct in giving credit to Lelong for being the first to distinguish clearly between the red and yellow scales.

Two reports by W. G. Klee, State Inspector of Fruit Pests from 1886 to 1889, are pertinent to the history of red and yellow scale in California. In his first report, Klee wrote:

... In some parts of Los Angeles County, also in Sacramento City and about Marysville, a distinct variety of red scale is found. According to the best authorities 
(Riley and Comstock) it cannot be considered specifically distinct from Aspidiotus aurantii, yet its appearance and manner of attack are so different that we have thought it worthy of a special plate. The difference of opinion in Los Angeles County as regards the efficacy of certain remedies, and also as regards the more or less dangerous character of the red scale, is doubtless due to the fact of the two varieties being confounded. Of the two, the first named or true type must be recorded as the most dangerous. (Klee, 1887.)

\section{In his next report, Klee wrote:}

Red Orange Scale (Aspidiotus aurantii). The great importance of knowing this, one of the most destructive species of scale insects, causes me to reproduce the plates of two varieties of orange scale; true type [plate III]. This variety was evidently brought to Los Angeles from Australia, where it is considered by far the most destructive scale. This variety infests all parts of the tree alike-leaf, branch, and fruit. The massing of the scale along the shoots causes them to wither from the tops downward, and afterwards causes the tree to lose all its leaves. In color the scale is darker than the other variety in [Plate II].

[Plate III] aims at representing the natural appearance of the true type. The branch at No. 1 shows the characteristic dying off.

[Plate II] is a representation of the light colored red scale, by some called the San Gabriel scale, because of its prevalence in the valley of that name. This variety has evidence of having been imported from Japan, as orange trees brought from that country are always more or less infested with it. Although a more persistent and difficult scale to eradicate, it does not seem to have proved as formidable an enemy as the true type.

From what I can learn about this scale in Japan, it appears that it is not troublesome there, at least the native gardeners with whom I have conversed do not consider it so. The slight damage done must undoubtedly be attributed to parasites keeping the scale in check. These it might do well to import. (Klee, 1888.)

Klee's opinion that yellow scale was introduced into California from Japan, and not Australia as generally believed, may be correct. Klee's recommendation that parasites be introduced from Japan into California to control yellow seale is especially noteworthy as it was made July 2, 1888, prior to the departure of Albert Koebele on his first mission to Australia.

In 1890 Lelong reiterated his conviction that the scales in the San Gabriel and Santa Ana valleys were different insects, citing their differences in habit, effects, and color (Lelong, 1890c). He gave Australia as the source of both insects, disagreeing with Klee's opinion that the yellow scale was introduced from Japan. He maintained that while trees arriving from Japan were generally infested with this scale, no orange trees had been imported from Japan previous to 1880 .

This last statement is incorrect. It is perhaps true that the nurserymen of southern California made no direct importations of citrus from Japan prior to 1880 , but records show that citrus trees from Japan were imported into the United States prior to that year. The orange tree purchased by L. J. Rose from a hothouse in San Francisco in 1872 may well have been of Japanese origin, or if this particular tree was not of Japanese origin, it could have become infested with yellow scale from trees of Japanese origin growing in the same hothouse. Prior to 1880, ships returning from the Orient often brought citrus into New York and probably San Francisco as well. Glover's scale, Lepidosaphes gloverii (Packard), is said to have been introduced into Florida in 1838 on some trees of the mandarin orange which had been procured in New York from a ship from China (Glover, 1855). 
Even after red and yellow scales came to be recognized as distinct species, the lack of any reliable morphological character to distinguish them continued to cause confusion in the attempts to find an effective parasite for red scale. Later the failure to distinguish Aonidiella taxus from the other two species caused similar confusion. Bodenheimer (1931) again raised the question of the identity of red and yellow scale (see p. 261). Confusion among the Aonidiella species persisted until 1937.

\section{PARASITES OF THE YELLOW SCALE}

Coquillett discovered parasites destroying yellow scale in March 1887 on one tree in the orchard of A. B. Chapman, San Gabriel Valley. He reported this discovery in a speech before the Eleventh State Fruit Growers Convention, April 1889 (Coquillett, 1889). In the interval between the discovery of the parasites and the speech, the parasites had increased to such an extent that Coquillett was able to report that a great many of the scales in the San Gabriel Valley had been destroyed by them. He expressed the hope that eventually the parasites would control the scale, but cautioned the orchardists not to wait for this and to use artificial methods of control where the scales were threatening. Coquillett was impressed with the abundance of parasites in the San Gabriel Valley and their absence in the Santa Ana Valley and raised the question as to whether parasites might account for the difference in the injuriousness of the scales in the two places. The San Gabriel scale was referred to as the red scale, Aspidiotus aurantii, but mention was made of the fact that it was generally supposed that the scales in the two valleys were different species, largely owing to the difference in injuriousness.

In November of that same year, Coquillett (1890) spoke before the Twelfth State Fruit Growers' Convention. He was by then much less optimistic concerning the possibility of the parasite's eventually controlling the scale in the San Gabriel Valley. Its progress had not been as rapid as that of the Australian ladybug (Rhodalia cardinalis Muls.). He referred to an orchard in Los Angeles where parasites had almost eliminated the San Jose seale but which later became almost as badly infested as it was originally. He pronounced the red scale to be of two kinds and told of having transferred parasites from the San Gabriel Valley to the Santa Ana Valley but was not prepared to say whether they would attack the scale in the latter locality.

The same year Coquillett's speech was published, Lelong (1890, p. 284) published a long letter from Coquillett concerning the situation in the San Gabriel Valley, in which the latter stated that Howard had written him that the parasite in question was probably a new species belonging to a genus near Coccophagus. The new species did not long remain unnamed. Lelong instructed Craw, Quarantine Officer and ex officio entomologist of the State Board of Horticulture, to investigate the red-scale situation in southern California and make a report. In his reports Craw (1891a, $b$ ) not only used Coquillett's manuscript name, Aspidiotus citrinus, to designate the yellow seale, but formally described the parasite in question as Coccophagus citrinus new species, original. Craw was not qualified to identify or describe hymenopterous parasites, and his precipitate venture in systematics aroused the ire of Howard, and justly so. The history of this parasite is discussed in detail under "Systematies" (p. 266). 
Craw was most optimistic concerning the work of the parasites and unlike Coquillett, believed that the evidence was sufficient to convince even the most skeptical that the scales were succumbing to "nature's remedy." Although this is only implied in Craw's reports, Howard (1894, p. 229) stated that it was his understanding that Craw advised the discontinuance of spraying by orchardists in the San Gabriel Valley where the parasite was abundant.

The publicity and excitement in California about the parasite of yellow scale did not escape the attention of Riley. Possibly he may have proposed to the Secretary of Agriculture that a survey of the situation be made by an impartial observer. In any event a survey of the citrus scales in California, with particular attention to the parasite of yellow seale in the San Gabriel Valley, was made in the summer of 1889 by A. W. Henry, Director of the Wisconsin Agricultural Station. Henry's report to the Secretary of Agriculture follows.

At Sierra Madre Villa, in the orchard of W. D. Cogswell, a chalcid fly was found to be parasitic on what is there called red scale. In company with the county insect commissioners and Mr. Coquillett we visited this orchard. It is quite evident that the so-called red scale of this orchard has been greatly checked and may yet be entirely destroyed by the chalcid. At E. J. Baldwin's the commission also found the same scale being destroyed by the same parasite. In this case each parasite destroys but a single insect and the commissioners were very solicitous and also skeptical as to its ability to rapidly destroy the red scale, as they did not believe that the scale on the orchards mentioned was identical with that about Orange. (Henry, 1889.)

This report clearly reflects an opinion that two different species of scales were involved: the yellow scale in San Gabriel, the increase of which had been checked by a parasite, and the red scale in Orange, about which the commissioners were skeptical as to the chances of controlling with the parasite.

Riley $(1890,1891)$ commented on the parasite in two articles presumably written before the Henry survey but published some time after. In the first of these, he noted favorable reports of reduction in scale numbers in the San Gabriel Valley attributed to increased numbers of parasites and predators; but in the second, he warned growers against relying on the parasite because the tree upon which the insect was originally discovered was still badly infested with scales.

Craw (1891b) obtained a second species of parasite from yellow scale. This he designated as the "golden chalcid." It was found parasitizing yellow scale at Duarte, San Gabriel, and Alhambra. This species is discussed in detail in the systematic section of this article dealing with Aphytis citrinus Comp.

Craw was favorably impressed with the work of these parasites of yellow seale and wrote: "We will undoubtedly always have the yellow scale; but no doubt the trees and fruit can be kept in a healthy and clean condition by the parasite. I would therefore recommend the colonization of it wherever the 'yellow scale' is found."

Contradictory testimony concerning the effectiveness of the parasite on yellow scale was published in 1891, in a small pamphlet issued by the Yuba County Horticultural Commission:

The orange trees in Marysville, Sacramento, and several other places in the Sacramento Valley are infested with a mild species of red scale which has been termed the yellow scale (Aspidiotus citrinus). This yellow scale is not so difficult to eradicate 
as the true type (A. aurantii).... The Board of Horticulture are recommending as a remedy for the yellow scale the cultivation of a chalcid fly parasite...

In March, 1891, G. W. Harney of our commission in company with U. S. Govt. Ent. D. W. Coquillett inspected several orange groves in southern California that were infested with the yellow scale. Numbers of the flies were discovered at work on the scale, but it was also discovered that certain trees upon which the flies had been at work for 4 years were badly infested. It was found that the identical tree upon which the fly was discovered in March, 1887, was still very badly infested. (Harney, 1891.)

When Quayle wrote on yellow scale in 1911, its great severity as a pest in San Gabriel was a thing of the past; but in central California it remains the most important citrus pest. Today some authorities on biological control attribute the disappearance of injurious infestations in San Gabriel to the work of parasites. Later the yellow scale became a pest of importance in some orchards in San Bernardino and Riverside counties, but in recent years it has rarely been abundant enough to require control measures in these counties. One possible reason for subsidence of yellow scale in southern California is discussed under "Unfavorability of Citrus to Red Scales."

\section{EARLY REPORTS OF RED-SCALE PREDATORS IN CALIFORNIA}

Three predators were found feeding on red seale in southern California by Coquillett in 1892. Chilocorus bivulnerus Muls. was the most common and widely distributed, but it never became numerous enough to keep red scale within limits. According to Coquillett, in 1890 or thereabouts, A. Kercheval of Los Angeles released large numbers of these ladybirds under a tent that enclosed a tree badly infested with red scale. After several months the scales were as numerous as when the ladybirds were first released in the tent.

Chrysopa californica Coq. attracted attention in connection with red scale, but more for its strange appearance and habits than for its value as a redscale feeder.

The third predator feeding on red scale was an unnamed ladybird that Coquillett described in all its stages. Shortly afterwards it was described by Blaisdell (1892) as Scymnus lophanthae [=Lindorus lophanthae] from specimens taken feeding on San Jose scale at Coronado, San Diego, California.

Riley's (1892) account of the introduction of Lindorus lophanthae has never previously been questioned. According to this account, the vedalia was not the only scale-feeding coccinellid sent or brought to California from Australia by Koebele in 1889 :

Among others, he brought several species of the genus Scymnus which in due time were set at liberty in the vicinity of Los Angeles. One of these, subsequently described by Dr. Sharp as Scymnus restitutor [=Rhizobius ventralis Er.] ..., was lost sight of, while another much smaller species, originally collected by Mr. Koebele near Sydney, New South Wales [Koebele, 1890], turned up the present year in a rather amussing way. In the March number of Entomological News ... Dr. F. E. Blaisdell [1892] describes a new California Scymnus under the name S. lophanthae. He found it preying on San Jose scale (Aspidiotus perniciosus) which infested the limbs of Acacia lophantha at the Coronado Parks, near San Diego in southern California. It is a very inconspicuous species of reddish color, the thorax often having an indefinite dark spot on the disk, and the elytra being of a blackish bronze color. The 
last-mentioned character is foreign to our native species of Scymnus, which never show any trace of metallic color, and, for this reason, I at once suspected, upon reading the description, that $S$. lophanthae was one of the species introduced from Australia. Upon comparing Dr. Blaisdell's description with the sample specimens sent by Mr. Koebele from his first and second trips to Australia, I had no difficulty in identifying $S$. lophanthae with the species from Sydney mentioned above. Subsequently, Mr. D. W. Coquillett sent me a specimen, recently captured near Los Angeles, which fully confirmed this identification.

The beetle and its larva are quite abundant in Coronado Parks, according to Dr. Blaisdell; and since it also occurs near Los Angeles, there can be no doubt that this useful little coccinellid has fully established itself in southern California. (Riley, 1892.)

Marlatt (1906, p. 63) gives a similar account.

In all probability Lindorus lophanthae was introduced into California from Australia; but whether it became established here from a few beetles set at liberty in the vicinity of Los Angeles in the spring of 1889 is open to question.

History shows that Lindorus lophanthae has been widely distributed over the world unintentionally, having been found in such widely separated places as Morocco in North Africa and isolated Mendoza in Argentina. It feeds and reproduces upon many kinds of scales, and was probably transported to Moroceo and Mendoza as a stowaway on scale-infested plants. The records show that all the living coccinellids sent or brought back by Koebele in 188889 were forwarded to Coquillett in Los Angeles (Koebele, 1890, p. 32). The records also show that Coquillett was observant, careful, and qualified to recognize the coccinellids that he released. No species was too obscure or represented by too few specimens to be overlooked by him; otherwise mention would not have been made of such a minor item as "a single specimen of an unidentified scymnid" (Coquillett, 1893a, p. 253). Coquillett repeatedly visited the localities where releases were made to observe the results. $L$. lophanthae is a voracious feeder and both adults and larvae are conspicuous and catch the eye when feeding (see also Flanders, 1930, on this point). To me it seems inconceivable that Coquillett could have overlooked a population of $L$. lophanthae that reproduced from the beetles reported to have been released near Los Angeles in 1889.

If Lindorus lophanthae became established in California from such beetles, it must have reproduced exuberantly and from the point of release spread at an astonishing rate; otherwise it could not have become abundant at Coronado 100 miles away within less than three years (Blaisdell, 1892). The coccinellids were called to Blaisdell's attention by Wm. Vortriede, the head gardener. It would be of interest to know when Vortriede first noticed them.

When Lindorus lophanthae appeared in South Africa east and west of the Cape, Lounsbury (1940, p. 16) was more cautious than Riley and only conjectured that the species became established there from the importation made in 1900, when 17 species of coccinellids were shipped from America.

The role of Chrysopa californica as a natural enemy of red scale was discussed by Coquillett. His account of a phenomenon that has been observed by other entomologists at intervals during the past 60 years in connection with both red and black scales follows:

Besides the above-mentioned enemies of Red Scale there are also other agencies not at present clearly understood, but which occasionally very materially lessen the 
numbers of these pests. A few years ago [1889 \&] Mr. H. F. Gardner, of Orange, in the adjoining county of the same name, drew my attention to the fact that a large percentage of the Red Scales of all sizes upon his orange and lemon trees, as well as of the Black Scales (Lecanium oleae Bern.) upon his olive trees were dead, although they had not been treated with any kind of an insecticide. A close inspection of his trees revealed the fact that fully 80 per cent of the Red Scales upon these particular trees were dead, while upon the adjoining olive trees we found only a single colony of Black Scales still alive. This latter colony was in a sheltered position and contained about a dozen individuals of all sizes. All the other Black Scales upon the trees that I examined were dead and dry. In neighboring orange groves I also found several trees upon which fully 60 per cent of the Red Scales of all sizes were dead. Thinking that perhaps these might have been destroyed by some low form of fungus, I submitted specimens of them to Mr. Galloway, the Mycologist of this Department, with the request that they be examined for traces of such fungus....

But, notwithstanding the great number of these scale insects that annually fall prey to their various insect enemies, and the thousands that perish from some cause as yet not clearly understood, still these pests manage to multiply at an astonishingly rapid rate, making it necessary for owners of infested trees to employ artificial means in order to save their trees from destruction. (Coquillett, 1892.)

Coquillett's report contains several items of historical interest. It shows that there was need for treating citrus trees with insecticides to save them irom injury by red scale at this early date. It singles out Kercheval as the first to attempt to control red scale with a predator on an enclosed citrus tree (see p. 191). It raises a question as to when and how Lindorus lophanthae was first introduced into California (see pp. 191-192). It calls attention to an occasional high mortality of red scale in all stages of development before any species of Aphytis were prevalent on it, when host feeding and mutilation by adult Aphytis could not have been a cause of the extensive mortality.

\section{EARLY REPORTS OF RED-SCALE PARASITES IN CALIFORNIA}

By 1890 it was becoming evident that the parasites thus far discovered were not going to control the red scale. Thus Hamilton (1890), speaking of the true red scale, the one in Orange, wrote, "... no effectual parasite has yet been found." He mentioned the efforts being made by the State Board of Horticulture and the Entomological Bureau at Washington to find parasites, but said, "The work has been in progress for over two years without success."

\section{A few years later Riley wrote:}

We have recently received from Mr. Coquillett, of Los Angeles, four female specimens of Aphelinus [=Aphytis] diaspidis Howard [fig. 9], three of which were captured upon orange leaves infested with Aspidiotus [=Aonidiella] aurantii, while the fourth was found engaged in ovipositing in one of these scale insects. This is a new habit for this species... The fact that this species is now found to attack the red scale (and we consider Mr. Coquillett's observations to indicate more than a probability) is interesting and important, since but one true parasite has previously been recorded from this insect, viz. the so-called Coccophagus citrinus Craw which does not seem to be multiplying rapidly. (Riley, 1893b.)

These four insects, collected in 1892, are preserved in the United States National Museum. It is almost a certainty that they were identified for Riley by Howard. These specimens were examined by me first in 1932, and again 


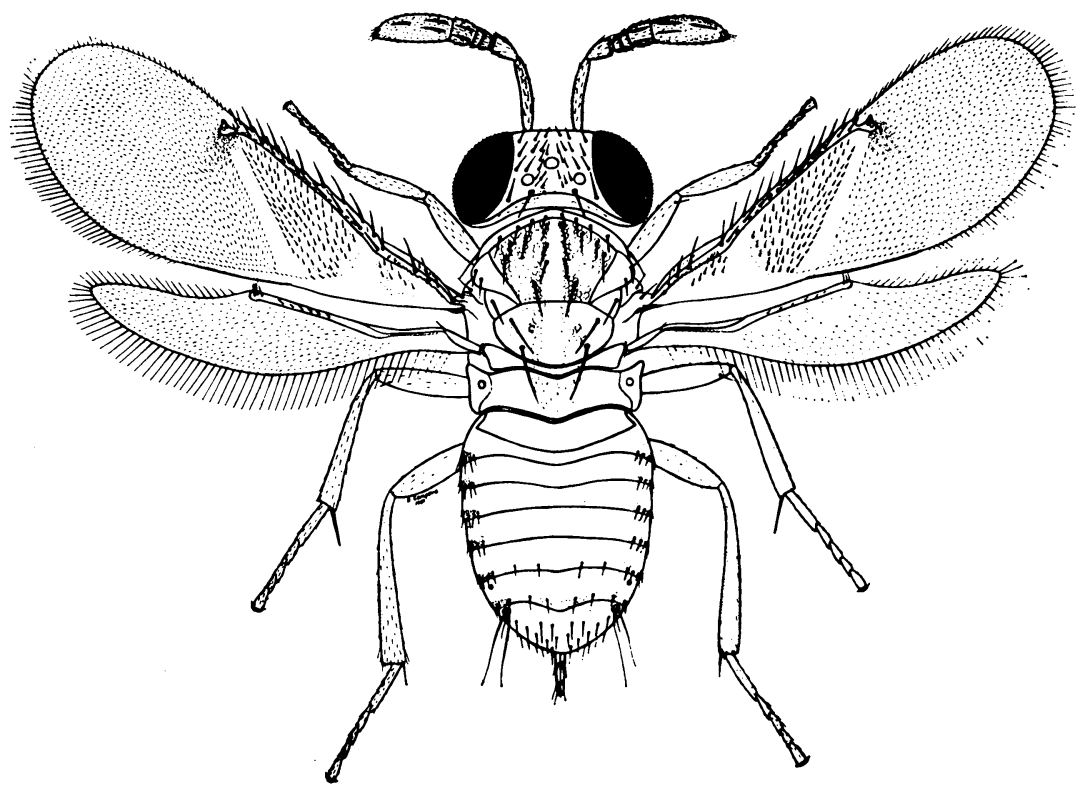

Fig. 9.-Aphytis diaspidis (Howard), one of the species collected by Coquillett at Santa Ana in 1892 associated with red scale.

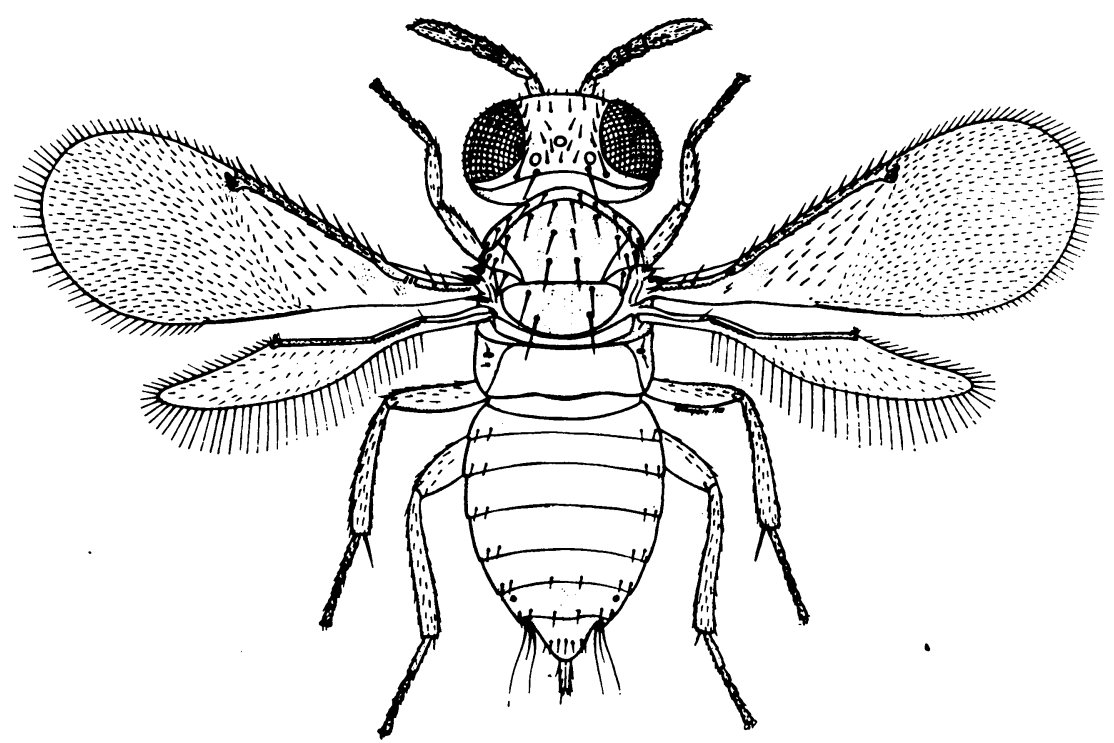

Fig. 10.-Aphytis chrysomphali (Mercet), the parasite of red scale that first came into prominence at Santa Ana in 1902 and was described as quaylei by Rust. 
in 1956 by B. D. Burks, Insect Identification and Parasite Introduction, U. S. Department of Agriculture, and me. Two of the specimens are indistinguishable from Aphytis diaspidis (Howard) and A. proclia (Walker), respectively. The identity of the other two specimens is uncertain. One of them may possibly be $A$. chrysomphali. Thus whether chrysomphali was present here as early as 1892 cannot now be determined. If a red-scale-inhabiting form of diaspidis existed in California in 1892, it probably perished; and if chrysomphali existed here in 1892, it was too scarce to attract attention.

The second notice of a parasite attacking red scale appeared in one of Craw's Horticultural Quarantine Reports. Craw wrote:

Early in September, Dr. W. B. Wall, the well known orange grower of Santa Ana, sent me parasites he had bred from red scale. Upon examination I found them to be the "Golden Chalcid Fly" referred to on p. 221 of your report for 1891. Dr. Wall states that they are very numerous and are reducing the red scale. Roy K. Bishop, of Orange, and others, write favorably regarding it. This parasite was found formerly only in districts where the "yellow scale" (Aspidiotus citrinus) prevailed. Other growers have written favorably regarding the parasite. (Craw, 1902, p. 203).

Aphytis chrysomphali (Mercet) (fig. 10) is the only species of Aphytis reared from red scale collected in southern California during the years from 1909 to 1948. The fact that both Craw and Coquillett failed to establish the yellow-scale-inhabiting golden chalcid on red scale has already been mentioned. There is every reason to believe that Craw's identification was incorrect, that the original golden chalcid was the yellow-scale-inhabiting species now known by the scientific name Aphytis citrinus, and that the species found as a red-scale parasite in 1902 was A. chrysomphali.

The Orange County Horticultural Commission (Bishop, 1902) reported of this same parasite, "... a minute yellow fly which is present this year in great numbers, in many instances has proved as destructive to the red scale as fumigation. We therefore believe that the treatment of orchards for red scale will soon become unnecessary."

In 1902 and 1904, Aphytis chrysomphali was reared by the State Commission of Horticulture and colonies were sent to growers on request (Ehrhorn, 1905).

These early optimistic hopes for controlling red scale with $A$. chrysomphali were not realized, for in 1906 Rafferty reported that in Orange County, "The chalcid fly is destroying many of the red scale, but not enough to hold it in check." In the same year H. K. Smith (1906) reported that in Riverside County, "The parasites that were introduced, bred out, and colonized by our Commissioners for red scale have been of small benefit so far, as they were indifferent breeders and had little appetites."

These early reports concerning Aphytis chrysomphali as a parasite of red scale in southern California are noteworthy, as some of the same statements made concerning it as an important factor in controlling red scale have been repeated.

Some present-day entomologists are of the opinion that a species of Aphytis was common on red scale in California at an early date, for both Coquillett and Craw reported a high mortality of red scale from an unknown cause. Coquillett, as previously noted, suspected it to be a fungus and sent specimens 
to Galloway for an opinion. The following excerpt from Craw is out of place here chronologically. It is inserted to show that Craw made a painstaking examination of red scale.

Early in October [1892] my attention was called to the fact that the red scale (Aspidiotus aurantii) was decreasing in the orange and lemon groves south of Los Angeles, but I was inclined to believe it was only the natural result of such insects after reproducing their kind. But an examination of the infested branches, leaves and fruit soon convinced me that something more than old age was the cause of the great mortality, for small and half-grown scales were numbered among the dead. Specimens were numerous where the disease was in the incipient stages. This was indicated by a chocolate blotch or discoloration of the insect; sometimes this would appear on the abdominal segments and on others the body of the scale would have from one to four shrunken brown spots. When in an advanced stage of the disease, some of the specimens placed under the microscope showed unmistakable signs of a fungus growth. Whether this fungus is an after result of the disease or is the primary cause of the great death rate cannot be determined unless by cultural experiments with the fungus in new groves. (Craw, 1894.)

These symptoms-chocolate blotches and shrunken brown spots on the bodies of the scales-are ascribed by present-day authorities solely to the work of Aphytis. Yet it seems strange that Craw could have observed these symptoms and overlooked fecal pellets, cast skins, eggs, larvae, pupae under the exuvia, and exit holes in male scales, not to mention unemerged adults. That Craw was parasite-conscious is indicated by other parts of the report quoted above, dealing with yellow-scale parasites, as well as his 1891 report previously mentioned (p. 189).

The parasite George Compere found on red scale in San Diego County in 1909 was probably Aphytis chrysomphali (see p. 207).

A contribution to our knowledge of red scale and its natural enemies in California was made in 1911 by Henry J. Quayle (fig. 11). In connection with the study of red scale, Quayle gave the life history of Aphytis chrysomphali under the name Aphelinus diaspidis, together with an opinion on its economic value. The figure of the adult is of Aphelinus diaspidis after Howard, but the species actually studied and reported upon was Aphytis chrysomphali. Quayle wrote:

The most common parasite of the red scale at the present time is Aphelinus diaspidis Howard. Indeed, in the examination of red scales from many parts of the citrus belt during the past three years this has been practically the only one met with in any number....

While it is not uncommon to find the parasite on red scale from many sections of the citrus belt, it has never been seen occurring in large numbers. Examination and counts have been made at various times during the past three seasons, and thus far, we have not found the number of parasitized scales to exceed 10 per cent. This amount of parasitization is, of course, of little value in checking the number of scales. The parasite was usually found most abundant where the scales were most numerous. (Quayle, 1911.)

Quayle was on the alert to detect the host feeding by adult parasites, but never succeeded in witnessing this phenomenon, although it is now known to occur under certain conditions.

For later reports on this parasite, see "Observations on Aphytis chrysomphali” (p. 217). 


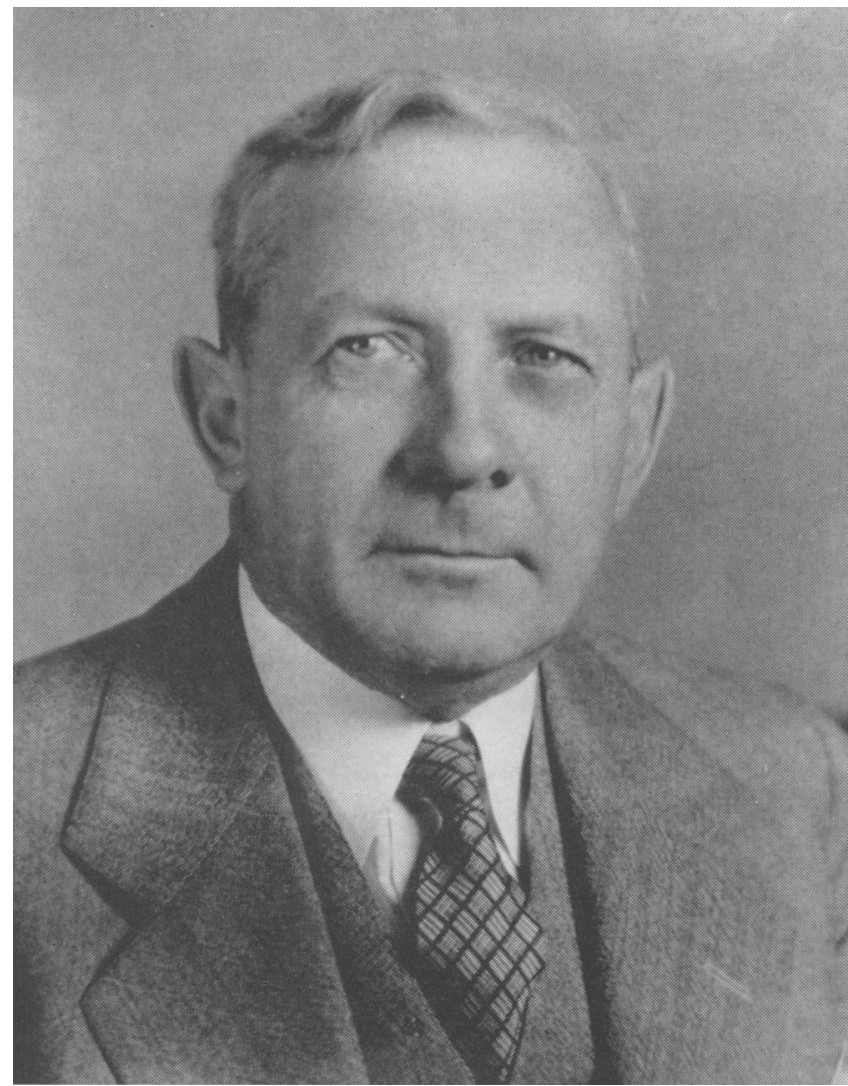

Fig. 11.-Henry J. Quayle (1876-1951), Professor of Entomology, University of California, Riverside, an authority on citrus-infesting insects.

\section{KOEBELE'S REPORTS ON HIS SECOND TRIP TO AUSTRALIA, AND RHIZOBIUS}

Albert Koebele (fig. 12) was the first to search for enemies of the red scale in foreign countries. On his second trip to Australia in 1891 under the direction of Ellwood Cooper, he was instructed to search specifically for enemies of red scale. After Kocbele returned from his first trip to Australia, Lelong (1890a, p. 22) reported: "Mr. Albert Koebele says in his opinion that it is useless to send an agent to Australia or New Zealand in search of parasites. He says that no parasites were found in those countries preying on red scale, and also says that the red scale is even worse than in this state, thus indicating that no parasites exist there." After returning from the second trip to Australia, Koebele prepared two reports giving his observations and opinions. With reference to red scale in Australia, Koebele wrote:

Aspidotus [= Aonidiella] aurantii Mask. is perhaps the most numerous coccid upon citrus trees through Australia. Whether the insect is in reality introduced, and if so 
when, will be difficult to decide. The Hon. Robert E. Scobie, of West Maitland, New South Wales... informed me positively that this same insect was very numerous fifty years ago upon his trees. Only in rare instances are holes found from whence minute chalcid parasites have issued, and these in the majority of cases on the male scales. From this very fact, I hardly think it to be indigenous... This insect is at present the most injurious to citrus trees in Australia.... Australia is in possession of more than enough natural enemies to keep this coccid in check with ease...

A large number of predaceous insects were found preying upon the red scale in Australia. Of these the most numerous were Orcus chalybeus Boisd., O. australiasia Boisd., and [Rhizobius satellus Blackb.] was always present in extremely large numbers ... R. hirtellus Crotch is numerous around Sydney, but more so at Toowoomba. $R$. toowoombae Blackb., R. debilis Blackb., R. caecus Blackb., R. plabeius Blackb., R. pulcher Blackb., were all found upon this scale, as also various species of Scymnids, Midus pygmaeus Blackb., Lipernes subviridis Blackb., were always numerous. Serangium maculigerum Blackb., and $S$. hirtuosum Blackb. were also found on trees with this scale and several more of which I have as yet found no names. (Koebele, 1893.)

He reported that the red scale was most numerous and damaging on neglected trees planted in unsuitable localities or soils. The predators were not found on such trees, he said; they preferred trees with dense foliage and shade. In contrast, in one wellfertilized, unsprayed orchard where

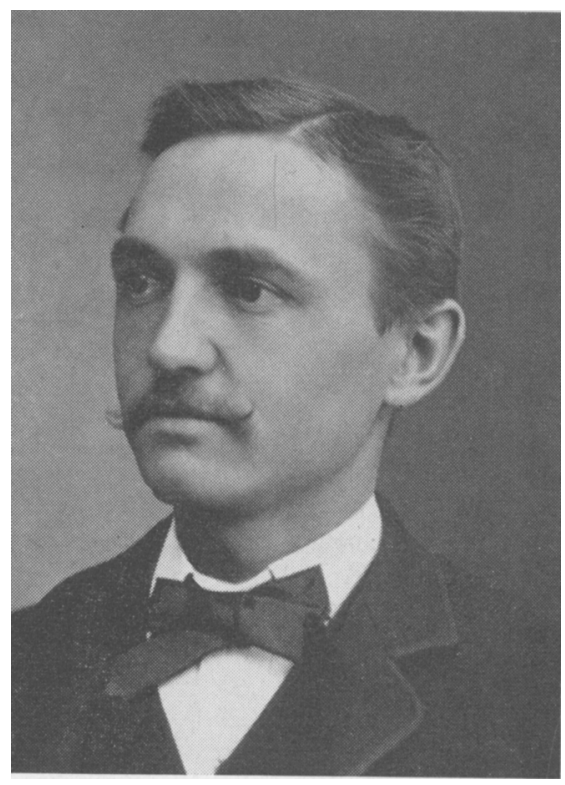

Fig. 12.-Albert Koebele (1852-1924), the world-famous collector who discovered the vedalia in Australia and sent it to California, where it controlled the cottonycushion scale. (From a photograph in the Brunner Collection taken in 1882.) the red and other scales had been present from the beginning, he found only a few trees along one border that "showed any traces of them." He warned that spraying or fumigating destroyed the beneficial insects or forced them to leave the orchard, "and the consequence would be that in a few months the trees would again become infested, with no enemies present, and the scales would do great damage unless the spray.were again applied."

Three of the 40 or more species of coccinellids sent to California by Koebele in 1891-92 became established. The most valuable species to become established was the mealybug feeder Cryptolaemus montrouzieri Muls. Orcus chalybeus became established near the seacoast at Santa Barbara, where it has persisted ever since. It was propagated and widely distributed at the time of its introduction, and again about 25 years ago by county officials in Orange County, and eventually became established at Costa Mesa in Orange County near the ocean. Rhizobius ventralis became enormously abundant, especially in the coastal region, and this introduction gave impetus to the 
biological-control movement. Prior to the introduction of Rhizobius, the black seale was notorious in the large olive orchard owned by Ellwood Cooper at Santa Barbara. Cooper had been fighting black scale continuously for about 20 years prior to the introduction of Rhizobius. When Rhizobius became abundant, he discontinued spraying, and so far as the records show never resumed this practice for the control of black scale.

According to Cooper, and much contemporary testimony seems to substantiate the claim, the black scale subsided at Santa Barbara and was not injurious following the work of Rhizobius. The only dissenter was C. V. Riley. A bit of conversation between Riley and John Scott, the Horticultural Commissioner of Los Angeles, was overheard by George Compere. Riley gave it as his opinion that causes other than Rhizobius were mainly responsible for the subsidence of black scale. Riley (1893a) believed that in many cases periods of excessive abundance of a pest are followed by periods of excessive scarcity irrespective of parasites and predators, and he was reluctant to accredit to Rhizobius a searcity of black scale that might have been caused by some other factor. As noted earlier, Coquillett, the most reliable of Riley's agents in California, was denied admittance to Cooper's ranch to appraise the work of Rhizobius. George Compere was angered by Riley's remarks and wrote an indignant letter to Howard complaining about Riley's lack of faith in beneficial insects. Whether or not Rhizobius controlled black scale at Santa Barbara in the early days, Cooper and his associates believed it did so, and this greatly stimulated their enthusiasm for biological control.

The claim by Cooper and his contemporaries that Rhizobius controlled black scale at Santa Barbara back in 1892-93 is regarded with skepticism by those who witnessed the attempt to control black scale in Ventura County by mass releases of Rhizobius about 1928-29. Rhizobius often destroys an enormous percentage of the young scales, but within the knowledge of the present generation it has not demonstrated a capacity to destroy a sufficient number of scales to prevent the infestations from quickly becoming injurious again.

\section{GEORGE COMPERE'S WORK}

The California State Legislature made a second appropriation of $\$ 5,000$ in 1899 to have the search for beneficial insects in foreign countries resumed. The position of foreign collector was offered first to Koebele, who declined, having a more remunerative position with the Board of Agriculture and Forestry. of the Territory of Hawaii. On the recommendations of Koebele and Craw, the position of foreign collector was then offered to George Compere (fig. 13) and accepted. Since Compere did not publish on his work, it is reported more fully here than Koebele's.

George Compere was a disciple of the men who recommended him and shared with them the unshakable conviction that no insect is a pest of sufficient gravity in its native home to warrant artificial control measures, as nature always provides a means of control in the form of parasitic and predaceous insects. Probably no man was better fitted than Compere to carry out the policies of the State Board of Horticulture. A program of such questionable merit and great magnitude might have deterred a scientifically 
trained man. Compere was rugged physically and indefatigable in the quest for enemies of injurious pests. He lacked formal training and his background was such as to give him unlimited confidence in the potentialities of biological control. In 1878, at the age of 20 , he was in charge of the old Vejar orchard, which was seriously infested with black scale. The control of black scale on

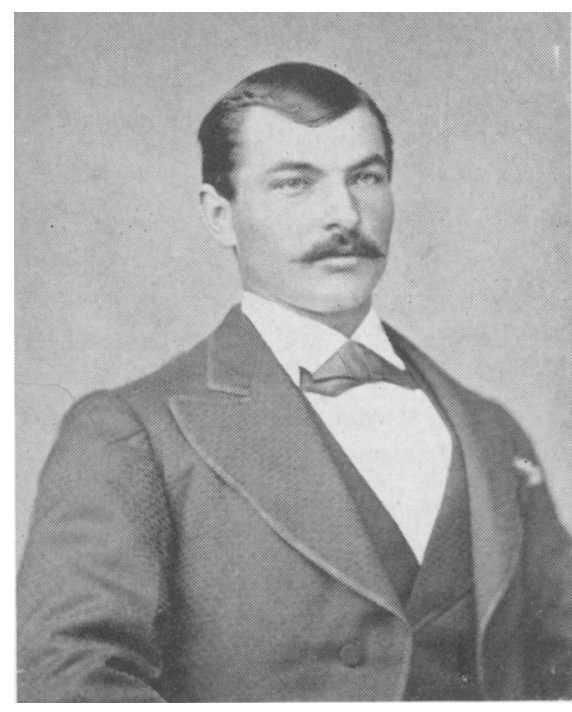

Fig. 13.-George Compere (1858-1928), from 1899 to 1909 , collector of beneficial ininsects for the California State Board of Horticulture. (From a photograph taken in 1888 when he gave his occupation as "farmer.") orange trees was his first insect problem. This became of secondary importance when cottony-cushion scale spread from the near-by nursery of Thomas A. Garey to the Vejar orchard. Compere experienced at first hand the difficulty of controlling scale insects with insecticides, and later witnessed the dramatic control of cottony-cushion scale by vedalia and the subsidence of black scale in the coastal area after the introduction of Rhizobius ventralis in 1892. From practical experience he learned that the most important problem confronting the citrus growers in southern California is the control of insect pests, and the most satisfactory way of controlling them is by the introduction of effective natural enemies. The control of pests by natural enemies became almost an obsession with him.

In 1891 he accepted a position as horticultural inspector for the San Antonio district of Los Angeles County and served in this position until 1898, when he accepted a special position created by the Los Angeles County Board of Supervisors to obtain enemies that were reported to control the purple scale, Lepidosaphes beckii (Newm.), in Hawaii. This position was discontinued by the county four months later when the California Legislature appropriated the money for a search for beneficial insects in foreign countries.

\section{Australia}

On July 17, 1899, Compere was -commissioned "Special Agent to search for practical and predaceous insects, beneficial to horticulture, for general distribution among the orchards of California," and sent to Australia. He was quickly disillusioned by what he found there so far as the coccinellids on red scale are concerned. Four months after arrival, he advised Craw that so far as he could see, the vedalia and Cryptolaemus were the only beneficial insects doing their work as it should be done, and that red scale was so severe that growers cut their trees back to the trunks, which were then scrubbed with brushes. In the same letter to Craw, Compere reported the discovery of an old seedling orange orchard at Singleton, New South Wales, severely 
infested with yellow scale without any signs of parasites, and near-by a lemon orchard severely infested with red scale on which Rhizobius satellus were feeding. This is the first record of the occurrence of yellow scale in Australia. $^{7}$

Compere spent seven months in Australia traveling almost continuously, and collecting and shipping all the beneficial insects that were found. Shipments to California were made on nearly every outgoing steamer. From Australia, side trips were made to New Zealand and Fiji. Nothing of practical value was obtained.

\section{Hong Kong}

Early in 1900, Compere received a letter from Koebele, dated February 27, 1900, Hong Kong, advising on the citrus-scale situation there. Koebele wrote that the purple scale was heavily parasitized, that only a few specimens of red scale were found, and that no black scale had been seen on this last trip, although previously it had been quite numerous at Amoy. When winter set in and the collecting of coccinellids in quantity became impossible in Australia, Compere decided to follow the lead provided by Koebele and proceeded to Hong Kong. En route the ship called at various ports, and he took advantage of these stops to collect and ship to California all the insects found feeding on scales. Red scale was reported to be the most abundant of the seale insects seen in Java.

The Boxer Rebellion broke out about the time Compere arrived in Hong Kong and it was impossible for him to go inland. A small plant was found in Hong Kong infested with red scale, some of which were parasitized. With reference to this plant he wrote:

... The balance of the time I spent investigating red scale, A. aurantii. I am pleased with what I have found.... There are only a few citrus trees here, with one exception, I have not been able to find more than one or two aurantii. Most of them contain the telltale hole in the back, but on the small tree is the exception. On this I found fifty or more scale scattered over the leaves and branches, and also a parasite actually at work depositing her eggs in the backs of the adult scales. Two parasites were seen but I could only capture one of them and this I send you. By the next steamer leaving here, the Doric, I will send the whole tree. I shall try to dig it up with a ball of earth and pack it in a box with wet moss and cover it with cloth. ${ }^{8}$

Craw (1902, p. 192) reported receiving from Compere one small orange tree, the basal part of the trunk of which was protected by weeds and badly infested.with red scale. These scales hatched and the young infested the upper part of the tree and leaves.

A total of 647 parasites were obtained from the red scale on this plant. These were released in Los Angeles and Orange counties. The greater number of parasites were released in an orchard at Anaheim that shortly afterwards was cut down and burned. Craw described the parasite as like Aspidiotiphagus only smaller. There has been some speculation concerning the identity of this parasite (Essig, 1931, p. 343). Howard's expert testimony on this

\footnotetext{
${ }^{7}$ The observation that the yellow scale infested old seedling orange trees tends to corroborate the determination. In southern California old seedling orange trees are apt to be much more severely infested with yellow scale than budded varieties.

${ }^{8}$ From letter of George Compere to A. Craw, October 19, 1900 ; from Hong Kong.
} 
question is of paramount importance; he wrote: "I shall be interested in your reply to my letter in which I reiterated my opinion that your red scale parasite is nothing but what I have all along taken them to be, Aspidiotiphagus citrinus (Craw)." It is unlikely that Howard could have mistaken Aspidiotiphagus for Casca, as has been suggested.

\section{Cooperative Project between Western Australia and California}

Compere was instructed to leave China until the fighting ended, the appropriation for foreign collecting was spent, and Compere was recalled to California after having spent one year and nine months in almost constant travel, making shipments of beneficial insects on nearly every steamer bound for California. Cooper informed Compere, on his arrival in California, that there was no possibility of continuing the search for beneficial insects since the State Legislature had failed to appropriate additional money, and nothing more could be done until 1903, when the Legislature met again. Compere returned to Australia and accepted a position as Entomologist with the State of Western Australia. In 1903 an agreement was made between Western Australia and California to make the collection and introduction of beneficial insects a coöperative project and share the expenses. Compere was employed under the terms of this agreement.

When in Brazil in 1904 on a fruit-fly project, Compere wrote Cooper that red scale was seen once on rosebushes in Baía and again in São Paula on the same plants, but never on citrus. This is the first record of red scale in South America. Later, in 1905, when in Israel on another project, Compere sent shipments of a red-scale-feeding coccinellid to California and Western Australia. This coccinellid was identified later as Chilocorus bipustulatus (Linn.). Since then at least two attempts have been made to establish this species in California. It may have been this same coccinellid that Compere reported having seen feeding on red scale in Asiatic Turkey.

The attempts to introduce parasites from South China into California and Western Australia having failed in 1900 and 1902, Compere returned to China in 1905. This time, advance preparations had been made. Some small trees infested with scale were sent from California and he took others with him from Perth. The plants shipped from California were never received, but those from Perth were in good condition on arrival. After the scales had been exposed to parasites in China, the scale-infested trees were returned to Perth in. cold storage, but no parasites were reared from them. However, a parcel of parasitized scale that was not shipped in cold storage but carried in person produced some live parasites after arrival in Australia. Newman, Government Entomologist in Western Australia, reported upon these as follows:

In November [1905] Mr. Compere, the Government Entomologist, on his return from China brought with him a small colony of parasites of the red scale. On opening up the package in which these little insects had made their journey, it was found that only 15 had survived the trip. These were liberated on a small orange tree infested with red scale, which had been enclosed in a breeding-out box in the Entomological Room of the Department, for the purpose of supervision and prevention

${ }^{\circ}$ From a letter of L. O. Howard to A. Craw, May 22, 1902, Washington, D.C. See footnote 3. 
of releasing any secondaries should they happen to be present. Within a few weeks a number of the true parasites were found to have bred out. These were liberated in local orchards, where they at once started to attack the red scale. The result, so far as can at present be seen, is that there are thousands of these little flies to be seen in and about the vicinity of their first liberation. Orchardists are warned not to spray for red scale, but to give the parasite an opportunity to establish itself. A visit to the Department, where specimens can be seen, will assist the grower to identify the parasite, and thus be able to protect it. (Western Australia Minister of Agriculture, 1906, vol. 13, p. 383.)

\section{Later Newman reported:}

It is pleasing to know that we have the assurance of our orchard inspectors that the red scale parasite has thoroughly established itself in this State, and can be seen on infested trees in and around Perth, where it is multiplying with great rapidity. This is a chalcid fly that was found in China, and is an internal parasite. An enlarged illustration of this insect will be found on page 573 of the Handbook of Horticulture and Viticulture published by this Department. A ladybird [Chilocorus bipustulatus] from Jerusalem has also worked great havoc by feeding on the red scale. Both these friendly insects were introduced in November of last year by Mr. Compere, the Government Entomologist, and were received by Inspector Newman, who is in charge of this work. They were at once placed in breeding jars and as they bred out were distributed on infected trees, where they were watched and cared for. It is anticipated that there will be sufficient numbers hatched out in the spring to supply most of the demand likely to be made. (Western Australia Minister of Agriculture, 1906 , vol. 14, p. 5.)

After the introduction of the parasite of red scale into Western Australia from Hong Kong, Compere attempted to introduce it into California, Hawaii, and South Africa. In 1906 Lounsbury wrote from Cape Town acknowledging receipt of a box of lemons bearing parasitized red scale. From Sydney, June 11, 1906, Compere wrote $\mathrm{Craw}^{10}$ in Hawaii as follows:

In charge of the butcher of the "Aorangi" I have placed two packages. One package contains three small boxes of lemons which are thickly covered with red scale, the other, two rose plants also infested with the same scale; all of these have been exposed to the attack of the little Chinese parasite at Perth, W. A. Keep one box of lemons and one plant for yourself, and the others I would kindly ask of you to send to the State Commissioner of Horticulture, San Francisco, by the first steamer leaving your port for San Francisco, and be sure and request the butcher not to place them where they will be too cold, any cool place will do.

Craw acknowledged receiving the material in good condition at Honolulu and forwarded part of the material to Ehrhorn at San Francisco.

Compere was convinced that red scale was controlled in South China by parasites, and that if these parasites were once established in California the control of red scale in California would follow. He shipped an enormous amount of material from South China to California during the years from 1905 to 1909. The greater number of shipments were made in 1906 and 1907. The following excerpt from a letter of E. K. Carnes sheds light on the identity of the parasites involved:

Your new parasite on the red scale, the one with patches on its wings is Comperiella bifasciata Howard. The other, Howard says, is a variety of Aphelinus mytilaspidis

${ }^{10}$ Alexander Craw resigned from the California State Board of Horticulture in 1905 to accept a position as Head of the Division of Entomology, Board of Agriculture and Forestry, Territory of Hawaii, and Edward M. Ehrhorn was appointed to fill Craw's position as Deputy Commissioner of Horticulture. Edward K. Carnes was appointed assistant to Ehrhorn to care for the beneficial insects received from abroad. 
and is found all over the East, West, North, South, Honolulu, Japan, Europe, and was described by him 25 years ago. Was bred by Koebele in many countries and from many things, etc. The other [a third species] is a new genus and a new species. ${ }^{11}$

The description of Comperiella bifasciata Howard was not published until April 1906. C. bifasciata was a manuscript name when used by Carnes in 1905. The original description is based on one female recorded as having been reared from Aonidiella aurantii, collected in South China by Compere. If this female actually issued from $A$. aurantii, the name $C$. bifasciata applies to the form now known as the "Chinese red-scale-inhabiting race."

The species referred to by Carnes as a new species and new genus is the species now known as Casca chinensis Howard.

\section{The Dispute over Apbytis Species}

In all probability, the species identified as Aphelinus mytilaspidis by Howard was not this species but Aphytis [=Aphelinus] lingnanensis (fig. 14), the same as that referred to as the "little, yellow, Chinese parasite" by Compere. A series of slide-mounted specimens in the collection of the Citrus Experiment Station and the old correspondence reveal an error, the consequences of which were tragic for Compere. Compere was convinced that the red seale was controlled by parasites in South China and that the most important parasite was the "little, yellow, Chinese parasite." The identity of this species became a matter of dispute during the lifetime of the persons involved. Howard first identified it as mytilaspidis, as shown by preceding information from one of his letters to Craw. Compere believed otherwise, and from Hong Kong wrote as follows:

It is almost impossible to find a single specimen of red scale here at present and the little yellow parasite is responsible for it more than Comperiella bifasciata. I don't care if all the entomologists in creation would coincide with Dr. Howard that the yellow species here on red scale is the same as that in California, I would still be of the contrary opinion. ${ }^{12}$

Following this, Compere gave some reasons for the contrary opinion and cautioned Carnes not to confuse the yellow parasite from red scale [=Aphytis lingnanensis Comp. ?] with the little yellow parasite from purple scale $[=A$. lepidosaphes Comp ?].

According to Howard (1930, p. 399), Compere was the right hand of the element that really delayed the progress of entomology in California. If the progress of entomology was delayed in the early years by Compere's claims that the red scale was controlled by its enemies, then its progress has been delayed in recent years by others making similar claims (DeBach, Fleschner, and Dietrick, 1948).

More than once Howard warned Compere that he was wasting his time and the state's money attempting to introduce parasites into California that

\footnotetext{
${ }^{11}$ From letter of E. K. Carnes to George Compere, March 15, 1905. Samples of the parasites collected by Compere in China and reared by Carnes in California were submitted to L. O. Howard for identification and may be preserved in the collection of the United States Museum. If so, an examination of the specimens with modern optical equipment might lessen the guesswork.

${ }^{12}$ From a letter of George Compere to E. K. Carnes, November 27, 1908.
} 
already existed here. Howard repeatedly identified Aphytis lingnanensis and chrysomphali with mytilaspidis, diaspidis, or fuscipennis. If my interpretation is correct, this misidentification of lingnanensis was largely responsible for ending the career of Compere as foreign collector, and the discontinuance of foreign work by the state from 1909 to 1913 . What follows is partly conjecture.

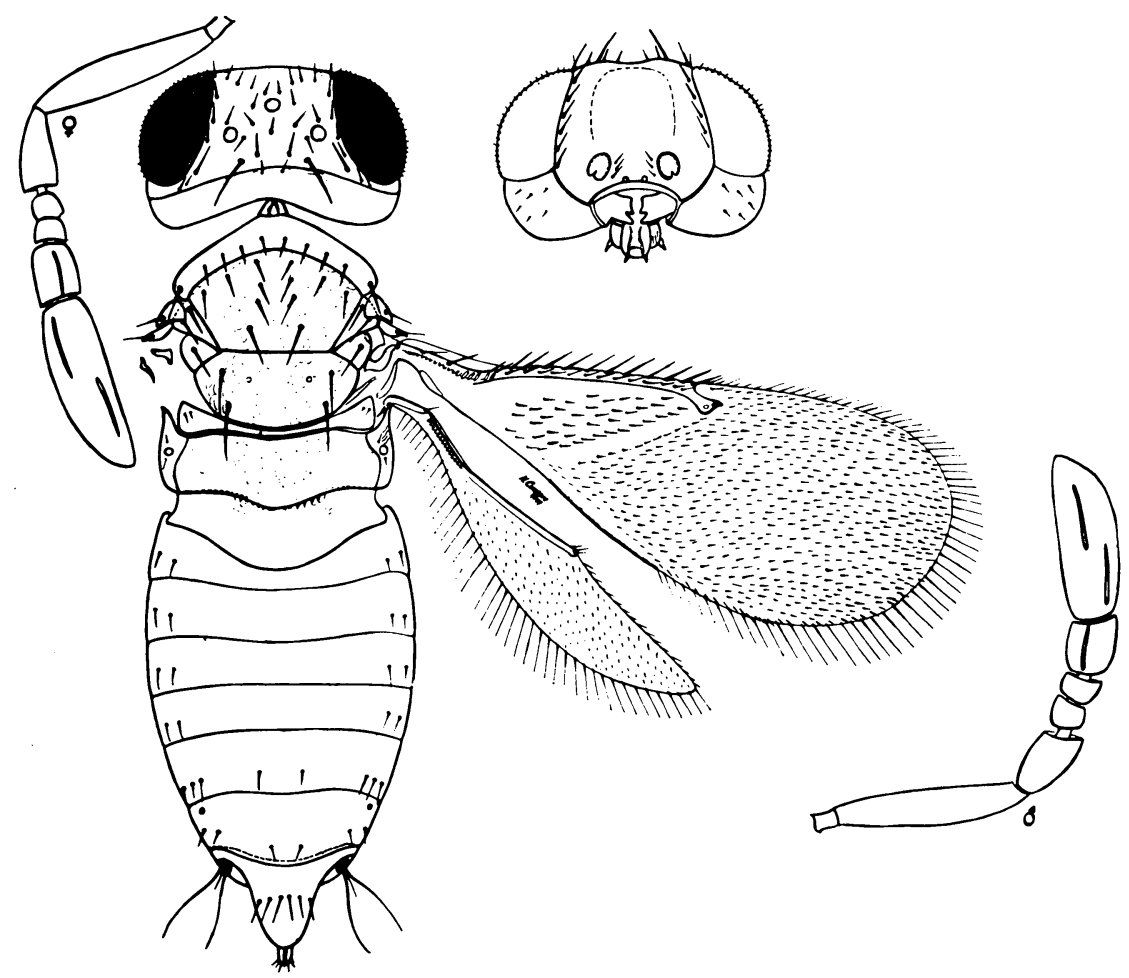

Fig. 14.-Aphytis lingnanensis Compere, the species presumably collected in South China by George Compere and referred to by him as the "little, yellow, Chinese parasite," and incorrectly identified as mytilaspidis by Howard.

In all probability, Howard gave the same advice to Jeffery that he gave to Compere in regard to the waste of time and money in the attempt to introduce into California parasites that already existed here. Before taking office as State Commissioner of Horticulture in 1907, Jeffery expressed himself as being very favorable toward foreign work. Shortly after taking office, he expressed great skepticism, questioned whether even a single parasite imported from China for use against the red and purple scales had become established in California, and instructed Compere to make a survey in southern California and report his findings.

As a result of a survey made in 1909, Compere reported that the red scale was at a very low ebb in San Diego County and that this favorable condition was due to the work of the "little, yellow, Chinese parasite." The specimens 
reared from red scale collected on this survey were mounted in balsam and carefully labeled in ink in the handwriting of Frederick Maskew. The labels also bear Howard's characteristic identification mark, "MYT" [= mytilaspi-
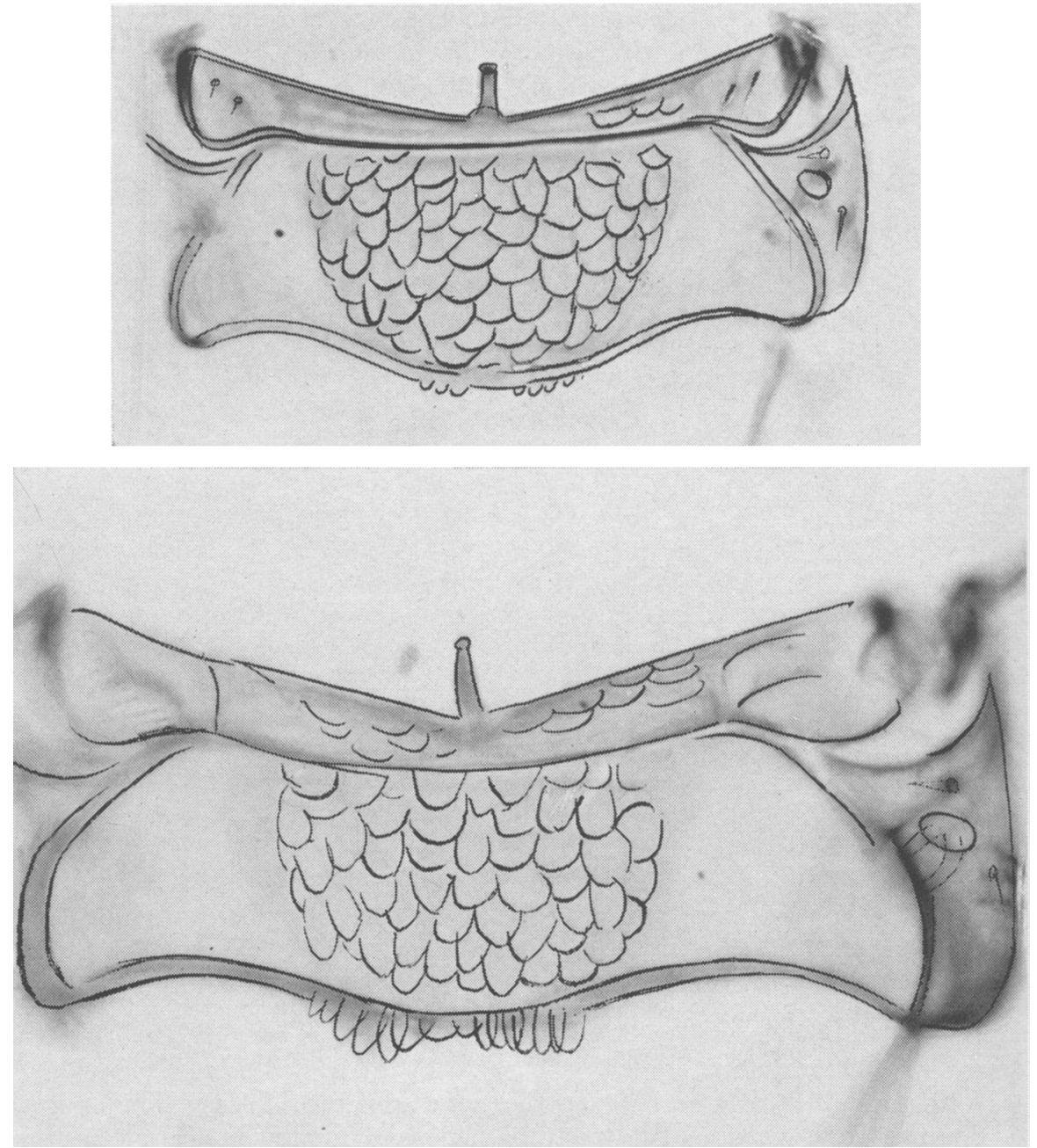

Fig. 15.-The difference in crenulae on the posterior margin of the propodeum that was used to separate Aphytis lingnanensis (hottom) as a species distinct from $A$. chrysomphali (top). (From retouched photographs.)

$d i s]$ in the latter's handwriting. The specimens were sent to Washington for identification, and presumably Howard advised Jeffery that the species allegedly introduced from China by Compere was already in California and not introduced from China as claimed by Compere. Regardless of whether or not my interpretation is correct, Compere's career as a foreign collector was ended. 
The specimens from California identified by Howard as mytilaspidis and referred to as the "little, yellow, Chinese parasite" by Compere are at hand. In my opinion, the species is Aphytis chrysomphali. The most important diagnostic character (fig. 15) by which $A$. chrysomphali can be distinguished with certainty from $A$. lingnanensis cannot be seen. The characters of supplementary diagnostic value, discovered by DeBach, that have been used with some success, indicate that the species is chrysomphali. It is certainly not mytilaspidis as identified by Howard. Howard's error, made at a higher "scientific" level than that of Compere, had more serious consequences.

Compere's appraisal of the red scale as being at low ebb in 1909, and his claim that the favorable condition was owing to the work of a parasite, is not without support. In his report as Entomologist, Howard wrote:

Incidentally in connection with this work, studies have been made of the scaleinsect enemies of citrus trees in California from the standpoints of life history and habits and of control by parasitic and other enemies. The most interesting outcome of this phase of the investigation has been the demonstration of the abundant parasitism of the red scale (Chrysomphalus aurantii Maskell), a scale pest of first importance, which has hitherto been believed to be remarkably free from parasitism. (Howard, 1908, p. 555.)

Compere believed that neglect, poor care, or faulty methods of colonization were responsible for the failure of Comperiella and Casca to become established in California. There is no record of Carnes' ever attempting to establish Aphytis lingnanensis after Howard pronounced it to be a variety of mytilaspidis. The criticism by Compere of improper care was not justified. In recent years a great amount of work has been done in attempting to establish Casca chinensis in California with negative results.

\section{CHANGES OF POLICY AND PERSONNEL}

Under Jeffery the search for beneficial insects in foreign countries by an agent of the state was discontinued, George Compere's position abolished, and Carnes was placed in charge of all work with beneficial insects. By correspondence, Carnes solicited the aid of forty-five entomologists in different parts of the world, offering in exchange to send any beneficial insects available in California, or to collect entomological specimens. So far as obtaining parasites of red scale is concerned, the results were negative.

Under Carnes, both native and introduced beneficial insects were collected and distributed within the state. His most important project was the release of large colonies of Hippodamia convergens G.-M. in the melon fields of Imperial Valley to control aphids each spring (fig. 16). Some of the work done by Carnes may have had value, but much of it is very questionable. A detailed account of the work under him is beyond the scope of this article. John Isaac appraised the work of these years in a newspaper article entitled "Bugs and Humbugs," presumably as a sequel to his publication, "Bug vs. Bug" (Isaac, 1905).

In 1910 Hiram Johnson, an implacable political enemy of Harrison Gray Otis, was elected Governor of California. Jeffery, the protege of Otis, was unacceptable to the new governor, who appointed A. J. Cook to replace Jeffery as State Commissioner of Horticulture in 1911. On January 1, 1913, Cook 
appointed Harry S. Smith Superintendent of the State Insectary to succeed Carnes, as the latter's work did not meet with Cook's approval. With the appointments of Cook and Smith, the long and bitter quarrel between the officials of the Bureau (earlier "Division") of Entomology and the State Commission of Horticulture came to an end.

In the spring of 1913, Smith announced a new program for the State Insectary, with the control of the citrus mealybug, Pseudococcus citri (Risso),

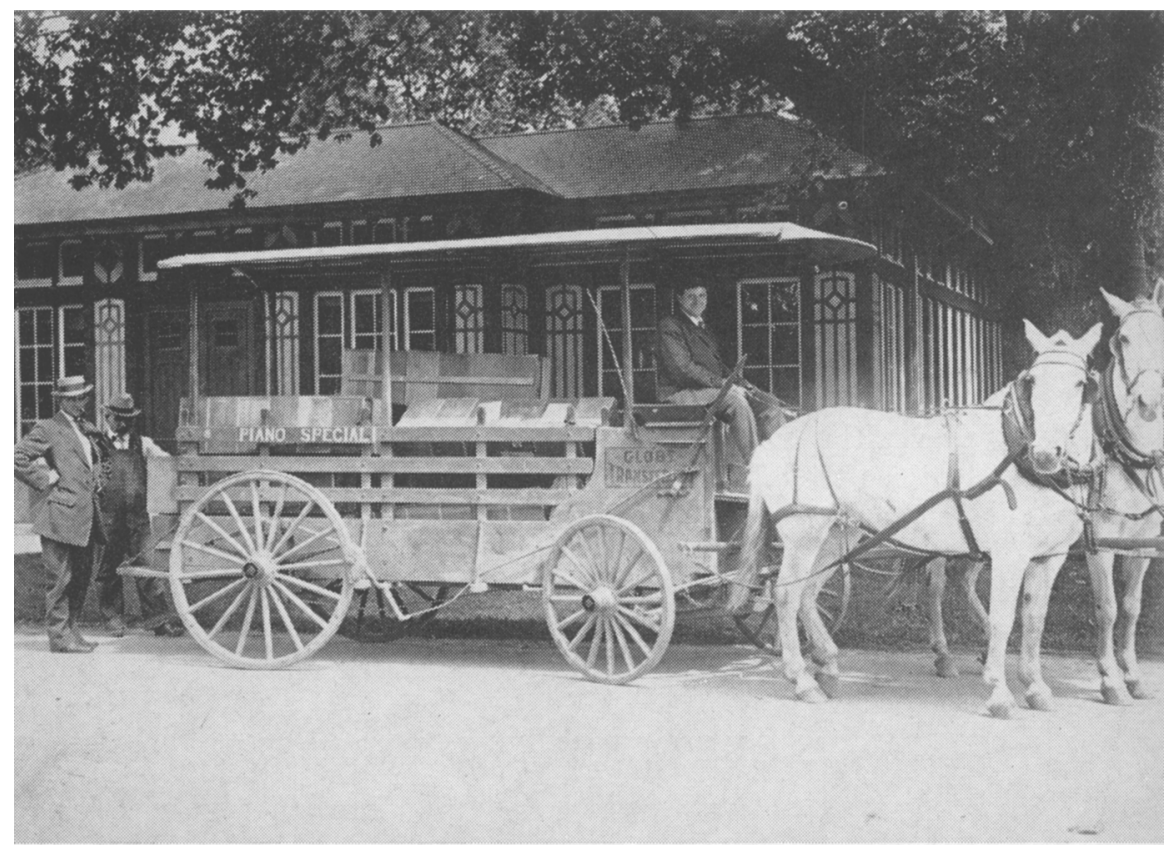

Fig. 16.-Crated Hippodamia convergens in front of the State Insectary at Sacramento, circa 1912, ready for transport to the Wells Fargo Express Office. Wells Fargo shipped the crated Hippodamia free as a public service to the farmers of California. Edward J. Branigan and George Compere (in overalls) standing at the tail gate.

as the number-one goal. For some years prior to this the citrus mealybug had become increasingly injurious, especially in Ventura County, where the most influential men in California agriculture owned valuable orchards. In August 1913 Smith made a trip to Japan and the Philippine Islands to collect beneficial insects. According to Vosler (1913, p. 770), a small internal parasite was reared at Sacramento from red scale collected in the Philippine Islands. Smith's trip to the Orient was not without value. The observations made in the tropics in 1913 profoundly influenced his thinking and future planning. In a report to Cook, he wrote:

In my opinion there is but little to be gained just at this time in attempting to obtain parasites in the Philippines and other tropical countries. The climate of the Islands is so very different from that of California that I believe there is little possibility of parasites obtained in these regions ever becoming effective checks to their hosts in this state, even if they become established. 
... I would not be in favor of attempting any future work in the tropics at this time, but would advise spending all our funds and time in obtaining parasites in Japan and the Mediterranean regions of Europe and North Africa, and possibly after these two regions have been exhausted, in South Africa. ${ }^{13}$

The control of mealybugs and black scale had priority over red scale from 1913 to 1922. Curtis P. Clausen (fig. 17) made a trip to the Orient in 1916-17. In a letter to Clausen, Smith wrote: "Shipment of Florida red scale [sent by

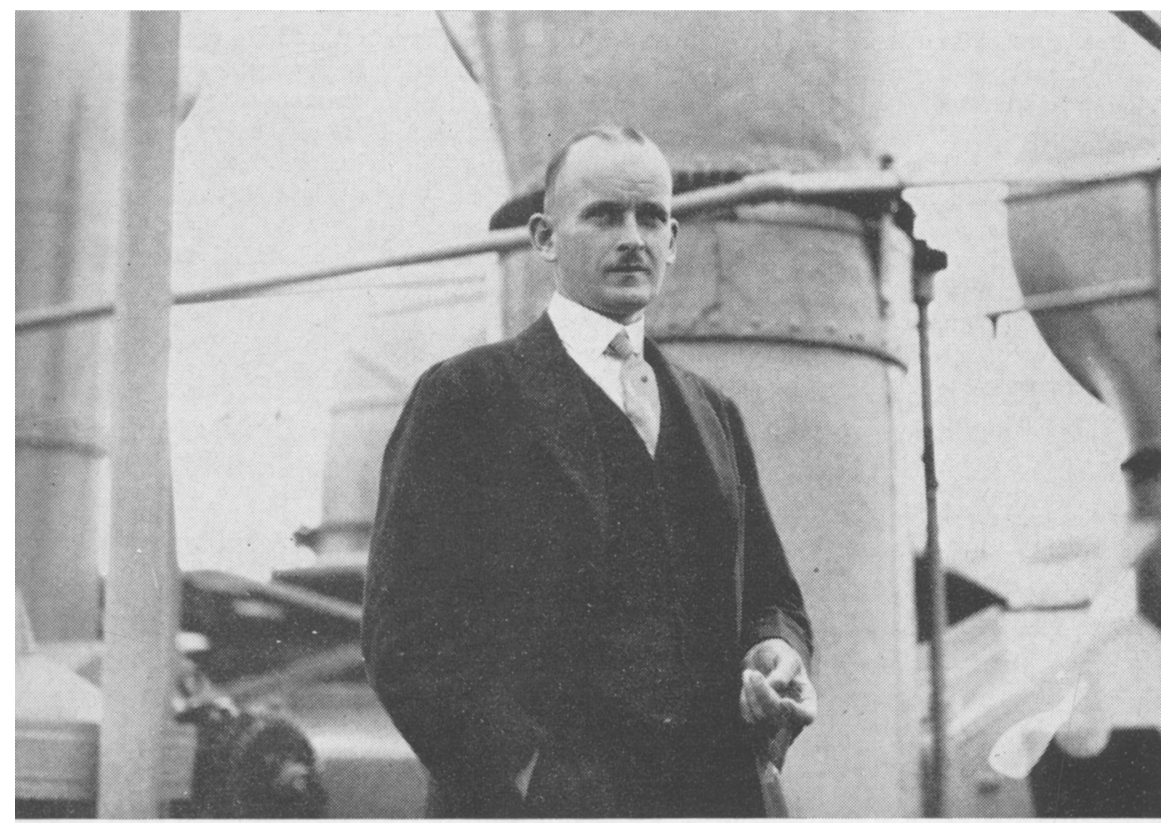

Fig. 17.-Curtis P. Clausen (1893- ). Bureau of Entomology 1920-1951; Chairman, Department of Biological Control, Citrus Experiment Station, Riverside, 1951-1958.

Clausen] yielded a large number of Comperiella bifasciata. Breeding these in insectary and hope to get them to work on California red and yellow. It is recorded from these species.",14

In another letter, dated July 21, 1916, Smith reported the propagation and colonization of 300 Chilocorus similis Rossi [=C. kuwanae Silv.] on yellow scale. After returning to California, Clausen wrote a report ${ }^{15}$ the most noteworthy item therein being information regarding his discovery of citricola scale in Japan.

After leaving the state service in 1920, Clausen was employed by the United States Bureau of Entomology. He spent sixteen years in the Orient collecting beneficial insects. Apparently he did not see anything there which indicated to him that the red scale was controlled by its insect enemies, although he was

\footnotetext{
${ }^{13}$ From a letter of H. S. Smith to A. J. Cook, December 31, 1913; see footnote 3.

${ }^{14}$ From a letter of H. S. Smith to C. P. Clausen, June 7, 1916; see footnote 3.

${ }^{15} \mathrm{C}$. P. Clausen. Report of a trip to the Orient in search of mealybugs and the black scale, Jan. 8, 1916, to June 23, 1917. Typewritten. See footnote 3.
} 
not especially concerned with this insect after leaving the state service, except in 1921-22, when he was in Japan (see p. 213). In reporting on his trips to tropical Asia, Clausen said of the red and yellow scales:

The California red scale, Chrysomphalus aurantii, is one of the most destructive of the scale insects on citrus in the Far East and is of very general distribution. In Malaya it ranks with Parlatoria pergandii as among the most important of these pests. Its attack in Malaya and the Dutch East Indies is largely restricted to the younger trees. At Kuala Lumpur the infestation was very heavy upon several plantings of orange trees, and in some instances resulted in the death of the smaller branches. A similar condition was noted at Medan, Sumatra, and Rangoon, Burma. On lemon, even in the case of very severe attack, relatively few scales were found upon the fruit. The species was very abundant on some pummelo trees at Pasar Mingoe, Java, while in the hill sections of that island it was only occasionally encountered. It was noted in Ceylon, but was not at all injurious. In all of the sections the evidence of parasite attack was very slight. During the rainy season in the tropics there is a heavy mortality from fungus attack.

The yellow scale, Chrysomphalus aurantii var. citrinus, is recorded from China, though it has not been seen in any of the countries included in the present investigations. (Clausen, 1933.)

In 1915, with the cooperation of Filippo Silvestri, Smith imported two species of scale-feeding coccinellids into California from Italy. It is recorded that 700 Chilocorus bipustulatus and 350 C. quadripustulatus (Linn.) were released at Fairoaks, near Sacramento.

In 1917-18, Everett J. Vosler made two trips to Australia primarily for parasites of the beet leafhopper. Incidentally he obtained Metaphycus lounsburyi (Howard). It was established here from material collected in New South Wales by Vosler. M. lounsburyi is native to Africa, having been introduced into New South Wales by Walter Froggatt in 1903 from material sent by Charles P. Lounsbury in Cape Town.

A. J. Cook died in September 1916, and shortly thereafter George H. Hecke was appointed to succeed him as State Commissioner of Horticulture. Hecke was enthusiastic concerning the possibilities of controlling pests by the introduction of parasites and predators and supported the work of the State Insectary.

E. W. Rust was employed as foreign parasite collector in 1918 and served in this eapacity until 1925. He spent the greater part of this time in South Africa. In an unpublished report ${ }^{16}$ made after returning to California from the first trip, which covered June 25, 1919, to December 20, 1921, Rust made one reference to red scale in Africa. In the Rustenburg area the citrus trees were found to be suffering from infestations of Aonidiella aurantii, Chrysomphalus dictyospermi (Morg.), and C. aonidum, and no parasites were reared that were considered of value to California. ${ }^{17}$ Rust was concerned primarily with the parasites of the black scale and citrus-infesting mealybugs. At this date the shipments from Cape Town to Whittier, where the receiving station was located, usually took 6 weeks and the insects were mostly dead on arrival. Rust was successful in bringing in person a colony of Scymnus binaevatus (Muls.) to California on the return trip. This mealybug predator ap-

\footnotetext{
${ }^{10}$ Now in the Department of Biological Control archives; see footnote 3.

${ }^{17}$ The species known there as Aphytis chrysomphali (Mercet) was repeatedly reared by Rust as shown by specimens in the collection of the Citrus Experiment Station.
} 
peared to be most promising and was colonized in California by the tens of thousands, but failed to become established. Subsequently, as a result of Rust's sending from South Africa, two species parasitic on black scale were established in California, namely, Coccophagus capensis Comp. and Lounsburya trifasciatus (Comp.). Exochomus flavipes Thunb. (fig. 18), a coccinellid of generalized feeding habits, and Oenopia cintella Muls, which feeds on aphis, were received from Rust, propagated in the insectaries, and colonized in California, but these did not become established.

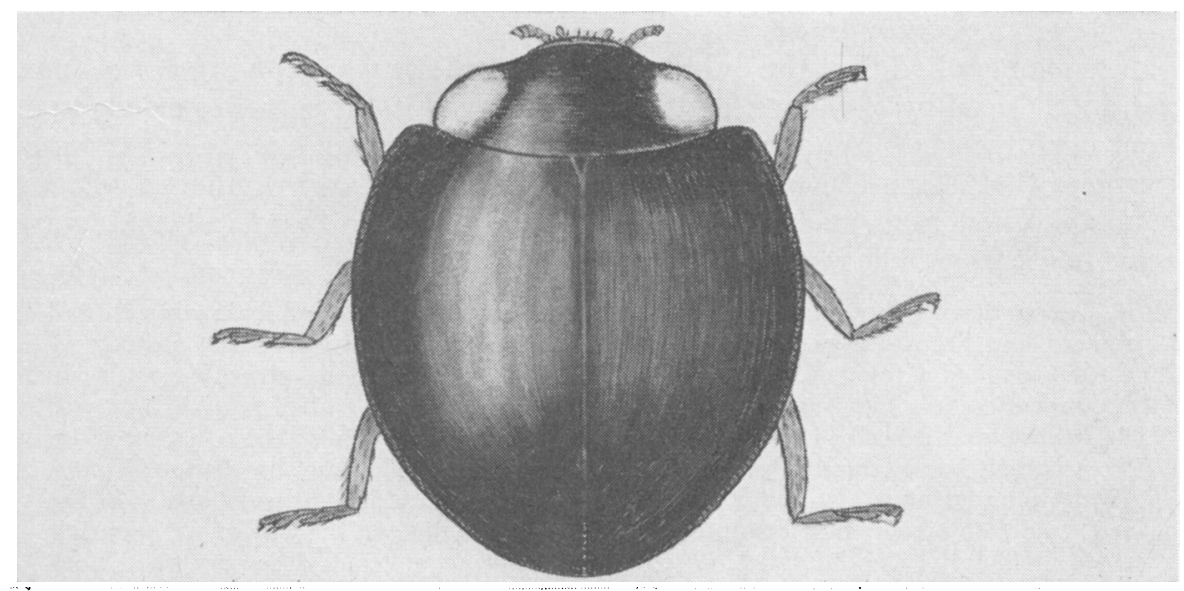

Fig. 18.-Exochomus flavipes Thun., a coccinellid introduced from South Africa that failed to become established in California. This species was propagated by the tens of thousands in Orange County and released there on various hosts including red scale.

The establishment of Metaphycus lounsburyi in California was the most important accomplishment of the 1910-1920 decade. In Ventura County the control of black scale by $M$. lounsburyi was so convineing that the management of the famous Limoneira Ranch believed that fumigation for this pest on their ranch was a thing of the past and sold their fumigation tents. Unfortunately the spectacular success of $M$. lounsburyi was short-lived; but it had an electrifying effect and aroused great enthusiasm for controlling the other citrus seales with their insect enemies. H. S. Smith (1920) wrote: "Work looking towards control of red and purple scales (Chrysomphalus aurantii Mask. and Lepidosaphes beckii Newm.) of citrus by the biological. or parasite method has begun."

An article published in 1920 in the California Citrograph aroused worldwide intercst and speculation and led to an exchange of letters over several months between Lounsbury in South Africa, Newman in Western Australia, and Smith in California. The article was a communication from a citrus grower testifying that his orchard at Keybrook, Western Australia, had been badly infested with red scale until a small yellow chalcid wasp had become established there three years previously, but the orchard had remained perfectly clean since then (Shaw, 1920). 
When Lounsbury read Shaw's communication he immediately wrote Newman and sent a copy of the letter to Smith. In this letter Lounsbury commented:

In So. Africa the Red Scale is little molested by parasites. The species most commonly observed is Aspidiotiphagus citrinus. Predaceous insects help materially at times, but it is thought by our entomologists that much of the temporary decline of the pest attributed to them is really due merely to the food plant having become for a time unfavourable to the scale. Our entomologists hold that our common pest scales fluctuate greatly in prevalence quite apart from influences exerted through natural enemies; and they consequently think it possible that the subsidence of the Red Scale in Mr. Shaw's grove may not be due to the parasite as he now believes. ${ }^{18}$

Newman replied that the only successful parasite was Aphelinus fuscipennis, introduced by Compere, and that he believed it "at certain periods to do very useful work. ${ }^{, 10}$ When Smith was advised of Newman's reply he expressed surprise that $A$. fuscipennis was attacking red scale and wondered whether a mistake had been made in its identification. Of the insects attacking red scale in California he reported:

The species which we have here that is most abundant on the red scale you will find recorded in literature as Aphelinus diaspidis. Mr. Rust, however, made a study of these parasites a few years ago and concluded that the parasite attacking red scale was not diaspidis but was an undescribed species which he called quaylei. You will find this insect described in the Canadian Entomologist I think about 1915 or 1916. This parasite occasionally does very effective work in California, but is not reliable. We have undertaken a study of this parasite along with other natural enemies of the red scale with a view to determining just what can be done in the way of propagating them artificially. The ladybird, Rhizobius lophanthae, at times does very good work on the red scale in the coast counties. I believe, however, that this ladybird already occurs in South Africa, at least I have seen specimens which Mr. Rust sent that I am not able to separate from this species. Orcus chalybeus also does pretty good work at times, and if you do not have this ladybird in South Africa, I would suggest that you attempt to introduce it. ${ }^{20}$

Lounsbury told Smith ${ }^{21}$ he had been rearing parasites locally present in red scale and, though "it seems to do little good," had sent specimens to Howard for identification, before trying to import the West Australian parasite. Howard had replied: "The parasites from the red scale have been mounted, and the species proves to be a true Aphelinus which I cannot distinguish from some of the A. fuscipennis mihi of which the wings are clearer than with others." "Now I am stumped," said Lounsbury; "I am writing to Newman asking him to send some Western Australian specimens to Howard with a view to learning if the species is the same."

Smith replied:

... I am inclined to think that you will find the Australian parasite is the same that you have in South Africa, and it is undoubtedly the same thing which we have here in California. In fact, I have been so convinced of this that I have never taken

${ }^{18}$ Letter from C. P. Lounsbury to L. J. Newman, February 24, 1921, from a copy sent to H. S. Smith. See footnote 3 .

${ }^{19}$ For a systematic account of Aphytis fuscipennis see Compere, 1955, pp. 297-98. More detailed information about the identity of the parasite in Australia referred to as fuscipennis is to be found under the heading, "Reports from Australia."

${ }^{20}$ Letter of H. S. Smith to C. P. Lounsbury, June 30, 1921.

${ }^{21}$ Letter of C. P. Lounsbury to H. S. Smith, August 18, 1921. 
the trouble to attempt the introduction of these red scale parasites from Australia. I do hope, however, that we will be able to locate something for the red scale in some other parts of the country. George Compere still insists that there are valuable natural enemies of the red scale in China. Perhaps some day we will be able to obtain them. ${ }^{22}$

\section{IMPORTATION OF PARASITES FROM JAPAN}

In the Annual Report of the Director of Agriculture, G. H. Hecke (1921) stated that the black scale was under control and "An attempt is now under way to apply the same method to the red."

In 1923, H. S. Smith included in his report to Hecke the following note, actually written by H. M. Armitage, who was in charge of the Southern Branch of the State Insectary, with headquarters at Whittier: "The carrying on of preliminary investigations relating to the possibilities of controlling the red, purple, and citricola scales and the orange tortrix by the biological method, particular attention being given to the development of host material under laboratory conditions."

This new movement to control red scale biologically had the support of some of the most influential citrus growers, notably C. C. Teague of Santa Paula and C. E. Utt of Tustin. The latter initiated a campaign in Orange County to obtain contributions from citrus growers to finance the cost of further biological control work. When a fund was eventually collected, a committee of growers decided to spend it on the construction of a county insectary for the propagation of Cryptolaemus montrouzieri Muls. rather than on explorations for natural enemies of red and purple scales as planned originally.

At this date, 1921, no state money was available for sending a collector to the Orient, and an arrangement was made between Harry S. Smith and L. O. Howard to have C. P. Clausen ship parasite material from Japan to California. Clausen was then a federal employee stationed in Japan on a mission for the U. S. Bureau of Entomology. His shipments from Japan were forwarded to Whittier and cared for by me.

Owing to the horticultural quarantine laws which prohibited the importation of citrus in any form from the Orient into California, Clausen was of necessity required to ship parasitized scales on plants other than citrus. At that date, 1921, and as late as 1937, a species of scale commonly found on Podocarpus spp. in Japan was repeatedly mistaken for red scale, Aonidiella aurantii. The greater part of the red-scale material sent to California from Japan by George Compere in 1909 or earlier, C. P. Clausen in 1921-22, and F. Silvestri in 1924-25, consisted of $A$. taxus Leonardi (not the California red scale, $A$. aurantii, as reported) and Chrysomphalus bifasciculatus Ferris (not the Florida red scale, $C$. aonidum, as recorded). The failure to identify these scales correctly resulted in much confusion; this is further discussed under "Systematics."

The first shipment from Clausen was a failure-only a few parasites issued and these died shortly after emergence. A second shipment was more successful. A letter from Clausen to Smith, dated Yokohama, Japan, October 21,

${ }^{22}$ Letter from H. S. Smith to C. P. Lounsbury, September 27, 1921. 
1922, advised the latter that the material was collected at Nagasaki on October 18 and shipped on October 22. It was rcceived at Whittier, November 11, 1922. The following excerpts from Smith's report pertain to this shipment.

A large shipment of parasitized red scale (Chrysomphalus aurantii) comprising eighteen large boxes. This shipment became lost in transit at San Francisco, went into dry dock with the vessel which carried it from Japan and was fumigated with the vessel before it was located. It, however, came through in apparently good condition. (H. S. Smith, 1923).

The following notes of mine were included in Smith's report to Hecke.

Compericlla bifasciata Howard. A parasite of both Florida and California red scales. ${ }^{23}$ The same as ... recorded from No. 1468. Two hundred and seven specimens were recovered, part of which were liberated in the field on the Bastanchury Ranch at Fullerton in Orange County, on a covered lemon tree infested with citrus red scale (C. aurantii), and the balance retained in the laboratory for propagation purposes.

(b) Perissopterus carnesi How. A secondary parasite apparently working on Comperiella and recorded in a previous shipment. One hundred sixty specimens issued and were killed for the collection. (H. S. Smith, 1923, p. 336).

\section{Later in the same article Smith reported:}

Comperiella bifasciata How. This parasite of the red scale attacking both Chrysomphalus aurantii and C. aonidum gave evidence from observation of the original parasitized material from Japan of being a very desirable parasite. It oviposited freely in both of the scales mentioned and its propagation seemed a simple matter. The results, however, were very disappointing. Only a few adults emerged from $C$. aonidum and a single male from $C$. aurantii. No recovery of them has ever been made from the covered tree on which a fairly large colony was placed. There may be some difference, overlooked, between the Japanese form of $C$. aurantii and our native form, although this point has been investigated by Ferris who reports that they are indistinguishable. With that in mind two crates of plants infested with a local form were made up and forwarded to Mr. Clausen at Yokohama to be used in a direct effort to establish this parasite on them. Results are being awaited with interest. (H. S. Smith, 1923, p. 337).

The appraisal of the material from Clausen in 1922 led to the belief that Comperiella bifasciata was an effective and valuable parasite and that every effort should be made to establish it in California. The belief was warranted on the basis of our knowledge at that date. A very high percentage of the scales on the Podocarpus had been parasitized by Comperiella although both scales and parasites were nearly all dead on arrival. It was not learned until many years later that this optimistic appraisal was based on the work of C. bifasciata as a parasite of Aonidiella taxus and not on A. aurantii as was supposed. In Japan Comperiella may be an important factor in holding $A$. taxus in check.

The form of Comperiella bifasciata (fig. 19) common in California today on yellow scale, Aonidiella citrina, is that which attacks $A$. taxus in Japan. This form never succeeds in reproducing generation after generation in the California red seale, A. aurantii, and the Florida red scale, Chrysomphalus aonidum, and it reproduces poorly in Chrysomphalus bifasciculatus.

${ }^{23}$ It is now known that this particular race of Comperiella bifasciata breeds freely in Aonidiella taxus and $A$. citrinus but not in either Florida or California red scale as reported. I misidentified $A$. taxus as $A$. aurantii and $C$. bifasciculatus as $C$. aonidum. 


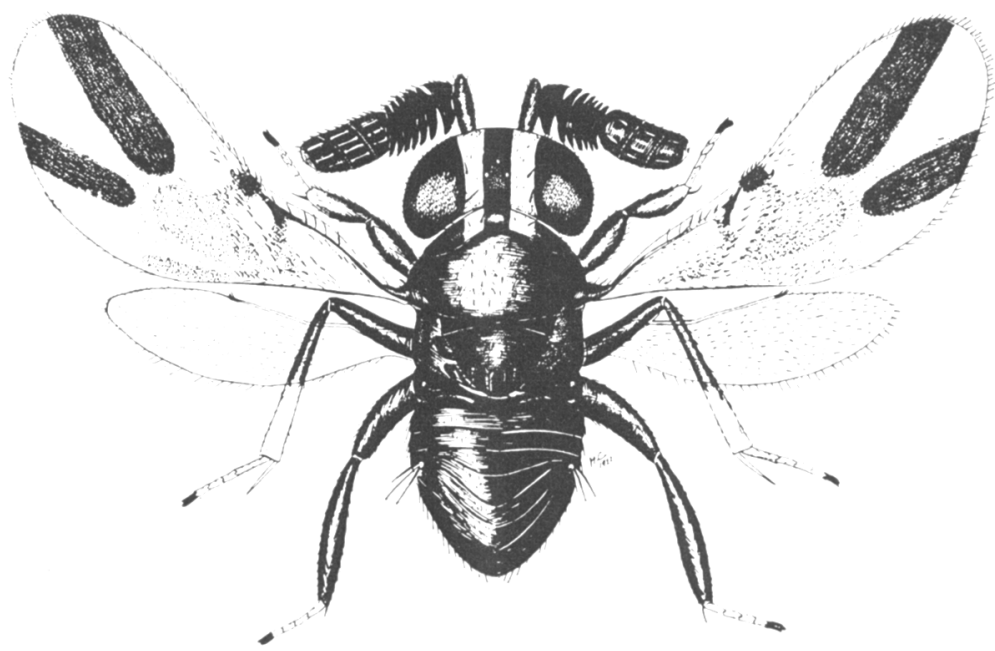

Fig. 19.-Comperiella bifasciata How., the form reared from Aonidiella taxus on Podocarpus sp. collected in Japan by Clausen.

\section{TRIALS WITH LOCAL PREDATORS}

In 1921 Smith inaugurated a program to test the capacity of the ladybirds already in California to control red scale. He wrote:

Certain work is being carried on in connection with the red scale in an effort to determine the efficiency of some of the predators and parasites of that pest already in California. From ten to fifteen thousand of the steely-blue lady-bird beetles (Orcus chalybeus) have been placed in each of five plots of trees heavily infested with the red scale and are being carefully checked up in order to determine their value as red scale feeders. The plots which vary in size from five acres down to fifty trees, are located in Tustin, Orange, Placentia [all three in Orange County], Corona [Riverside County], and Whittier [Los Angeles County]. It is intended to place in some of these plots as soon as possible Rhizobius [Lindorus] lophanthae and Chilocorus bivulnerus, two ladybird beetles which have been noted as doing exceptionally good work in controlling this pest. The small golden chalcid, Aphelinus diaspidis [=Aphytis chrysomphali], an external parasite of the red scale, is present in nearly all of the plots and its work will be kept under careful observation. (H. S. Smith, 1923.)

This new program was inspired by the belief that Chilocorus bivulnerus, Lindorus lophanthae, and Orcus chalybeus (fig. 20) controlled red scale in Santa Barbara County. Certain orchards in that county, particularly the Ogilvy and Crocker-Sperry orchards at Montecito, had been under observation for several years prior to 1921. In these orchards the red scale remained relatively innocuous until the fall of 1922, when an injurious infestation was reported to have developed in the Ogilvy orchard. According to Armitage:

The Ogilvy orchard at Montecito in Santa Barbara, which has been under observation for some years as regards the natural control of red scale, was visited on the 9 th [February, 1923] at that time it was learned that the red scale had appeared 
so abundantly last fall that spraying became necessary. The grove was fairly clean at the time visited and very few of the natural enemies of the red scale were observed. ${ }^{24}$

The three species of ladybirds believed to control red scale in Santa Barbara County were collected there in large numbers and released in the test plots in Orange, Los Angeles, and Riverside counties, although with one exception Chilocorus bivulnerus and Lindorus lophanthae already occurred in them, as did Aphytis chrysomphali. The exception was the plot at Corona, where no predators or parasites were found prior to their colonization.

In addition to the ladybirds mentioned, Scymnus marginicollis Mann. was released in all the test plots in colonies numbering as high as 50,000.

In an attempt to find a useful host plant for propagating red scale in large numbers under insectary conditions, Armitage experimented with rose, willow, and fig cuttings and datepalm seedlings, with unsatisfactory results.

The Whittier plot in Los Angeles County, a 10-acre tract known as the Volkmore orchard, was most amenable to biological control. When the plot was selected in the fall of 1921, it was said to have been seriously infested with red scale. The infestation subsided after the ladybirds were colonized, and the plot remained commercially clean for three years, when the increase of purple scale made it necessary to fumigate to protect the trees from injury by this pest. Armi-

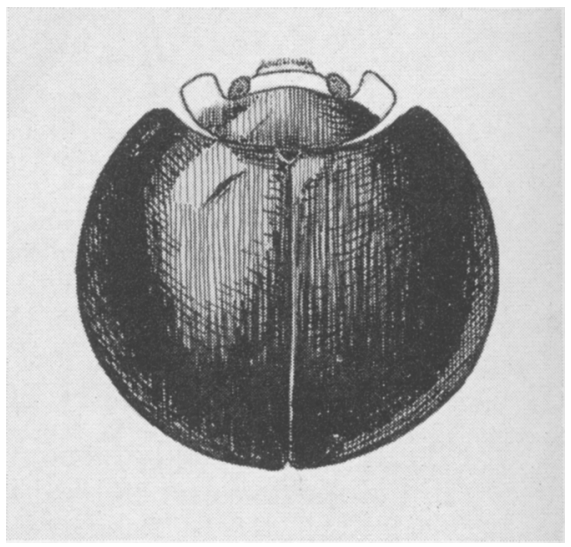

Fig. 20.-Orcus chalybeus (Bdv.), the red-scale-feeding ladybird introduced into California from Australia by Koebele. tage attributed the subsidence of red scale to Chilocorus bivulnerus. There is nothing in the records to indicate that $C$. bivulnerus became any more numerous, or appeared more effective, in the Volkmore plot, where the red scale subsided, than in some of the other plots where the red scale increased.

Orcus chalybeus disappeared in all the experimental plots, as it did in 1893, except in Santa Barbara. I suspect that Chilocorus bivulnerus was no more effective in 1921-1923 than in 1893, when Kercheval first experimented with it.

The Corona plot in Riverside County was the most refractory to biological control. Here the increase of red scale was so rapid that before the observations were completed it was necessary to fumigate to save the trees from further injury. Shortly before the plot was fumigated, Armitage was unable to find a single ladybird, although they had been colonized by the thousands.

If judged by temperature requirements alone, one would prophesy Corona as an area favorable for the multiplication of both the ladybirds and the

${ }^{24}$ From a letter of H. M. Armitage to H. S. Smith, March 10, 1923. My knowledge of the outcome of the work with local predators is based largely on the monthly reports and letters which Armitage sent to Smith, from March 1, 1922, to March 10, 1923. See footnote 3 . 
parasites which prey upon red scale. There the winters are warmer and the summers cooler than in many citrus-growing areas in Orange and Los Angeles counties, where the ladybirds and parasites are occasionally reported to do good work. Why the red scale reproduces so exuberantly and its enemies disappear in Corona remains unanswered. To this day Corona is avoided as an area in which to demonstrate the capacity of parasites to control red scale.

The Tustin plot in Orange County is discussed under the heading, "Observations on Aphytis chrysomphali." Other plots not discussed above revealed little or nothing of historical interest.

$\Lambda$ program of controlling red scale with local ladybirds that was a replica of that of Smith and Armitage was conducted in Orange County, first by Anson A. Brock and later by Dixon W. Tubbs. Brock became concerned with controlling red scale with its enemies while serving as Horticultural Commissioner of Ventura County, although the red scale was not known to occur in that county. After witnessing the spectacular but short-lived control of black scale there in 1919-1921, Brock became an enthusiastic advocate of controlling red scale biologically. His enthusiasm was contagious. It was transmitted to the Orange County Board of Supervisors, and Brock was appointed Horticultural Commissioner of Orange County to replace Earl Morris, an advocate of chemical methods of pest control. According to Armitage,${ }^{25}$ orchardists from Orange County were taken on tours of inspection in Santa Barbara County by Brock, so that they could see at first hand the control of red scale there by ladybirds. The attempt to control red scale with ladybirds in Orange County was continued by County authorities for some years after this kind of work was discontinued (in 1923) by State authorities.

\section{OBSERVATIONS ON APHYTIS CHRYSOMPHALI}

According to Armitage ${ }^{20}$ the red-scale parasite Aphytis chrysomphali was present in appreciable numbers when the Tustin plot was selected in the fall of 1921 . He reported a decline in the number of parasites in the spring of 1922 and an increase in June of that year. Armitage's final report on the Tustin plot is in a letter to Smith, which reads in part:

In the plot on the Hewes Ranch at Tustin, the infestation of the red scale is at a very low ebb. This condition cannot be attributed to any of the predators placed in the plot as they have practically been absent since last September. Part of the mortality is inexplainable, the scale in all stages having died and the shells been removed from the trees by the elements. Part of the mortality has been caused by the golden chalcid (Aphelinus quaylei) [=Aphytis chrysomphali]. While the trees in the plot are excellent shape at the present time the fact must be taken into consideration that the small amount of live scale present at this season of the year is capable of reaching very serious proportions before the end of the year. ${ }^{27}$

Armitage's observations on the work of Aphytis chrysomphali at Tustin in 1923 is in substantial agreement with those of earlier observers-Bishop

${ }^{25}$ In a letter of H. M. Armitage to H. S. Smith, July 22, 1922.

${ }^{20}$ Summarized from letters and reports of H. M. Armitage to H. S. Smith under dates of March 1, 1922; April 15, 1922 ; July 22, 1922 ; January 10, 1923; and March 10, 1923; see footnote 3 .

${ }^{27}$ From a letter of H. M. Armitage to H. S. Smith, March 10, 1923 ; see footnote 3. 
(1902), Rafferty (1906), Howard (1908, 1909), George Compere in 19092and also those of DeBach and associates after 1948 (DeBach, Fleschner, and Dietrick, 1948).

It is reasonable to assume that only those scales that were inhabited or showed signs of having been inhabited were recognized as having been killed by Aphytis by Armitage and other early observers. Host feeding and mutilation by adult parasites was not recognized as a cause of red-scale mortality prior to 1948. Today when Aphytis is abundant a high percentage of "unexplained mortality" is apt to be credited to host feeding and mutilation by adult Aphytis; yet long before Aphytis came into prominence as a parasite of red scale, both Coquillett and Craw were puzzled as to the cause of "unexplained mortality" in both red and black scales.

After the early enthusiasm subsided, Aphytis chrysomphali was not regarded as having a capacity to control red scale until 1942, when Flanders propagated this parasite in large numbers in the insectary and presented to citrus growers the "inundative" method of controlling red scale with Aphytis (Flanders, 1951). In 1948 DeBach and associates announced that in citrus orchards that had not been treated with insecticides for at least seven years the red scale was controlled by its insect enemies of which Aphytis chrysomphali was the most efficient, and that this parasite was the only enemy apparent in groves having very low scale densities (DeBach, Fleschner, and Dietrick, 1948).

\section{SILVESTRI'S MISSION TO THE ORIENT}

Filippo Silvestri (fig. 21) investigated citrus scales and their enemies in the Orient for the University of California from August 1924 to November 1925. A resumé of the situation that led to his employment by the University follows.

All attempts to establish parasites and predators from the Orient had failed. There was every reason to believe that Comperiella bifasciata was an important parasite of red scale in China and Japan. It had been repeatedly colonized in California under supposedly the most favorable conditions without becoming established. A puzzling situation existed and Smith proposed to solve it by obtaining the most competent authority to investigate citrus scales in Asia and introduce into California the enemies of Aonidiella aurantii, Lepidosaphes beckii, and Saissetia oleae. Smith entered into negotiations with Silvestri in 1922, when the biological control work was under the California State Department of Agriculture. The negotiations were not completed until 1924, after this work had been transferred to the University of California. This transfer was authorized by an act of the State Legislature in Senate Bill No. 400, Jan. 30, 1923. It contained a provision for employing an expert entomologist for work in foreign countries. Silvestri was selectcd as the most competent entomologist of the time and no one was better qualified. His knowledge of injurious and beneficial insects was most comprehensive, and biological control was a special interest. Silvestri accepted a temporary appointment from the University for one year, later extended six months.

\footnotetext{
${ }^{28}$ Letter of George Compere to J. W. Jeffery, San Diego, December 1909.
} 
Silvestri arrived in Hong Kong, August 20, 1924. War and banditry restricted his movements in China, but he ranged from Hong Kong in the south to Peking in the north and as far inland as Hankow. From China he made side trips to Indo-China, Korea, Japan, Formosa, and the Philippine Islands. He terminated his investigation at Shanghai, November 20, 1925. Silvestri eventually published descriptions of many new species of injurious and beneficial insects discovered by him in the Orient. Aside from a systematic article in which some species of Prospaltella reared from citrus-infesting scales are described (Silvestri, $1930 b)$ and a seven-page article in the nature of a summary on citrusinfesting scales and their insect enemies in the Orient (Silvestri, 1930a), the only source of information concerning Silvestri's work in the Orient for the University of California are the letters in which he reported his findings to Smith and records made by me concerning shipments from him.

Silvestri (1930a) listed 29 scales found on citrus, at least occasionally, during this trip, and mentioned parasites and predators he found on them. Of the red scale, Aonidiella aurantii, he said:

I found this species on Citrus and on many other trees in all localities I visited from Indochina to Peking and the Philippine Islands, Formosa, and Japan. For me it is certain that the original home of the species is in the Far East, where it is generally well controlled by natural agencies, comprising several parasites I bred. Some of these are well known, others belong to new species discovered by me: Comperiella bifasciata, Casca sp. n., Prospaltella aurantii, Aspidiotus spec., Aphelinus spec., Chilocorus kuwanae, and $\dot{T}$ elsimia emarginata. (Silvestri, 1930a.)

Elsewhere he speaks of the last two

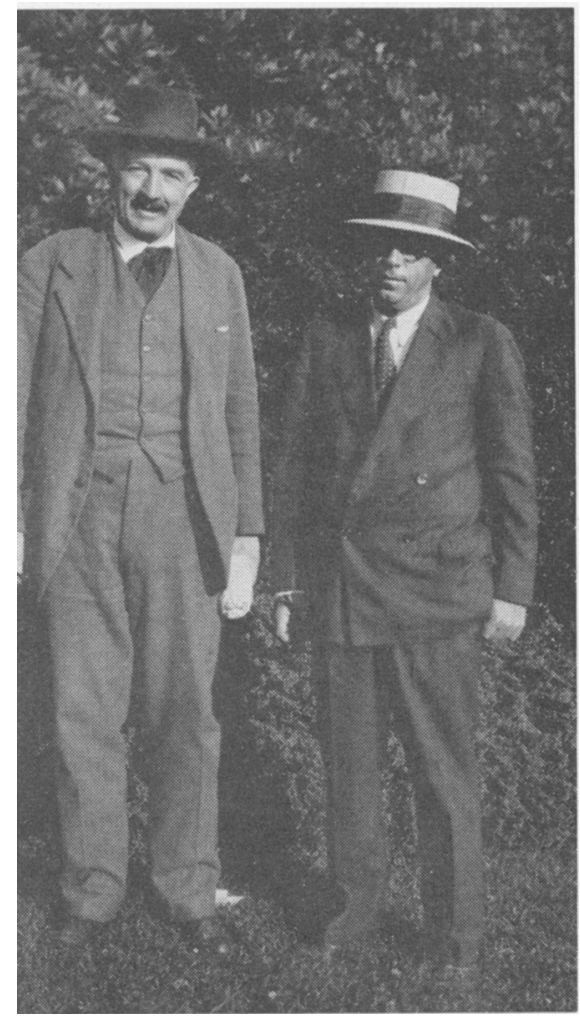

Fig. 21.-Filippo Silvestri (1873-1949) left, Harry S. Smith (1883-1957) right. (From photograph taken by E. O. Essig at Berkeley, California, August 13, 1930).

\section{and Eleurodothrips fasciapennis}

Fakl: as the most common predators. He does not mention his shipments to California.

Smith wrote Silvestri as follows:

Mr. Timberlake has carefully compared the specimens of Aphelinus which you sent on a slide and which you reared from $C$. aurantii with our Aphelinus chrysomphali. He says that he can find no difference which would justify us in considering them a different species. I am of the opinion, however, that it would be worthwhile to liberate such Chinese material in California, since it may have possibly developed 
a strain there that would be more effective under our conditions. While I doubt if it would be worthwhile to spend any great amount of effort in collecting and shipping this Aphelinus we would consider it advisable to colonize whatever material appears in your shipment. ${ }^{20}$

My records of red-scale enemies sent by Silvestri follow.

Aphelinus diaspidis Howard and Aphelinus chrysomphali Mercet

Both of these species, which are common in California, were bred from several of Silvestri's shipments. $A$. chrysomphali was especially abundant working on Florida red scale infesting Aspidistra. Several colonies comprising several hundred individuals were liberated in the Citrus Experiment Station orchards..$^{30}$

Chilocorus kuwanae Silv. was propagated in the insectary and colonized in different red-scale-infested districts. It was established, at least temporarily, on red-scaleinfested lemon trees on the Crocker Estate at Santa Barbara. Nine hundred adults were released here. The average colony released ranges from fifty to one hundred adults. In the eages $C$. kuwanae reproduced on black and red scales.

A species of Notalipernes was collected in large numbers at Foochow, in October and November 1924, and shipped to California by Silvestri. Thousands of beetles were received dead and only six alive. These six reproduced on red scale in cages in the insectary and colonies were released. The results were negative.

A species of Cybocephalus was obtained from Aspidistra lurida infested with Chrysomphalus bifasciculatus Ferris received from Silvestri. In the quarantine room this predator reproduced freely on the imported scale-infested plants. The attempts to propagate this species of Cybocephalus on $A$. aurantii were unsuccessful.

Specimens collected by Silvestri at Foochow and identified in 1924 as Aphytis chrysomphali are preserved in the collection of the Citrus Experiment Station. In the males the venter of the abdomen is microscopically stippled, and in my opinion the species is A. lingnanensis.

The names Notalipernes sp. and Cybocephalus sp. (fig. 22) were given me by Timberlake, and Chilocorus kuwanae by Silvestri and Timberlake. The species referred to as Notalipernes is known today as Telsimia emarginata Chapin (fig. 23, A). The species identified as Chilocorus kuwanae Silv. (fig. $23, B)$ is the same as that repeatedly introduced into California earlier under the name Chilocorus similis Rossi, and extensively colonized prior to 1906 in different parts of the United States by the Bureau of Entomology on San Jose scale. An account of this common Asiatic ladybird is given by Marlatt (1906).

Silvestri was the most competent of collectors and appreciated the importance of studying citrus-infesting scales on plants other than citrus. He examined native plants in uncultivated areas, and all kinds of plants in parks, gardens, temples, cemeteries, and along roadsides. Apparently he did not consider the possibility that some kinds of cultivated citrus, e.g., mandarin oranges in China, might be resistant or immune to red scale. This possibility should be considered when evaluating Silvestri's testimony regarding the control of red scale in China by parasites. It seems strange that Silvestri did

${ }^{20}$ Smith, H. S., letter to F. Silvestri, November 4, 1924; see footnote 3.

${ }^{30}$ Both Smith's letter and my records were overlooked in my previous accounts of Silvestri's work (Compere, 1953, 1955). Thus in the historical account published in connection with the description of Aphytis lingnanensis $(1955, \mathrm{p} .305)$, I reported that although A. lingnanensis was collected in South China more than once by Silvestri in 1924-25, no attempt was made to propagate or colonize it in Califorina owning to my mistaken belief that it was the same as chrysomphali. 

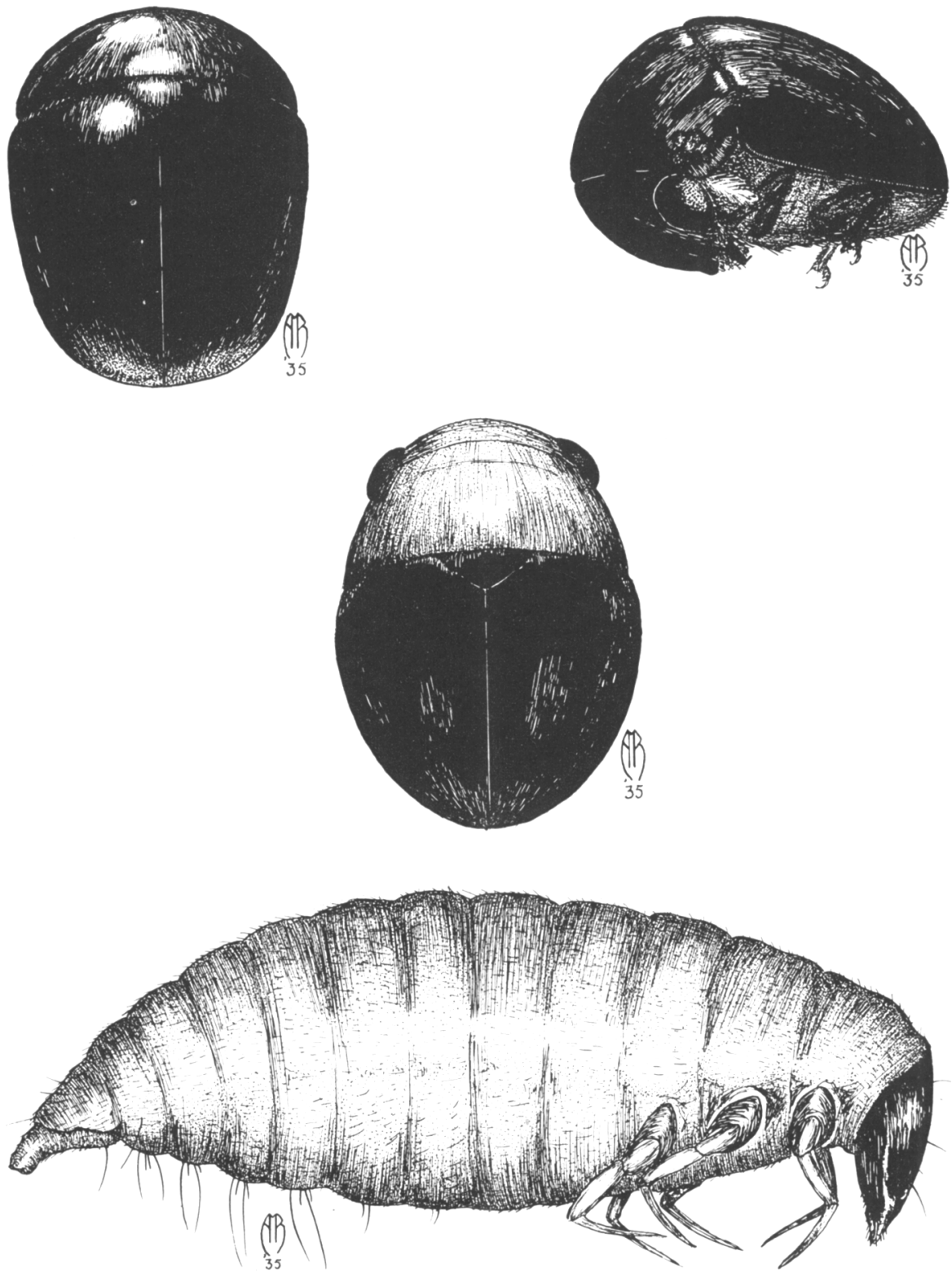

Fig. 22.-Cybocephalus sp., a red-scale-feeding nitidulid beetle intrnduced from China that became established in California. Top row from left to right: female dorsal view, female lateral view, male dorsal view. Larva below. 
not report finding yellow scale, Aonidiella citrina, in Japan or China, since he was on the alert to detect slight differences. With regard to $A$. taxus on Podocarpus, he questioned its identification as $A$. aurantii in a letter to Smith ${ }^{31}$ but was advised by Smith that the most competent specialist had identified it as aurantii. He also questioned the identification of several species of Aphytis when in Riverside and informed me in person that more than one species of Casca was involved under the name chinensis Howard.

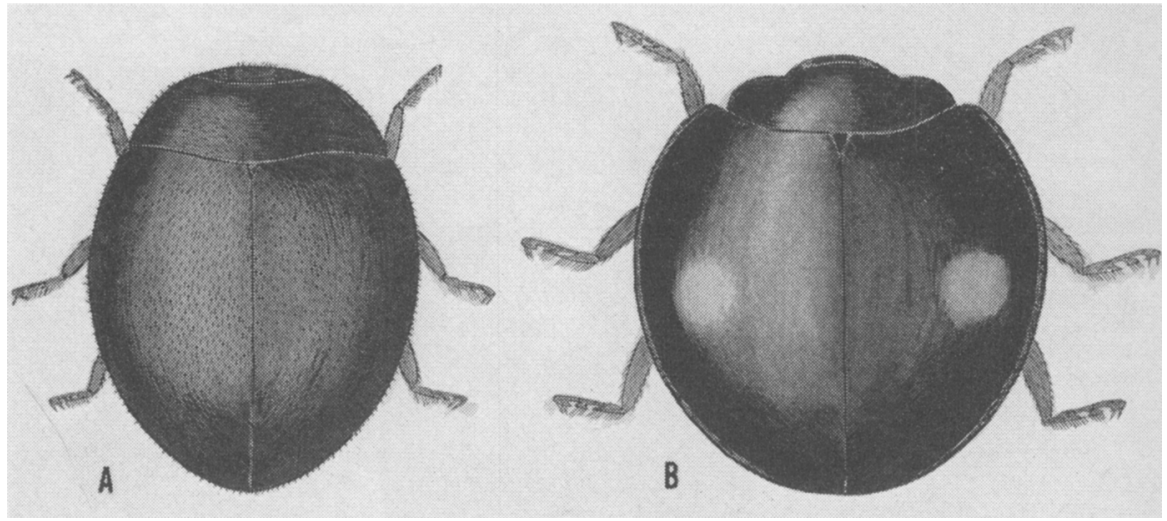

Fig. 23.-A, Telsimia emarginata Chapin, red-scale-feeding coccinellid imported from China in 1925, 1932, and 1948, and repeatedly colonized in California. B, Chilocorus kuwanae Silv., a red-scale-feeding coccinellid introduced from China that became established in Santa Barbara County.

\section{HAROLD COMPERE'S REPORTS}

My work with red scale and its enemies began in 1922-23 with material received from Curtis P. Clausen in Japan, and continued in 1924-25 with material from Filippo Silvestri in the Orient. An account of my work at this time was published (Compere and Smith, 1927). The errors of identification in this 1927 account were corrected recently (Compere, 1953).

Under the direction of Harry S. Smith, I searched for enemies of red scale in New South Wales in 1927-28, India and the ports of China in 1932, South America in 1934-35, and Africa in 1936-37 and 1947-48. Little has been published concerning these searches (Compere, 1935, 1937). Observations and opinions were recorded at the time in letters to Smith, and samples of the greater number of insects reported upon were saved for future study and reference. In 1937 Howard McKenzie identified the species of Aonidiella collected up to this time (see discussion under "Systematics"), and in 1940 the greater number of other diaspids. It is possible now to correct errors in identification, fill gaps, and summarize my reports to Smith.

\section{New South Wales}

In 1927 I made a trip to Australia for the primary purpose of obtaining enemies of the citrophilus mealybug, Pseudococcus gahani Green, then the

${ }^{81}$ Dated November 7, 1924; see footnote 3. 
most feared pest of citrus in California. This objective was attained. Within two years after the introduction and establishment of Coccophagus gurneyi Comp. and Tetracnemus pretiosus Timb. in California, the citrophilus mealybug was controlled (Compere and Smith, 1932). Incidental to the search for entmies of the mealybug, it was planned that the coccinellids alleged by Koebele to control red scale in Australia be obtained for further trial in California. The following excerpt from a letter to Smith reports the results of my search for these predators.

I would like to do what you delicately suggest [and ship ladybirds in quantity] but must first locate the coccinellids. Here again something is wrong somewhere. The unseasonable weather this year is supposed to be the cause of a "most extraordinary dearth of insects." The phrase is not mine, but that of Mr. Carter, the Coleopterist, whose very scholarly presidential address we both read in the proceedings of the Linnean Society of N.S.W. However, unusual weather does not account for my failure to locate the many coccinellids reported by Koebele to be effective enemies of the red scale. I believe that I can now read Koebele's report with more intelligence [better understanding] after being on the ground. However, I shall postpone my critical comments until after the warm weather arrives when conditions may change. I can get coccinellids by turning my back on the citrus reeking with pests and going into the bush where the various native coccids are attended by ladybirds, but I cannot believe that these beetles are of any more value than are the curious parasites that go into the cyanide bottle. It seems to me that if I go into the bush and collect indiscriminately it would be just about as scientific as if the Australian Government were to send a collector to California to collect the native coccinellids that occur in the Santa Ana river wash and Julian where Armitage collected so many beetles. I hold the belief that a species should give some indication of being of economic value to us by at least feeding upon related coccids or occurring upon citrus. Koebele mentions fifteen species of ladybirds as feeding upon citrus coccids at Paramatta. Paramatta is now just an industrial suburb of Sydney. When the orchards at Paramatta were destroyed the citrus plantings were extended about ten miles to the southwest into the districts of Baulkan Hills, Castle Hill, Rogan's Hill, Glenhaven. These are now considered old districts and the trees are on the decline and are probably comparable to what existed in Paramatta in Koebele's time. I have spent days here, walking from one dirty orchard to another looking for the elusive red-scale-feeding coccinellids without seeing anything else than the Scymnus notescens, O. chalybeus, O. australasiae, and Lindorus lophanthae. You have received practically all of the $O$. australasiae and $S$. notescens, so that you know just how abundant they are. A new citrus district extends out to Pennant Hills and Dural, beyond the railroad terminus. As yet I have not visited these plantings nor have I thoroughly worked the Gosford district. Mr. Carter suggested that I go further north to collect where insects are more abundant. I asked him what locality in particular. He replied, "Gosford." Then Mr. McCarthy, first assistant entomologist, stated that he had spent a good portion of his time in the Gosford district and that he had never encountered these beetles on citrus. He also stated that if a man could get eighty $O$. australasiae in a day's collecting it was about all that he could expect. However, I must not lose sight of the fact that if transplanted to a new environment some of the beetles may behave differently. It is a curious fact that with the exception of S. notescens, Orcus australasiae, Coccinella transversalis, and Leis conformis, all the beetles seen on citrus are the very ones already established in California and these are the only beetles so far seen in quantities. They are Rhizobius ventralis, Cryptolaemus, L. lophanthae, O. chalybeus. ${ }^{32}$

Another item concerning coccinellids on red scale appears in a subsequent letter:

For the past 10 days I have been trying to obtain coccinellids that feed upon red scale. The few that I have obtained are not worth the price of a shipping box. In fact,

${ }^{32}$ From letter of Harold Compere to H. S. Smith, January 2, 1928; see footnote 3. 
except for $O$. australasiae, they may not even be red-scale feeders. These were collected on citrus and that is all that I know about them. My failure cannot be attributed to rain nor inaccessability of the collecting rounds, since I hired a "drive yourself car" and the weather has greatly improved..$^{33}$

\section{Preparations for the Asian Trip}

In 1932 I made a trip to India to obtain parasites of red scale. A brief stop was made in Japan en route, and before returning a trip was made to several Chinese ports. This trip was decided upon for the following reasons. Com-

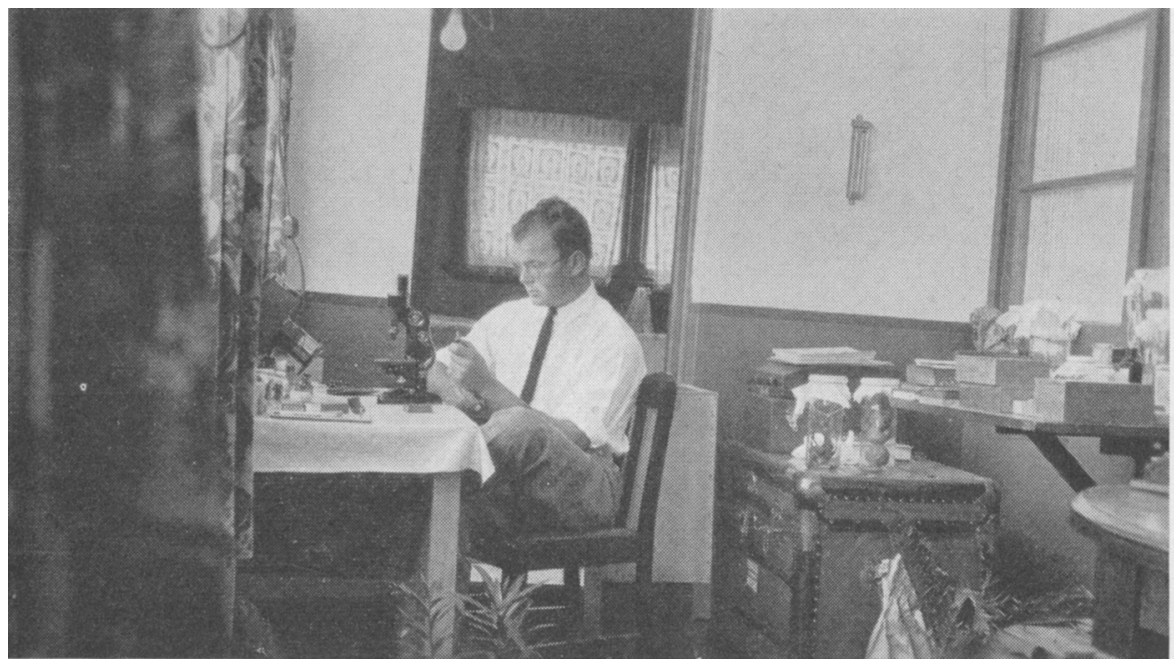

Fig. 24.--Equipment used by the writer for rearing parasites and making microscopic examinations displayed in the bedroom of hotel, Sydney, Australia, 1927.

periella bifasciata reproduced in Chrysomphalus bifasciculatus and in 192425 was established on this host infesting Aspidistra lurida, in the garden of the Huntington Estate, San Marino, and in Balboa Park, San Diego. Sometime during the winter of 1931, when discussing this situation, Smith suggested testing the parasites on yellow scale, Aonidiella citrina. It was then discovered that Comperiella bifasciata reproduced more freely in this host than in Chrysomphalus bifasciculatus, and Smith concluded the same old mistake had been made again, namely, yellow scale had been identified as red scale, and the scale on Podocarpus in Japan was yellow scale. In 1932, before the identity of the scales and parasites had been established correctly (see p. 265), Smith decided to send me to the Orient for the express purpose of distinguishing between red and yellow scales and to obtain parasites of red scale. China was considered to be the most promising country to find parasites of red scale. We were advised that it would be unsafe to travel there outside the European sections of Treaty Ports owing to wars and banditry. India was selected as the next most promising country in which to find parasites of red

${ }^{33}$ From letter of Harold Compere to H. S. Smith, January 2, 1928; see footnote 3. 
scale. In 1907 George Compere had reported red scale was destroyed by seven species of parasites in India $;^{34}$ and in 1913 Woglum had reported that it was controlled there by its enemies.

My first step in preparation for the trip to India was an attempt to distinguish between red and yellow scales by morphological characters. The results were unfortunate. A first mistake was made in the collection of the sample of yellow scale for systematic study and future reference. The sample included a few red scales overlooked or not recognized. This mistake was discovered when McKenzie studied the specimens in 1936. Drawings made by

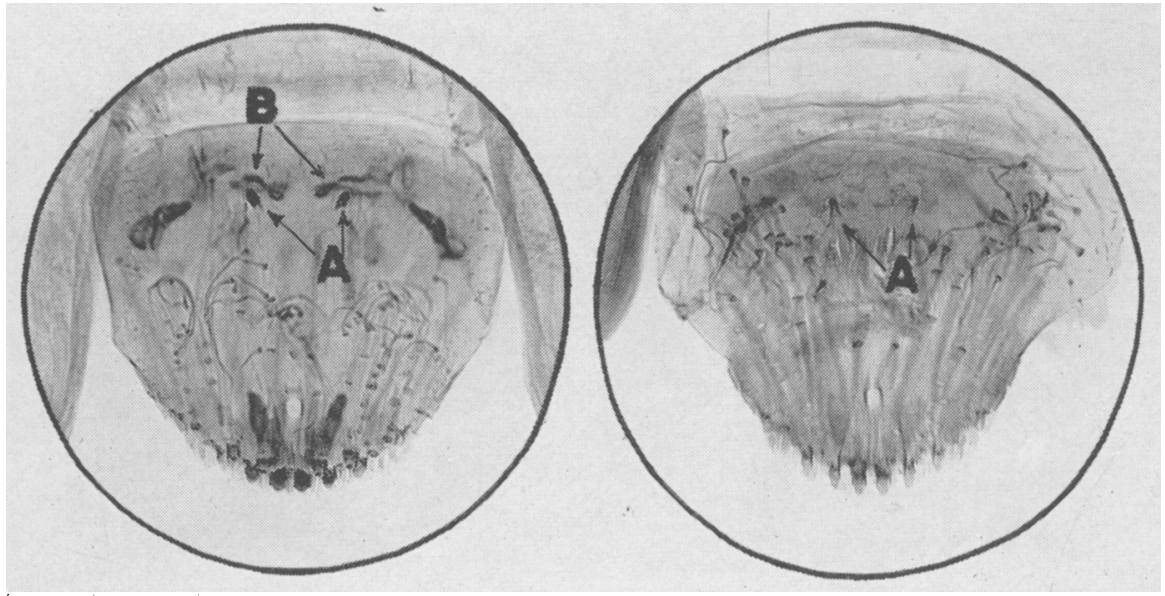

Fig. 25.-Red scale at left showing scleroses "B," the character that McKenzie used for distinguishing this species from yellow scale shown at right. Character " $\mathrm{A}$ " is common to both species. (After Ebeling, from retouched photographs taken by Roy Pence.)

me in 1931 show prevulvar sclerosis, the key diagnostic character of red scale (fig. 25) in some sketches and not in others; and the notation "no good" with reference to this character. The key diagnostic character was not overlooked, but its value was not recognized owing to the inclusion of red scale in a sample that was supposed to contain yellow seale only. The thoracic tubercles that distinguish Aonidiella taxus were completely overlooked by me. Had my systematie study been successful, many of the errors that followed could have been avoided.

After my failure to distinguish between aurantii and other species of Aonidiella by morphological characters, it was decided to use a biological method and to test on the spot the capacity of the different parasites to reproduce in $A$. aurantii. Red scale from California was taken to Asia for this purpose. This was done with the consent and coöperation of the quarantine and customs officials of the countries concerned. The return of citrus from Asia to California was prohibited by law, so Cycas revoluta was used as the host plant. Six cycads were infested with red scale and housed in crates especially constructed (fig. 26). The crates were designed to be used as portable in-

\footnotetext{
${ }^{34}$ In a letter from George Compere to Ellwood Cooper, Poona, India, June 4, 1907.
} 
sectaries for testing the Asian parasites on scales propagated from the California stock, and to transport to California the parasites that reproduced in them.

\section{Japan}

En route, while waiting for the ship to India, 9 days were spent in Japan, with headquarters at Kobe. This delay provided an opportunity to attempt to solve the riddle of red scale in Japan and to obtain a species of Casca there

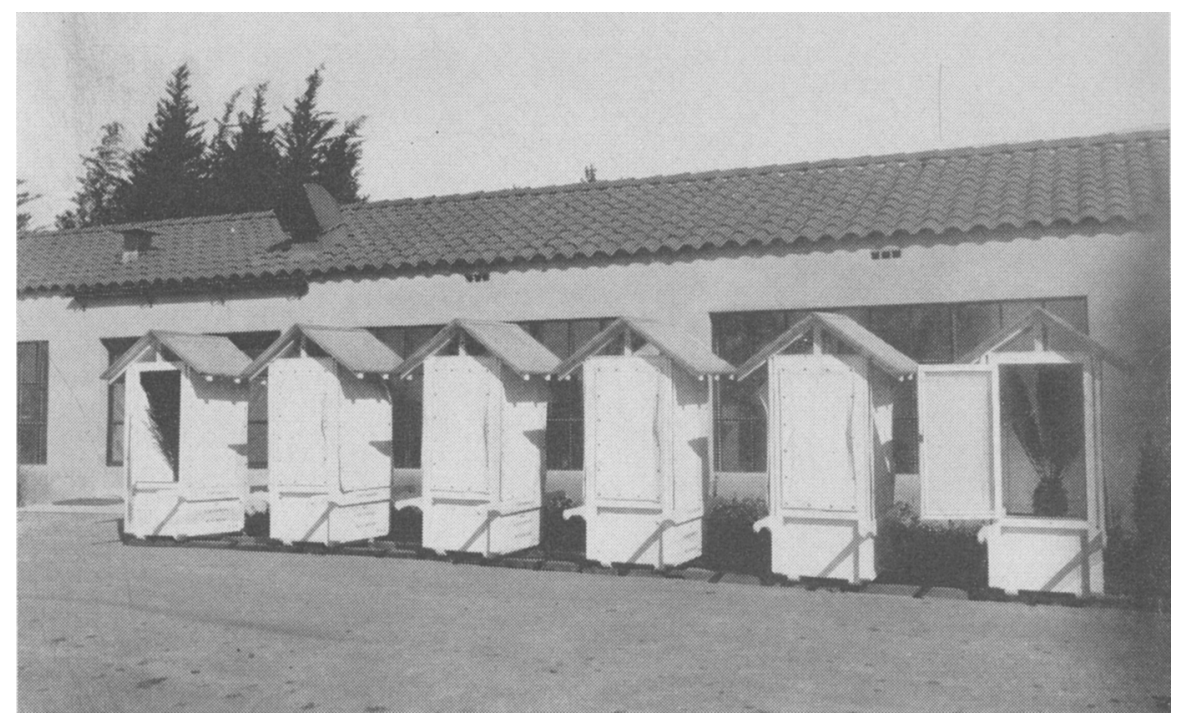

Fig. 26.-Crated Cycas revoluta infested with red scale in front of insectary at Riverside, March 1932. These crates were taken to India as personal baggage under a special agreement with the steamship companies.

recorded by Silvestri as a parasite of Aonidiella aurantii. I reported to Smith that under natural conditions the scales (later identified by McKenzie as $A$. taxus) on Podocarpus resembled A. aurantii more closely than $A$. citrina. Podocarpus spp. were found in dooryards or growing in pots throughout Kobe. Infestations of $A$. taxus in all degrees of injuriousness were seen. On some plants no parasitized scales were found, and on others all, or the greater number of the female scales were parasitized or had been parasitized by Comperiella bifasciata. Chrysomphalus bifasciculatus was noticed in abundance on dooryard plants in Kobe, some infestations with few and others without signs of parasites. A trip was made to the forest of Podocarpus nagae near the Deer Park at Nara, where in 1925 Silvestri spent 5 days and discovered a species of Casca working on the "red scale." The scales were difficult to find and the few seen showed no signs of parasitism. Comperiella bifasciata on yellow scale, $A$. citrina, infesting pummelo trees, was seen at Suma. The scales were few and scattered. Approximately 20 per cent contained either the eggs, larvae, pupae, or adults of Comperiella or its exit holes. 


\section{Bombay}

The red-scale-infested cycads were in excellent condition on arrival in Bombay, May 5, 1932. During the voyage through the tropics the scales multiplied and developed more quickly than ever before, and continued to do so while in the tropies. This was an unexpected development, since at that time we believed a tropical climate was unfavorable to the development of red scale. This belief was based on the geographical distribution of red scale as a pest of citrus. It was not known to us then as a pest of citrus in any tropical country with a climate corresponding to that of Florida.

It was considered prudent not to transport the infested plants any farther in India than necessary to accomplish our objective. The caged plants were kept in Bombay, the port of entry, under conditions that amounted to a quarantine. Parasites collected in different parts of India were brought to Bombay for testing on the scales of California origin.

Generalizations concerning the red scale and its enemies in India proved to be difficult, for the findings in one area often contradicted those in another, and nearly every different habitat presented a different picture. For example, some introduced varieties of citrus were injuriously infested with red scale near Bangalore, and the same varieties were free of it at Nagpur. In Bombay, red scale encrusted the canes of rosebushes in garden after garden, and in Poona it was difficult to find an infested rosebush. In Ceylon, Agave americana is listed as a favorite host plant of red scale, but red scale was not found on this plant in India. Yellow scale, Aonidiella citrina, appeared to be controlled by parasites in Poona but not in the Punjab.

In appraising the red scale and its enemies in India, some factors were overlooked and scant attention was given to others. Insufficient attention was given to the varieties of citrus on which red scale was found, to the possible effects of ants, dust, and chemicals, if any, and to the value of Aphytis as a controlling factor. ${ }^{35}$ No consideration was given to pubescence on plants, to host feeding by hymenopterous parasites, or to the possibility that red scale may be resistant or immune to parasitism when growing on one kind of plant and not on another.

In my opinion, nothing was seen in India to indicate that the red scale was controlled there, or that parasites, predators, or diseases materially reduced the infestations. This statement is made with the realization that it will be contradicted by others. Red scale was not found on the native varieties of oranges, but it was frequently found on pummelo trees and rosebushes. The red scale seriously infested Eureka and Lisbon lemons, Marsh grapefruit, Imperial limes, and several varieties of navel orange trees in the only commercial orchard visited that specialized in growing introduced varieties of citrus. Green $(1896$, p. 59) reported red scale in Ceylon as a pest of pummelo, Agave, and rose, and stated that it had never been noticed there on orange trees. Freeborn (1931) reported red scale to be almost entirely a pest of

\footnotetext{
${ }^{35}$ The species of Aphytis are the most common parasites of diaspid scales. All, or nearly all, of the most notorious diaspid pests are parasitized by one or more species of Aphytis. Rightly or wrongly this was regarded by me as evidence that the species of Aphytis lacked the capacity to control their hosts.
} 
ornamental plants in Egypt and particularly detrimental in nurseries and rose gardens, and not to be classified as a citrus pest since it only occasionally infested orange twigs. It is not unusual for a scale insect to be a serious pest on one kind of plant in one area and not be found on the same kind of plant in another area. This phenomenon is not limited to red scale: it has been repeatedly observed with other insects.

An attempt was made to collect and introduce into California all the parasites and predators found on red scale (and the scales that were mistaken for it), with the exception of the species of Aphytis. Samples of the scales were collected wherever any evidence of parasitism was noticed and then held in jars, test tubes, and small cages until any parasites that might be present had time to complete their development and emerge as adults. Nearly all the parasites reared from red scale, or scales that were mistaken for it, were tested individually on red scale from California in test tubes or were released in cages. Except for one or possibly more species of Aphytis mistaken for chrysomphali, none of the parasites developed when tested individually in test tubes or reproduced after release in the cages. Nothing was done with the Aphytis. It is now known that the species collected in India was not chrysomphali and that probably more than one species was involved. While in Hong Kong, on the return trip from India, a species of Aphytis reproduced in one cage as a contaminant. It was believed to be $A$. chrysomphali and the stock was destroyed. It is not known whether this species of Aphytis was accidentally obtained in India or China, or how it entered the supposedly insectproof cages.

The climate of Bombay is hot and humid during the summer months. ${ }^{38}$ In July, temperatures in the red scale cages ranged from $82^{\circ}$ to $92^{\circ} \mathrm{F}$ and nearly 40 inches of rain fell. Bombay was not considered a promising place to find parasites for introduction into California.

The search for enemies of red scale began in Bombay and was resumed there at intervals between trips to other parts of India. At the beginning of the search, red scale was found in abundance on rosebushes in the city. Coccinellids in small numbers were found in Bombay and other parts of India feeding on red scale and other diaspids. Adults were collected one by one until a sufficient number were assembled to warrant a shipment to California. None of the shipments was successful; the beetles all died in transit. One species, Pharoscymnus horni Weise, believed to be the most promising, reproduced in the cages on red scale and was brought back alive. Eventually, colonies of $P$. horni were repeatedly released in California but failed to become established.

Red scale was found in different degrees of severity on pummelo trees scattered in the gardens and parks of Bombay. In a small commercial orchard at Ghat Kopar, near Bombay, red scale encrusted the wood of pummelo trees and there was evidence of parasitism. A sample of the scale from Ghat Kopar, studied by McKenzie in 1940, was found to include both Aonidiella aurantii and $A$. compere $i \mathrm{McK}$. It is suspected, now, that still other species of scales may have been present and that the internal parasite inhabited $A$. comperei,

${ }^{38}$ Many of the climatological data given in this paper were obtained from Blanford, 1889. 
or possibly A. orientalis (Newst.) or Chrysomphalus dictyospermi, and not $A$. aurantii as reported to Smith.

Comperiella lemniscata Comp. and Annecke was found in abundance in Bombay, but at the time it was not recognized as distinct from $C$. bifasciata, nor was its host, Aonidiella orientalis, identified correctly. Colonies of this species of Comperiella were repeatedly released in the cages housing the California red scale, but the parasites never reproduced in these scales. The species of Comperiella was not recognized as new until all specimens of this genus resembling bifasciata that were saved for study were segregated into groups on the basis of host relations and rcëxamined. It was then discovered that what was originally believed to be a variable character of no systematic value was in reality a constant character that serves to distinguish all the specimens of Comperiella reared from $A$. orientalis collected in different parts of India and China as different from $C$. bifasciata.

What is now believed to be Chrysomphalus dictyospermi was seen in Bombay more than once with signs of parasitism by Comperiella. Parasites from this host were released in the cages with red scale brought from California. Unfortunately, no specimens of Comperiella that issued from the dictyosperm scale were saved. Silvestri (1930a, p. 902) reported that at Changsha, Hunan Province, China, the female dictyosperm scale on citrus and small plants of Euonymus were nearly all killed by Comperiella. In connection with this record, it should be remembered that Silvestri might have mistaken yellow scale for the dictyosperm scale unless the specimens were examined microscopically.

\section{Poona}

A special search was made in Poona for enemies of the red scale. Poona is located at an elevation of 2,400 feet and about 30 miles inland from the Western Ghats, a range of mountains which, by intercepting much of the moisture from the air moving inland from the ocean, gives Poona a relatively dry climate. The greater part of the rains in Poona fall during the summer from June to October. As compared with Bombay, the climate of Poona is dry, but still the climate of the latter is not similar to that in southern California, as in Poona the hot and wet seasons coincide.

In Poona the yellow scale was found infesting orange trees of the "Mozambi" (probably Mozambique) variety that lined Toddy Road. These trees were not far from the commercial citrus orchards. The yellow scale was mistaken for red scale. With the exception of several small pockets, the scales were found scattered one by one. A good percentage of all the scales found contained exit holes from which adult Comperiella had emerged. Dissections revealed the eggs or larvae of the parasite in about half the number of scales examined, and several adults about ready to emerge. The newly formed adults had a pale crescent-shaped band on the scutellum, a character that I had not noticed previously when working with $C$. bifasciata in California. I then made a second error and identified the parasite as a new species of Comperiella. When the specimens with the banded scutellum oviposited freely in red scale from California, my elation exceeded my discretion and, without waiting to complete the tests or to make a more thorough study, the following 
cablegram was sent to Smith: "New species of Comperiella controls red scale on citrus, not climate."

Dissections made 3 days after the parasites first oviposited in California red scale revealed Comperiella eggs in the process of being destroyed by the host's reaction, and a more thorough systematic study of the adults revealed that in some of the specimens reared from yellow scale collected in Japan, the scutellum was also banded. These discoveries ended my elation.

Rosebushes are numerous in Poona, but only three were found to be infested with red scale, unlike Bombay, where rosebushes were heavily infested in garden after garden. The infested rosebushes in Poona were adjacent to a nursery where red scale was found in abundance on a small pummelo tree.

A side trip was made by automobile from Poona to Ahmadnagar. Here, citrus and rosebushes in parks and gardens, as well as outside the city, were examined for red scale, but none was found. On the trip to Ahmadnagar I was accompanied by five entomologists, all of whom participated in the search for red scale in that city. Outside the irrigated areas of the city, the country was brown and bare and the opuntias were parched for lack of moisture. The rainfall in Ahmadnagar is recorded as 12 inches annually, and the temperatures are more extreme than in Poona. Ahmadnagar is about 125 miles inland from Bombay.

\section{Nagpur}

When the itinerary was planned, Nagpur was selected as a most promising place in which to search in India, owing to its central location, hot dry climate, and extensive citrus groves. The climate is wet by California standards, since the rainfall averages 44.9 inches annually and the orchards are not irrigated. Hot winds blow from the beginning of April until the onset of the monsoon about the first week in June. My visit to Nagpur, the second week in June, preceded the onset of the monsoon that year. In the commercial orchards the orange trees were wilted and shedding leaves for lack of rain, and were free of coccids of all kinds. In the city of Nagpur citrus is common in dooryards, and an experimental orchard of assorted citrus included Lisbon lemon, Washington and Australian navel oranges, and Marsh grapefruit, none of which were infested with scales of any kind. Clusters of rosebushes in the garden of the Central Province Club were encrusted with dead red scales. At the time of inspection, the temperature was $108^{\circ} \mathrm{F}$ and higher temperatures had preceded this. The scales had the appearance of having been "cooked." Other rosebushes encrusted with "cooked" red scale were seen in the open, adjacent to the experimental citrus orchard that was free of scale. Live red scales were found on rose cuttings in a moist sand propagating bed in the shelter of a lath-house, and on small potted lime trees and potted rosebushes in a moist locality in the shelter of a large Ficus tree in the Maharaja Bagh. A coccinellid, presumably Pharoscymnus horni, was found on red scale and its presence here in a hot dry region was regarded as a promising omen. On the basis of this obscrvation, $P$. horn $i$ was reportcd as the most promising of the predators found feeding on red scale in India. Previous to this, supposedly the same species of coccinellid was seen in Bombay. 


\section{Other Indian Districts}

An exceptional assemblage of plants and insects was inspected at the Gangenhalli Estate near Bangalore City, where the climate is about intermediate between that of the tropies and temperate zones. Pineapples were growing between rows of navel orange trees. The latter blossomed throughout the year, and oranges of all sizes and stages of maturity were present. The apple trees were semideciduous. The weather records for Bangalore City, 17 miles south of the Gangenhalli Estate, show that the annual rainfall is 35 inches and distributed throughout 8 months of the year, most of it occuring from May to October; the mean annual temperature is $73^{\circ} \mathrm{F}$, the winter temperatures ranging from $46^{\circ}$ to $56^{\circ}$, the highest summer temperature less than $100^{\circ} \mathrm{F}$. The citrus scale insects common to the tropics, such as Parlatoria pergandii Comst., Chrysomphalus aonidum, and Coccus viridis (Green), were mixed with Aonidiella aurantii. With the addition of the pummelo and Imperial lime to the list, the red scale infested exactly the same varieties of citrus that it infests in California and in the same order of severity, being most injurious to the Eureka and Lisbon lcmons, Marsh grapefruit, and navel oranges. The lemon trees were injured by it. The grapefruit and navel orange trees were not appreciably injured, although many of the fruits were covered with $A$. aurantii and other scales. The young grapefruit and navel orange trees grew more vigorously than in California and suffered less. In the markets scale-infested fruits were not discounted as in California, since the fruit was purchased on the basis of eating quality rather than on eye appeal. In Bangalore, fruit from the Gangenhalli Estate, both clean and infested, brought the highest prices.

Two towns only 12 miles apart in the Nilgiri Hills presented an interesting contrast in the geographical distribution of red scale, presumably owing to a direct effect of climate. At Ootacamund, red scale was not seen, while at Coonoor it was common and abundant on rosebushes, pummelo, and certain kinds of young citrus in a nursery. Although located only 11 degrees from the equator, the climate of Ootacamund is cool owing to the elevation of 7,100 feet; the weather records show the mean annual temperature to be $55^{\circ} \mathrm{F}$, the highest temperature ever recorded, $77.3^{\circ}$, and the lowest, $25.3^{\circ}$, with an average rainfall of 45 inches. It is suspected that the mean temperature at Ootacamund, and not the extremes, prevents the red scale from living there. At near-by Coonoor, at an elevation of 6,100 feet, the temperature averages $6^{\circ}$ higher than in Ootacamund. Another contrast was seen in Coonoor. A row of Sicilian lemon trees was free of red scale and the wood of adjacent pummelo trees covered with it. In 1951 Boyce $^{37}$ reported Aonidiella aurantii to be a pest of deciduous fruit trees in Coonoor.

Mature Australian navel orange trees were free of red scale and adjacent rosebushes were badly infested with it in the palace gardens of the Maharaja of Mysore, Bangalore. At the Bikashipur Estate, navel orange trees were free of red scale. No chemical methods of control were practiced and no internal parasites or effective predators were present.

At Coimbatore none of the scales observed showed evidence of parasitism

${ }^{37}$ A. M. Boyce, personal conversation. 
other than by an Aphytis. No samples of the scales seen at Coimbatore were preserved, so the identity of the species is uncertain. Although this city is in the tropics and at the low elevation of 1,398 feet, the climate is relatively arid. The moisture-laden clouds from the ocean are intercepted to the west of the city by a range of hills so that the annual rainfall is only 21 inches. The annual mean temperature is $78^{\circ} \mathrm{F}$. In the grounds of the Agricultural College, a scattering of either red or yellow scale was noticed on citrus in a small planting. Throughout the city, dooryard citrus were heavily infested with Parlatoria zizyphus (Lucas) and P. pergandii, two notorious tropical pests of citrus that rarely occur where Aonidiella aurantii is a pest of citrus.

Both red and yellow scales were observed on citrus in the humid climate of Delhi, Lahore, and Gujuranwala, regions of summer rain. In Delhi, winter temperatures drop below $36^{\circ} \mathrm{F}$. The peaks in heat are reached in May and June, when the mean maximum is $116^{\circ}$. The average rainfall is 27 inches. Red scale was repeatedly noticed on roses and pummelo trees, although at the time I was not always able to distinguish between this and other species of Aonidiella. An occasional scale on the wood of pummelo was parasitized by Comperiella, but the parasites obtained failed to reproduce in $A$. aurantii on cycads in cages. At the time, it was assumed that none of the scales on citrus could be $A$. aurantii since the Comperiella from them failed to reproduce in the $A$. aurantii brought from California. Many years later, J. Morris Smith (1957) reported that $A$. aurantii growing on Cycas revoluta is resistant to successful parasitization by Habrolepis rouxi and partially resistant to the red-scale-inhabiting form of Comperiella bifasciata.

In the government nursery in New Delhi, Lisbon lemons, Malta oranges, and pummelo were found associated with the usual varieties of Indian citrus fruits. The scales were most numerous on pummelo, lemons, and Malta oranges in that order. Unfortunately, it is now impossible to correlate the incidence of the red and yellow scales on the different kinds of citrus. Red scale was taken on roses here, but none produced Comperiella or any other coccid parasite, with the possible exception of Aphytis, which was disregarded.

A situation was found in Peshawar, Northwest India, on the border of Afghanistan, that corresponded closely to one seen 36 years ago in Sacramento, California, with regard to the host relations of red and yellow scales. In 1915, the old seedling orange trees in Capitol Park, Sacramento, where chronically infested with yellow scale, while Washington Navel trees growing near-by were free of them. At the Tarnab Experimental Farm, Tarujabba (Peshawar), mature Seville orange trees were moderately infested with yellow scale with a small percentage parasitized by Comperiella. Near-by Washington Navel orange trees were free of both yellow and red scales, although red scale occurred in Peshawar on rosebushes.

The climate of Peshawar is unlike that of all, or nearly all, other fruitgrowing districts of India. The average annual rainfall is 13.5 inches, of which 4 inches falls during the summer months. The rainy season extends from January to April. The highest mean temperature is $115^{\circ} \mathrm{F}$ and the lowest mean is $29^{\circ}$. The winter temperatures are sufficiently low and prolonged to cause dormancy in Hale and Elberta peach trees, but not low 
enough to kill the more cold-resistant kinds of citrus. In Peshawar, olive trees, Olea europea, and pepper trees, Schinus molle, attain as large a size as in the interior valleys of California.

Yellow scale was prevalent in the ornamental gardens in the city of Peshawar chiefly on the Rough lemon trees. A hedge of Rough lemons growing in front of the museum was badly infested with yellow scale, and there was little evidence of work by parasites.

\section{China ports}

The search in China occurred during the period October 5, 1932, to January 5 , 1933, and was limited to New Territory, Hong Kong, the south coastal ports of Macao, Swatow, Amoy, Foochow, and in the north to Shanghai and the Yangtze River ports of Nanking, Wuhu, Kiukiang, Hankow, and Wuchang.

My observations concerning red seale and its parasites in South China are at variance with that of others. The prospect of finding an effective parasite of red scale in South China received a severe setback with the discovery of heavy infestations of red scale, Aonidiella aurantii, on pummelo trees at Lingnan University near Canton, the International Cemetery at Foochow, and the orchard of Tong Lok Yeun, New Territory. The infestation at Lingnan was without signs of parasitism of any kind. The other infestations showed few signs of work by Comperiella. In contrast to the situation in India, where injurious infestations of $A$. aurantii were found on rosebushes in nearly every city visited, not one infested rosebush was found in China, although a special search was made for $A$. aurantii on these plants; nor did I (or Flanders in 1953-54) find it on the Cycas sp. in the Hong Kong Botanical Garden, where Silvestri reported finding it in 1924-25.

The largest aggregation of citrus-infesting insects seen in Asia was in the orchard of Tong Lok Yeun, New Territory, near the 171/2 mile post on the road to Fanling. Seventeen different kinds of coccids were collected on citrus trees in this one orchard. In addition to coccids, the trees were infested with mites, aphis, thrips, aleyrodids, psyllids, leaf skeletonizers, leaf miners, and wood borers. Scarcely a tree or fruit remained uninjured by insects or disease. This exhibit of so many citrus insects in abundance is the antithesis of that reported by others. Other orchards (in other localities) composed of orange trees producing loose-skin fruits were remarkably free of coccids. Tong Lok Yeun's orchard was exceptional in that it was planted to a variety of orange producing tight-skin fruits. In India, China, and Japan the loose-skin or glove oranges are commonly grown commercially. In the orchards of the Citrus Experiment Station at Riverside, California, where loose-skin and tight-skin orange trees grow side by side, red scale, Aonidiella aurantii, rarely if ever infests the loose-skin orange trees, although adjacent tight-skin orange trees may be injuriously infested. Yet a generalization that red scale is not a pest of orange trees in China owing to the unfavorability of loose-skin varieties meets with a contradiction, since in an experimental orchard at Lingnan University the tight-skin orange trees were also free of $A$. aurantii, although it was present there in injurious numbers on some of the pummelo trees. 
The failure of any parasites, except Aphytis, to reproduce on Aonidiella aurantii in the cages was regarded as evidence that no parasites capable of controlling red scale in California were to be found in China. The possibility that red scale growing on Cycas revoluta might be more or less resistant or immune to parasitization and that the reproduction of two or more generations might be impossible with parasites that reproduced freely when this scale was growing on other plants was not considered.

All the parasites in the genera Comperiella and Casca reared from Aonidiella aurantii in China, or scales that were mistaken for it, were released in the cages. No species of Aspidiotiphagis or Prospaltella were reared from Aonidiella aurantii collected by me.

\section{Predators}

Three predators found feeding on red scale in Asia were sent to California in 1932-33, namely, Pharoscymnus horni, Telsimia emarginata, and a species of Cybocephalus. These were propagated at Riverside and colonized, but the two coccinellids failed to become established (Flanders, 1934). The nitiludid, Cybocephalus sp., was recovered some years later in Orange County by R. J. Bumgardner but was not feeding on red scale.

\section{South America}

In 1933, a committee of growers representing the organized citrus industry of California met at the Citrus Experiment Station to consider the problem of red-scale control. The red scale had become increasingly important owing to the development of a strain resistant to cyanide. In some orchards in Corona and Arlington, growers resorted to two hydrocyanic gas fumigations spaced close together or a fumigation followed by an oil spray. In this era of low fruit prices the cost of treating red scale resulted in bankruptcy for some growers and forced others to sell groves at sacrifice prices. The growers' committee demanded that something be done. In the discussion concerning the possibility of controlling red scale biologically, H. S. Smith was questioned as to the status of red scale in South America. He stated that there it was not known as a pest of citrus, and that the species of the genus Chrysomphalus may have evolved in South America since a large number of such species were known to occur there. (At this time aurantii was classificd under Chrysomphalus.) The committee of growers requested that a search be made in South America for enemies of red scale and contributed $\$ 7,724.02$ to pay the traveling expenses. I was assigned to make the search. Eleven months were spent in South America on this project (August 1934 to June 1935) at a cost to the growers of $\$ 2,530$.

A report on my findings in South America was published (Compere, 1935). This report was published before McKenzie identified the scale taken in Buenos Aires on Podocarpus andina as Aonidiella taxus, and that on citrus and tung trees in Misiones as A. aurantii. Flanders (1936) published an account of the importation and colonization of Coccidophilus citricola Brèthes (fig. 27) in California from material collected in Brazil. This was the most common and widely distributed of the predators found feeding on 
diaspids in South America. I could not conceive of its ever being an important factor in controlling red scale, yet today it is alleged to do this very thing in South America. ${ }^{38}$ The reason for the freedom of citrus from red scale, $A$. aurantii, in some districts of Brazil presents as much of an enigma as the freedom of citrus from red scale in Florida.

A navel orange tree at Fazenda Pinheiros, about 12 miles from Campinas, was intertwined with the branches of a climbing rosebush. This rosebush was heavily infested with Aonidiella aurantii, Chrysomphalus aonidum, and $C$. dictyospermi, but only C. aonidum infested the navel orange tree. In locality after locality, $A$ aurantii encrusted rosebushes, but adjacent orange trees bearing tight-skin fruits were free of it. In an orchard at São Gonçalo, not far from Rio de Janeiro, $A$. aurantii infested pummelo trees, but orange trees in the same orchard were free of it. In Baía [= Bahia], where the Washington Navel orange originated, citrus trees of all kinds were extraordinarily free of coccids, although $A$. aurantii was present on rosebushes. George Compere reported $^{30}$ in 1904 that red scale existed in Baía on rosebushes but not on citrus. The freedom of orange trees in Baía from all kinds of coccids was a striking contrast to many other regions in Brazil, where many different kinds of coccids other than $A$. au-

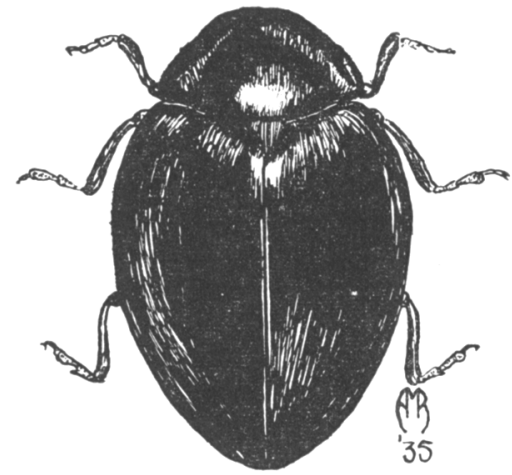

Fig. 27.-Coccidophilus citricola Brèthes, a discolomid beetle introduced from Brazil into California for use against the red scale. It was in connection with the propagation of this beetle that $R$. J. Bumgardner developed the method of growing red scale on gourds and squash. rantii were injurious to citrus.

Aonidiella aurantii was seen on lemon trees and the leaves and green wood of three-year-old grapefruit trees in the largest citrus orchard in Brazil, that of Dierberger and Company, located near Limeira. According to the manager, Henrique Jacobs, the red scale had been under observation for several years but there had been no appreciable increase or spread prior to 1934 . Several years after my inspection, the red scale was reported to have become serious and fumigations were used to control it. Cyanide was unobtainable in Brazil in 1942 and control by chemicals was discontinued. It was reported that the red scale subsided when the treatments were discontinued, and the subsidence was attributed to entomogenous fungi.

Aonidiella aurantii was first noticed in Argentina in 1930 by D. Sibbald on young trees in his orchard at Santa Eleana, La Concepción, Misiones. The infestation is said to have had its origin on trees imported from Australia in 1927. Sibbald noticed that the scale looked different from the common "circular purple scale," Chrysomphalus aonidum, and that it was more difficult to kill with insecticides. Specimens were sent to E. Blanchard and identified

${ }^{38}$ Letter of A. F. Camp to A. M. Boyce, October 26, 1956.

${ }^{8}$ In a letter from George Compere to Ellwood Cooper, dated Bahia, May 24, 1904. See footnote 3 . 
as $A$. aurantii. At about the same time (1927), other importations of citrus were made from Australia by the Ferrocarril Entre Ríos. These trees were also said to have been infested. In turn, the citrus nursery of the F. C. E. R. at Centinela became infested, and from this focal point $A$. aurantii was disseminated on nursery stock. This is the official version of the introduction of red scale into Argentina.

In Misiones the red scale, Aonidiella aurantii, was found to be as injurious to citrus trees as reported. It occurred there in association with Chrysomphalus aonidum, C. dictyospermi, and Unaspis citri (Comst.). A noteworthy feature of the infestations was the distribution of $A$. aurantii on the citrus trees. Here it appeared to have a preference for fruit and foliage, although on some orange trees large limbs had been killed. In general, the wood appeared less heavily infested than it would be in California if comparable numbers of scale were present on fruit and foliage. Tung trees, Aleurites fordii, were more severely injured by $A$. aurantii than the citrus, and large branches of the tung trees .were completely encrusted with it. In Misiones $A$. aurantii also occurred on a native tree known by the vernacular name "palo borracho." It was noticed by me on rosebushes in two gardens only. The same predators collected in Brazil feeding on diaspid scales were found on A. aurantii in Misiones, but their value in controlling the pest appeared negligible. No signs of parasitism were noted. Subsequently, a few specimens of a Prospaltella sp. and an Aspidiotiphagus sp. issued from $A$. aurantii collected at Misiones. The large seedling orange trees at the old mission, reputed to be more than a hundred years old, were free of coccids of all kinds.

At Tigre, near Buenos Aires, in the rich delta lands of the Paraná, a beginning was being made in lemon culture in 1935. The young trees were exceedingly thrifty, at least vegetatively, and were extraordinarily clean although lightly infested with Chrysomphalus dictyospermi. A few old trees were infested with Lepidosaphes beckii.

In the Tigre district the oriental fruit moth, Grapholitha molesta (Busck), was sufficiently injurious to cause some entomologists to express the opinion that peach growing in the Tigre district was probably a thing of the past, yet this same moth has failed to become a serious pest in California except in Orange County, and it scarcely more than survives in some districts in central California except under certain cultural practices that modify the tree condition. Insects other than coccids present similar unsolved problems of distribution as pests.

Aonidiella taxus was found severely infesting Podocarpus andina in a public park in the city of Buenos Aires. In 1935 the identity of this scale was not known to me and its presence was confusing. It was heavily parasitized by species that appear indistinguishable from Aspidiotiphagus citrinus and Aphytis chrysomphali. These parasites and a species of Chilocorus were sent to California but the results were negative. The parasites that were abundant on A. taxus were not found on Chrysomphalus dictyospermi infesting near-by plants. In contrast, in Brazil $C$. dictyospermi was parasitized by a species of Aspidiotiphagus and a species of Aphytis.

With reference to climate and vegetation, Mendoza, Argentina, was suggestive of Riverside, California, and Peshawar, India. Lindorus lophanthae 
was found in Mendoza feeding on diaspid scales other than Aonidiella aurantii. How $L$. lophanthae got there is a mystery. Observations were made in other parts of Argentina, but with negative results so far as A. aurantii was concerned.

As indicated earlier, the government entomologists were of the opinion that Aonidiella aurantii did not occur in Argentina prior to 1927, when it was imported from Australia on nursery stock. In 1935 I found red seale adjacent to Argentina, in Paraguay, under conditions that warrant the assumption that it had been there a great many years. In the absence of any quarantine on the movement of plants from one country to another, it seems unlikely that Argentina could have escaped importing nursery stock infested with red scale prior to 1927. The reason for red scale's absence, or my failure to find it, in Buenos Aires, La Plata, and Mendoza remains unexplained, since climatieally these cities seem to be favorable for this pest, and the host plants which it attacks most freely in California are common thère. In Buenos Aires and La Plata, the Spanish red scale, Chrysomphalus dictyospermi, plays about the same role as $A$. aurantii in Los Angeles. Laurus nobilis, Euonymous japonicus, Cycas revoluta, Hedera helix, and Citrus spp. are often badly infested with $C$. dictyospermi in Buenos Aires and La Plata, but no A. aurantii was found on them. In Los Angeles the same kinds of plants are often badly infested with $A$. aurantii but free of $C$. dictyospermi, although the latter is widely distributed in Los Angeles on avocados and palms. Why C. dictyospermi is not a serious pest in Los Angeles is as much of a puzzle as why A. aurantii is not a serious pest in Buenos Aires.

In Paraguay, red scale, Aonidiella aurantii, was found in abundance on rosebushes and rarely on citrus, with one exception. Two lime trees in the city of Asunción were badly infested with red scale, but in general the orange trees were completely free of it. In Paraguay as in Brazil, rosebushes were partly killed by red scale while contiguous citrus trees were free of it. Four specimens of a Thysanus sp. were reared from A. aurantii collected in Asunción and a few scales contained remnants of an Aspidiotiphagus. In Asunción many of the sidewalks are lined by bitter orange trees and these were frequently heavily infested with Chrysomphalus aonidum, Lepidosaphes beckii, and Unaspis citri. Probably in no other city is citrus more common and so much a part of the landscape as in Asunción. In almost every patio, park, vacant lot, and dooryard garden there are oranges, mandarins, limes, and lemons. In the jungle, not far from the city, citrus grows wild over vast areas. The city of Asunción was founded in 1536 and the first Catholic missionaries arrived in 1550, possibly bringing the seeds of citrus with them. It is recorded that citrus was probably introduced into the Western Hemisphere by the first missionaries at either Baía, Brazil, or Asunción, Paraguay.

Aonidiella aurantii was first noticed in Chile in 1928 by César Capdeville, then an agricultural inspector stationed in the famous "Valley of Quillota." It was discovered on lemon trees in the orchard of Luis Bozzole e Hijos in Quillota. When seen by me in 1935, there was much dead wood in the trees, the branches were encrusted, and the fruits and leaves specked with red scale. The situation was unique in that the lemon trees managed to survive with so much red scale. Obviously Quillota was not a place in which to find enemies 
for controlling red scale in California. According to scientists familiar with the situation in Chile today, the red scale has not spread beyond Quillota.

A limited search was made for red scale in Peru. It was not known to occur there, nor did I find it in 1935. In the areas inspected, Lepidosaphes beckii was exccedingly injurious to citrus. Next in importance was the West Indian red scale, Selanaspidus articulatus Morg. In Lima and Chosica, S. articulatus was about as abundant and infested about as many different kinds of plants as did Chrysomphalus dictyospermi in Buenos Aires, or Aonidiella aurantii in Los Angeles.

On the Caribbean coast of South America, Selanaspidus articulatus was seen in one locality only-Cartagena, Colombia-where a few hours were spent ashore inspecting citrus while the ship was in port.

\section{Africa, 1936-37}

In 1935, W. R. Roux (fig. 28), entomologist for the African Realty Trust Ltd., sent a small lot of parasites reared from coccids to Professor Quayle. These were given to me for identification. Among the parasites was an undescribed species of Habrolepis reared from Aonidiella aurantii. This I described under the name $\boldsymbol{H}$. rouxi (fig. 29) and made some generalizations that were as unsound as the systematics on which they were based (Compere, $1936 b$ ). Since Roux had reported favorably concerning the work of Habrolepis on red seale in Africa, I was sent there to obtain this spccies and any other parasites or predators of possible value to California. About $\$ 5,200$ of the fund contributed by the citrus growers for the South American trip was being held in trust by the University of California. Upon the recommendation of Smith, and with the approval of a committee representing the growers, it was used to defray the expenses of a trip to Africa.

I arrived in Cape Town in October 1936, where, at the request of Robert G. Nel, Government Entomologist, Union of South Africa, an excellent laboratory and insectary were assigned to me in the Low Temperature Research Laboratory by the Superintendent, Mr. Rees-Davies. It was planned to explore the western and eastern provinces while maintaining headquarters at Cape Town. Nel took a professional and personal interest in the red-scale project. While a student in the United States in 1930-1933, he studied both red and yellow scales and published the results of his studies (Nel, 1933). In 1935, on a second visit to the United States, Nel observed red and yellow scales being propagated on banana squash in the insectary at Riverside, and took seeds of the banana squash to Cape Town. The seeds were planted and produced mature fruits that were available for propagating red scale when I arrived in Cape Town.

Specimens of Habrolepis rouxi were seen by me in the collection of C. J. Joubert, an entomologist at the Stellenbosch-Elsenberg College of Agriculture. These had issued from Aonidiella aurantii, collected at Nelspruit by Joubert in 1930. When Nel learned that Habrolepis occurred in Nelspruit, he wrote to F. J. Stofberg, Government Entomologist stationed there, requesting that red-scale-infested citrus fruits be sent to Cape Town. Stofberg complied, and the fruits arrived in Cape Town December 14, 1936. Two Habrolepis had issued en route, and when given an opportunity readily 
oviposited in red scale on banana squash. Roux also sent orange fruits from Letaba bearing red scale parasitized by Habrolepis. The parasites freely reproduced and shipments of Habrolepis were sent from Cape Town to Riverside by air express and steamer. When advisc d by Flanders that the parasites were rcproducing in the insectary at Riverside (fig. 30), the shipping was discontinued and I turned my attention to collecting parasites of black scale and mealybugs.

In the laboratory at Cape Town, Habrolepis rouxi readily oviposited in scales ranging in age from 2 weeks to maturity, but preferred the more mature scales when given a choice. So far as could be judged by performance in the laboratory, $H$. rouxi appeared to have the attributes of an effective parasite, and I became overly optimistic regarding its possibilities as a control for red scale in California. In an attempt to rationalize the fact that this species of parasite was not controlling red scale, I speculated that originally $H$. rouxi occupied an area remote from that of the red scale in South Africa and that only at Letaba and Nelspruit had the two come together. This was quickly exposed as wishful thinking by rearing $H$. rouxi from red scale collected at points as widely separated as Pretoria and the Sundays River Valley. The performance of $H$. rouxi in California was a disappointment from the beginning. It was not even believed to have become established here until 1943 when R. S. Woglum discovered it on red scale in a lemon orchard at San Diego. An account of

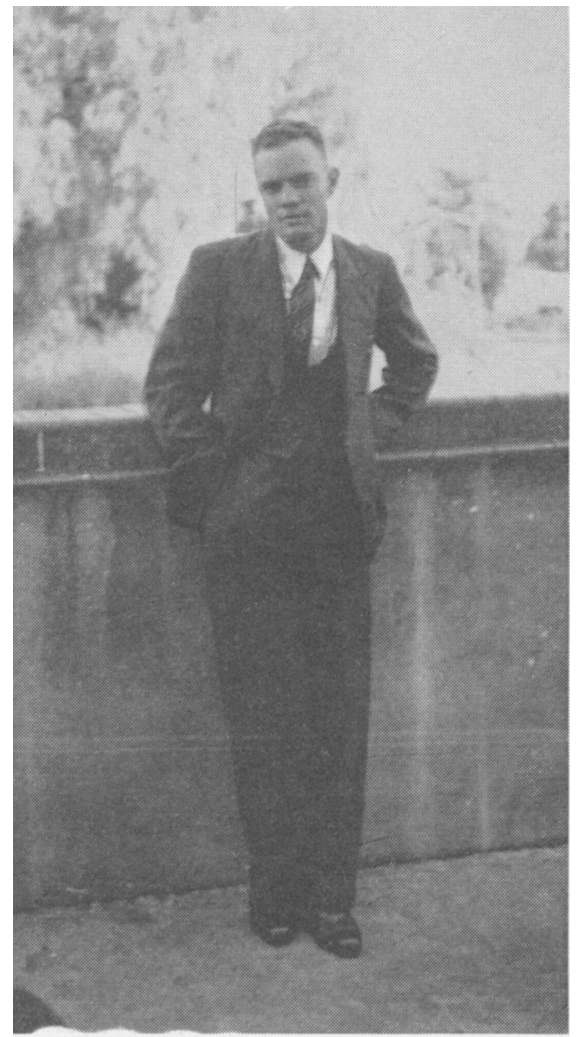

Fig. 28.-W. K. Roux, discoverer of the Habrolepis which bears his name. Formerly Chief Entomologist, Letaba Estates and Zebediela, Union of South Africa (from a photograph taken in 1936).

its introduction and colonization in California has been given by Flanders (1944a).

In 1936-37, it was the consensus that with the possible exception of Habrolepis rouxi, the value of which was questionable, no effective insect enemies of red scale were to be found in South Africa, and I spent the remainder of the time collecting and shipping parasites of the black scale to California. Observations made on red scale and its natural enemies in Africa were incidental to the work with the black scale and its parasites.

In some districts the red scale appeared to be just about as injurious as in California and its enemies no more effective. One noteworthy exception 
was a 200-acre citrus orchard on the De Vlei Estate, Clanwilliam, the largest shipper of citrus fruits. The leaves and fruits of orange and grapefruit trees were badly infested with red scale, but the wood was extraordinarily free of it. Because of the scarcity or absence of scale on the wood, and the relatively large numbers on fruits and leaves, it was suspected that the scale was yellow

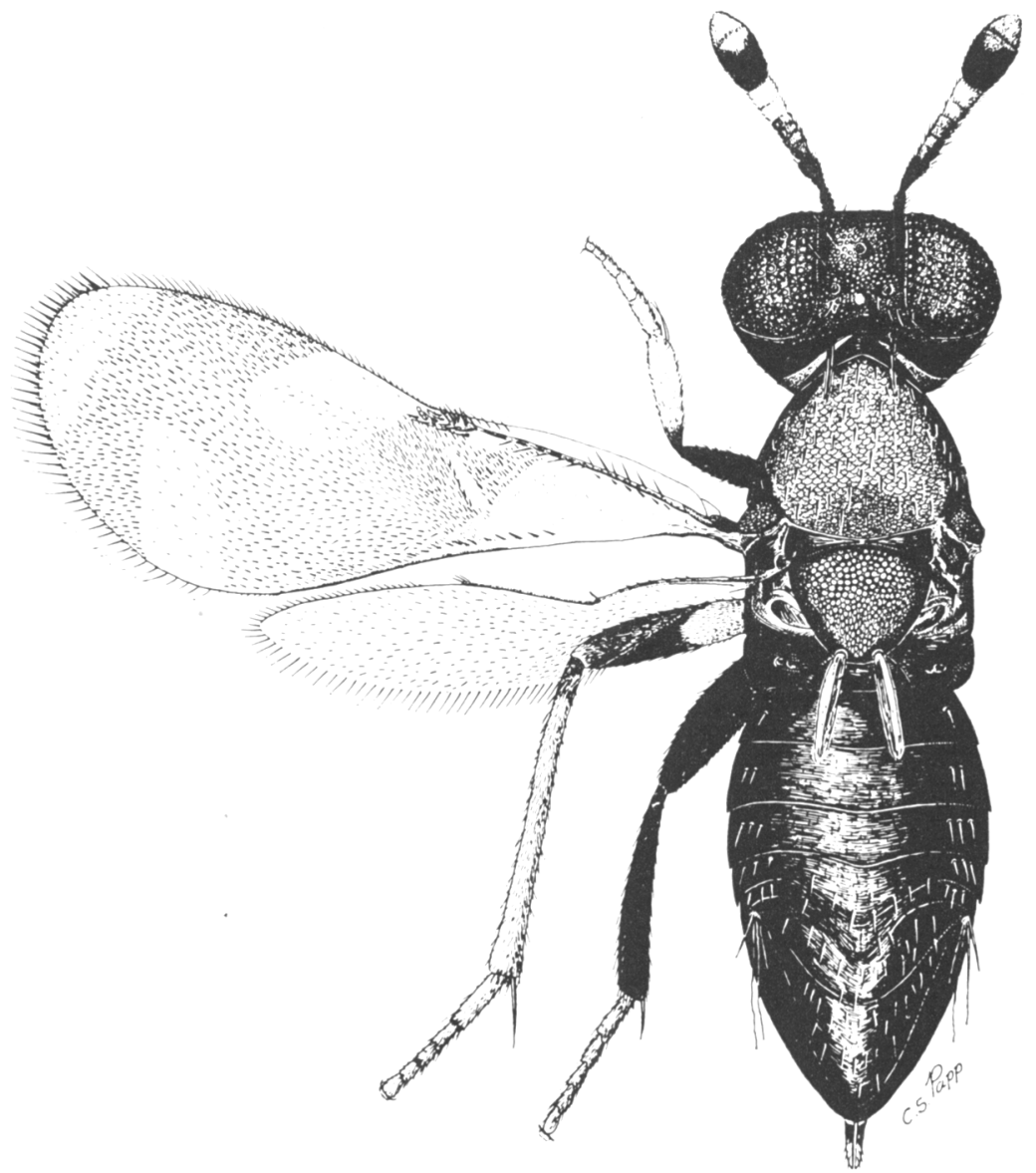

Fig. 29.-Habrolepis rouxi Compere, a parasite of red scale discovered by Roux in 1934 at Letaba Estate, Transvaal, Union of South Africa.

and not red. My suspicion was shown to be wrong when a letter was received from Howard McKenzie giving morphological characters for separating red and yellow scales. The citrus trees on the De Vlei Estate did not appear to be injured any more seriously by red scale than are citrus trees in California infested with comparable numbers of yellow scale, or orange trees in Santa. Barbara infested with red scale. The owner of the property did not regard the red scale as serious, since the trees did not appear to be badly injured by it and the fruit was grown not for export but for the Cape Town market, where scale-blemished fruits were acceptable. It was noted that Aphytis 
chrysomphali and Lindorus lophanthae were present and that no form of chemical pest control was practiced at the De Vlei Estate.

In the orchards of the Sundays River Valley, the red scale was more prevalent on the wood than on the leaves and fruit. The work of Habrolepis rouxi, Aphytis chrysomphali, and several coccinellids was noticed in orchards that were scale-infested. In my opinion the red scale was not controlled by those enemies. Injurious infestations of red scale were later seen in dooryard plantings in Pretoria where no methods of pest control were practiced, and the

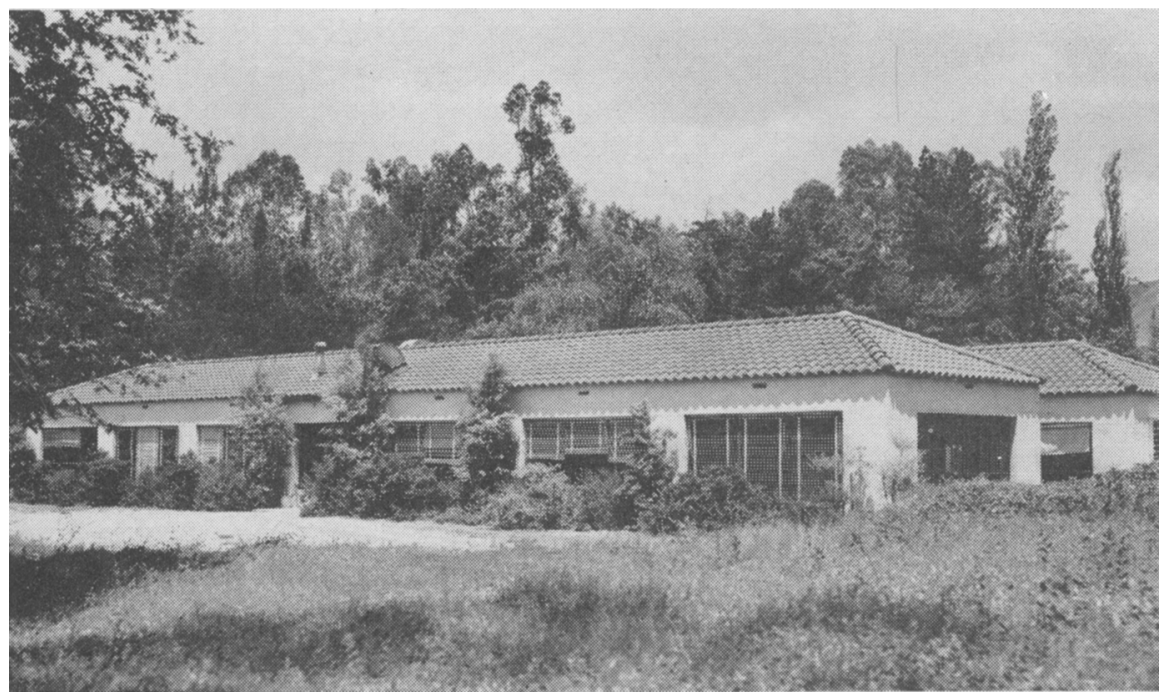

Fig. 30.- Insectary of the University of California at the Citrus Experiment Station, Riverside.

usual complement of parasites and predators was in evidence, but appeared to be no more effective than in the Sundays River Valley.

\section{Africa, 1946-47}

A new attempt to control red scale by the mass release of its parasites and predators was started in 1945 in California, and as many different predators and parasites as could be obtained were wanted for mass culture and trial. At this date plans were being made to send me to Africa for parasites of Pseudococcus longispinus (Targ.), a mealybug of concern to citrus growers in Orange County, and incidental to the search for parasites of mealybugs I was instructed to send to California all insect predators of the red scale found in Africa, even though they appeared to be of little or no value and had been colonized in California in previous years.

A trip was made from Cape Town to Clanwilliam principally to obtain a coccinellid, the identity of which remains unknown. In 1936, in company with C. J. Joubert, a few coccinellid larvae feeding on red scale had been collected in an orchard between Clanwilliam and Citrusdal. The larvae were characterized by long white waxy filaments around the margins of the body. 
An attempt was made to propagate the unidentified coccinellid larvae on red scale in the laboratory at Cape Town in 1936 but this was unsuccessful, and no further attention was given this coccinellid. In 1936 I did not regard it as of sufficient promise to warrant another trip to Clanwilliam. In 1947, others believed differently, and it was theorized that a predator of red scale which existed under the extremely arid conditions of Clanwilliam might be effective in California under somewhat similar climatic conditions. No signs of this predator were seen in 1947, and in Clanwilliam the situation with respect to red scale had changed greatly since 1936. Orange and grapefruit trees in untreated noncommercial dooryard orchards were very seriously damaged by red scale. On the De Vlei Estate only 10 of the original 200 acres remained in citrus. A new owner had removed approximately 10,000 dead and dying citrus trees. While overirrigation combined with a high water table may have been more important than red scale as a cause of tree injury, the remaining trees were badly infested, and red scale was prevalent on the wood as well as on the leaves and fruit. The owner was considering fumigating them to save them from further injury by the red scale.

Ullyett (1946) stated that the conditions necessary to enable the parasites and predators of red seale to reach such abundances as to allow them to control red scale were twofold - "suitable climatic conditions and a reasonably large scale population on which to breed." He argued that the climate of South Africa's citrus areas was satisfactory for red scale, and that thorough fumigation and spraying were rcsponsible for the failure of natural enemies. In this context he wrote, "Not only does this treatment [fumigation and spraying] destroy large numbers of the parasites and predators themselves, but it also reduces the seale population to such a low level that no breeding up of any large population of natural enemies is possible."

At the time of my visit, Ullyett's interest was focused on Letaba Estates, where E. C. G. Bedford, the estate entomologist, was working under his guidance on red scale and its enemies in the orchards and on the life histories of its predators in the insectary. At the suggestion of Alexander Matthew, formerly technical advisor of the South African Realty Trust, Ltd., I wrote to Bedford requesting a supply of the various predators. He replied that the life-history studies were nearly finished, and that upon their completion I could have all the stocks of predators on hand. I arrived at Letaba late in May 1947, before Bedford's studies were completed. Surplus coccinellids were given me and the balance promised for delivery in July. Advantage was taken of this delay to observe the red-scale situation at Letaba and the adjacent citrus-growing estates.

Among the numerous biological-control plots at Letaba were two that especially attracted my attention. ${ }^{.0}$ In these plots (nos. 98 and 470) the ratio of parasites to scales was exceedingly high and the scales were very searce-a condition which might be expected under successful biological control. Chemicals had not been used in the preceding years and the trces were extraordinarily clean. In plot 98 scales ranging in size from second instar to maturity were very searce and were found mostly one by one. With few exceptions the few dead scales that were scen had tell-tale evidence of having been

${ }^{40}$ The 2,000-acre orange orchard at Letaba was subdivided into 5-acre plots with approximately 500 trees to the plot. 
killed by either Habrolepis rouxi or Aphytis chrysomphali. In plot 470 the scales were more numerous, yet far below the danger point, and here the work of $A$. chrysomphali was more evident than that of $H$. rouxi, possibly owing to the presence of a greater proportion of second-instar scales. There were no coccinellids working in plots 98 and 470, and it appeared as if the red scale had been controlled by parasites. In nearly all other plots the scale was abundant and injurious even though parasites and predators were at work. In numerous untreated plots where parasites and predators were depended upon to control red scale, the ratio of parasites and predators to the red scale was generally low. $A$. chrysomphali was present in enormous numbers in some plots where red scale was most abundant. The most important of the coccinellids were Pharoscymnus exiguus Ws., Lotus neglecta Muls., Chilocorus distigma Klug., and C. wahlbergi Muls. They were no more numerous or impressive in their work than are the coccinellids that feed upon red scale in Santa Barbara. According to Bedford, in the experimental plots where red scale was abundant, ants prevented the enemies from controlling the infestations. He performed an experiment, the results of which were very spectacular and appeared to confirm his theory that ants prevented the parasites and predators from controlling red scale. In one block of trees badly infested with red scale that had been overrun with ants, alternate sets of trees were freed of ants by DDT applied liberally to the ground beneath the trees and on the tree trunks. Previously the trees had been "skirted" to prevent ants from gaining access by way of branches touching the ground. In June 1947, the sets of trees that were free of ants could be distinguished at a glance from those that were overrun by ants. The litter of newly fallen leaves in the waterways and the rows of partly defoliated trees with visible die-back, distinguished the rows of ant-infested trees from the ant-free trees.

Since it seemed evident from Bedford's experiment that ants at least aggravated the red-scale problem at Letaba, the question arose as to whether or not red scale would be a serious pest in the absence of ants. Plans were made to answer this question experimentally, but Bedford resigned before publishing the results of his experiments at Letaba. ${ }^{41}$ It was my opinion that red scale would have been serious at Letaba if ants had not been present, since in many plots where the ants were scarce the red scale was little, if any, less injurious than where ants were numerous. Outside the Letaba Estate, injurious infestations of red scale were seen where no ants were found.

Much earlier than this an increase in the injuriousness of diaspid scale insects in the presence of the Argentine ant had been reported in Louisiana by Newell and Barber (1913, p. 63). These investigators wrote, "The stimulation resulting from the attention of ants while collecting sweet liquids appears to have the effect of greatly encouraging the numerical increase of the aphids and coccids."...

An account is then given of an experiment performed by Barber in the summer of 1910 with the sugar-cane mealybug on sugar cane planted in large pots:

One half of the pots were isolated from the Argentine ants, while to the others they were allowed free access. The mealybugs grew and multiplied in both lots of

${ }^{41}$ J. J. Steyn replaced Bedford. For a comprehensive account of the work done at Letaba in more recent years, consult Steyn, 1954a, b, 1955. 
canes but there was a great difference between the thriftiness of the isolated and nonisolated insects. In the pots to which the ants had access the mealybugs multiplied so freely that finally they smothered out the sugar cane with their cottony egg masses. In the isolated pots, while the mealybugs increased in numbers, they were not nearly so numerous or healthy looking as in the ant-infested pots. At the end of two months the number of mealybugs in the ant-infested pots probably exceeded the number of mealybugs in the isolated pots to the extent of at least five to one. (Newell and Barber, 1913.)

The same situation with respect to the mealybugs was found in the cane fields. These investigators then stated that the same thing holds true with scale insects generally and particularly the chaff scale, Parlatoria pergandii.

Entomologists contend that the phenomenon reported by Newell and Barber is attributable solely to the protection from their enemies afforded the scales by ants. Newell and Barber were alert to this possibility and stated:

In considering the remarkable increase in scale insects and aphids which invariably accompanies heavy infestations by this ant, one cannot avoid taking into account the persistence with which the ants drive away ladybird beetles which attempt to prey upon the insects fostered by the ants. So thoroughly are the Coccidae and Aphididae protected in this manner that it is rare that a ladybird can be found at all on the infested trees. (Newell and Barber, 1913, p. 66.)

Red-scale-infested eucalyptus trees that served as windbreaks on the Letaba Estate were removed some years prior to 1947 when Roux considered eucalyptus to be reservoirs from which wind-blown red scale continually reinfested the orange trees. Owing to the large size of these trees, it was impractical to control the scale with chemicals. Some entomologists have suggested that eucalyptus trees may be repellent or unattractive to natural enemies of the red scale and that this accounts for the abundance of red scale on these trees in certain localities. In California a red-scale-infested eucalyptus tree is a curiosity, but according to Freeborn (1931) eucalyptus is a particularly good host of red scale in Egypt.

Prior to Bedford's announcement that ants were the principal factor in preventing a biological control of red scale at Letaba, ants were of concern there chiefly owing to their effect on the parasites of soft (brown) scale, Coccus hesperidum. The two ants most important at Letaba were Anoplolepis custodiens Smith, the pugnacious ant; and Pheidole megacephala (Fab.), the brown house ant. In some parts of the Estate, along roadways and in spaces between plots, the ground was literally honeycombed with ant nests, and the adults swarmed into the nearest orange trees for the secretions of honeydew produced by soft (brown) scale. Evidence indicates that in the absence of ants, soft (brown) scale is controlled there by parasites. These are not as effective as the aggregation of parasites that controls soft (brown) scale in California, where this scale rarely becomes a pest even in groves in which ants are abundant, and incipient infestations are often completely destroyed even though ants are present. In the plots at Letaba the ants were most abundant where soft (brown) scale and red scale were most abundant, namely, along the dusty roadways and in the open spaces between plots. Even in the absence of ants it has been observed repeatedly that scale insects are more injurious along dusty roadways and outer margins of orchards than inside where trees are crowded. In the Valencia Estate, a property containing 10,000 
orange trees immediately adjoining the Letaba Estate, the trees were kept free of scales by an annual fumigation and spot-treating incipient infestations between the annual over-all fumigation. Here, where the trees were clean, the ant nests were numerous along the roadways and in the openings between plots, and the ants foraged for food on the ground and not in the citrus trees.

No citrus property had more at stake on account of the red scale than the Letaba Estate. In size it is exceeded only by Zebediela, the largest citrus estate in the world. My estimate of a reduction of 25 per cent in the productivity of the trees at Letaba owing to red-scale injury was not regarded as an excessive figure by the resident manager, Andrew Matthew. As already mentioned, pest control was not under the direction of Matthew, the manager, but under E. C. G. Bedford, an entomologist employed by the head office as an expert. In the 2,000 acres of orange trees at Letaba more defoliation and dieback from red scale was seen by me in one place and at one time than can be seen in any citrus-growing county of California in an entire year, or perhaps in all southern California at any one time. Red-scale control far outweighed in importance all other cultural problems at Letaba.

My findings at Letaba and elsewhere in Africa were not in agreement with those of Ullyett and Bedford. Ullyett reported two species of Aspidiotiphagus attacking red scale at Nelspruit. Here, and at near-by White River, red scale was exceedingly abundant but I did not find Aspidiotiphagus. The government entomologist, F. S. Stofberg, located at the Subtropical Horticultural Research Station, Nelspruit, and the orchardists regarded fumigation as the best method for the control of red scale. At the large Crocodile Estate, fumigation was looked upon as a preventive as well as a cure, and it was the practice to fumigate before the trees were injured by red scale.

A trip was made to Waterval Onder to inspect Sycamore Ranch, where red scale was reported to be under biological control. This orchard had never been treated and in general the trees were quite free of red scale. An occasional tree was injuriously infested. At the time of my visit, the fruit had been picked and the cull fruits dumped into a large pit. An inspection of redscale-infested fruits in the pit failed to show any parasitized scales or a significant amount of feeding by predators. On the basis of this evidence, I concluded that red scale was not controlled by its insect enemies at Waterval Onder.

At the Muden Valley Estates in Natal, another property of the African Realty Trust, the climate is drier than at Letaba. If one were to prophesy on the basis of climatological data, it would be predicted that red scale would be much more injurious at Muden than at Letaba, but the reverse was the case.

In the coastal region of Natal, it is difficult to find red scale on citrus. Its noninjuriousness there has been attributed by some observers to the work of parasitic fungi. As evidence of this, my attention was called to an abnormal build-up of citrus scales after a copper spray to control "black spot" on oranges, in an orchard at Verulam. On the sprayed orange trees there was a very serious build-up of Lepidosaphes beckii and Chrysomphalus aonidum and little evidence of the "red-headed" and "white-headed" fungi that were alleged to control them. In check plots where no fungicide was applied, the scale infestations were normal and fungi much in evidence. 
The experimental orchard at Verulam presented an interesting and significant exhibit of Aonidiella aurantii. The orchard occupied the floor of a narrow valley, the slopes of which were planted to Fourcroya gigantea-a fiber-producing plant that resembles an oversized century plant, Agave americana. On the Fourcroya the red scale formed an almost solid mat on the older leaves, but none could be found on the lemon and orange trees about 100 yards distant. Several species of coccinellids and Aphytis chrysomphali were present in large numbers on the Fourcroya but appeared to have no appreciable effect in checking the red scale. In my opinion, the distribution of red seale as a pest in Natal is determined by factors other than entomophagous insects and entomogenous fungi.

While on a mission to Kenya and the Island of Zanzibar, a watch was kept for red scale. It was not found in Zanzibar on plants of any kind. In the highlands of Kenya, especially at Nairobi, red seale was exceedingly abundant on rosebushes but citrus in the town was free of it. At Chania, on the estate of Ivan Harris, a grove of 600 navel orange trees was examined. Here Aonidiella aurantii was present in injurious numbers and associated with it were Chrysomphalus aonidum and Lepidosaphes beckii. There are relatively few citrusgrowing regions in the world where $A$. aurantii and $C$. aonidum occur together and injuriously infest the same trees. Coccinellids were found feeding on scales at Chania, the most common of which was Chilocorus wahlbergi. This predator was sent to California.

\section{REPORTS FROM AFRICA}

There is evidence to show that red scale was injurious to orange trees at Sea Point, Cape Town, as early as 1857 (Stofberg, 1937). It was exceedingly abundant and injurious on a wide range of host plants in the Cape area when it first eame to the attention of Charles P. Lounsbury (fig. 31) upon his arrival there in 1895 to accept the position as Entomologist for the Colony of the Cape of Good Hope. He was the first entomologist to be employed full time to work on insect pest problems in all of Africa. In 1933 he wrote me:

The first white settlement in South Africa was at Cape Town in 1653 and orange trees were introduced there from St. Helena in 1654. Within a few years there were flourishing orchards of orange, lemon, and other citrus fruits in the Cape Peninsula and the culture of these fruits followed the course of settlement wherever the conditions were suitable. The presence of the fruits is mentioned in many of the early records, ...

But any reference to scale insects has been conspicuously absent from all the old publications which I have scanned; and I do not think red scale could have got in much before a century ago and it may not have got in until after the middle of the last century. ${ }^{42}$

According to Lounsbury, citrus seeds and possibly plants were brought from Batavia, Dutch East Indies, before the British occupation, which began in 1795, but red scale was probably not introduced that early. After 1820 seed at least came from the Canary Islands. The navel orange was imported from

${ }^{2}$ Excerpt of letter from Charles P. Lounsbury to Harold Compere, October 3, 1933 ; see footnote 3 . It contains many details of the routes of early voyages to the Cape Province, possible sources of citrus importations, and possible sources of red-scale importation and spread in that area. 


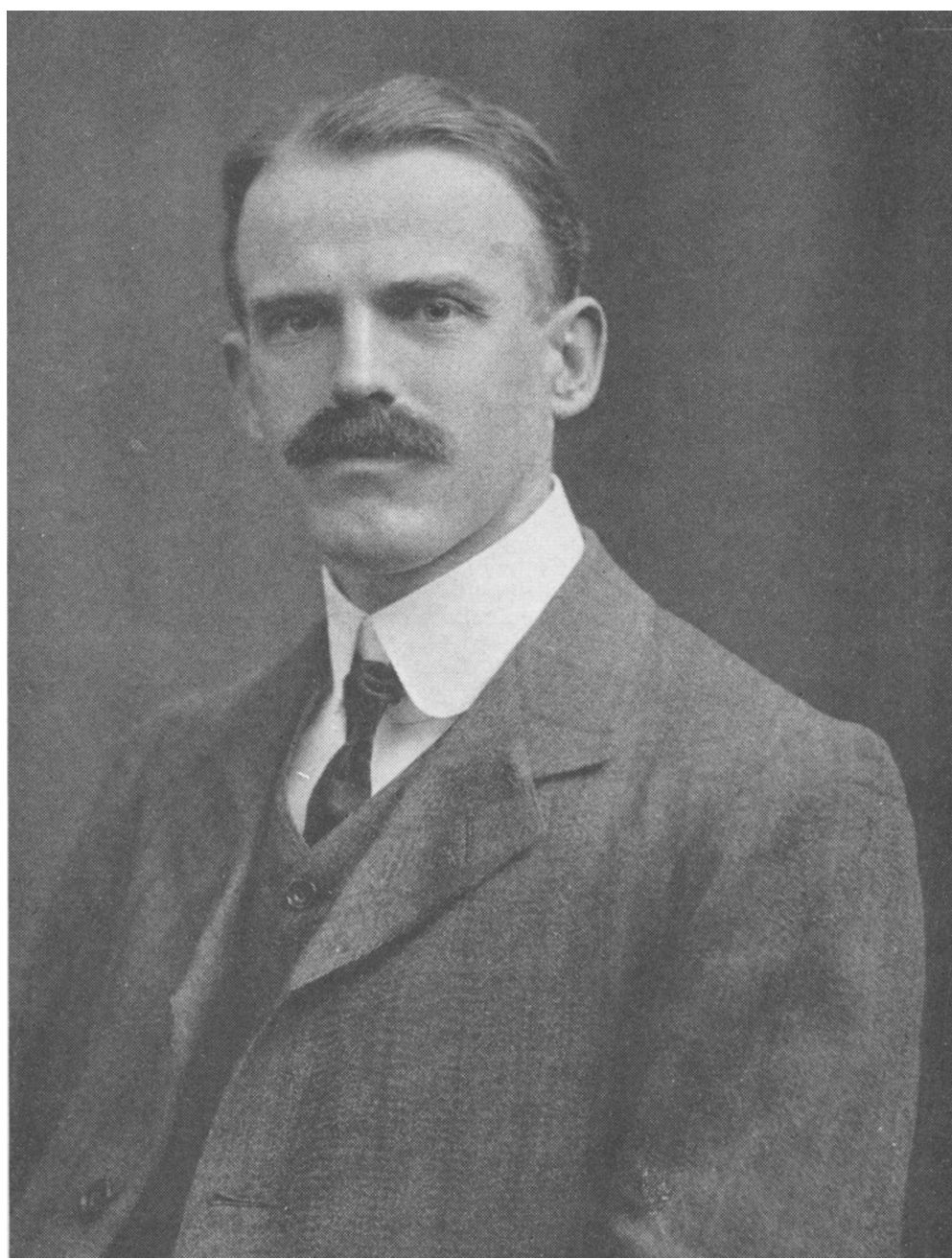

Fig. 31.-Charles P. Lounsbury (1872-1955) from a picture taken in 1907 and obtained through the courtesy of Dr. Paul Lounsbury, a nephew. In 1895 Howard recommended Lounsbury as the man best qualified to fill the newly created position of Government Entomologist of the Colony of the Cape of Good Hope. In 1900 Lounsbury called attention to the possibility of controlling black scale in California by the introduction of its parasites from the Cape of Good Hope and shipped much parasite material to California in the early days.

Brazil about 1850. He suspected that the red scale was introduced at Cape Town. It attacks a greater variety of plants-even oak and pine-in the Cape Peninsula than anywhere else in the country. But he could find no definite evidence as to its source. From the trade routes he concluded that it is as likely that Australia got red scale from South Africa as the other way round. He pointed out that trade routes would have permitted red scale to 
have spread to Cape Town from Madeira or the Azores, but considered it unlikely. Lounsbury said that as far as he knew the yellow scale had never been found anywhere in South $\Lambda$ frica.

Lounsbury was the first to call attention to South Africa as a promising place to obtain parasites for controlling the black scale, Saissetia oleae, in California, and sent Metaphycus lounsburyi and Scutellista cyanea Motsch. to California and New South Wales.

In his report for 1900 Lounsbury said:

The Red Scale (Aspidotus aurantii) is the scale in Cape Colony. It occurs practically everywhere in the country where oranges are grown for sale though there still remain occasional farms which by good fortune or great care, or both, have been kept clear of it. The extent of the damage done by it varies in different districts and localities, but it is deserving of the term "pest" wherever it is found with us and in general its presence spells little or no fruit and slow dying back of the branches to heavy wood or even to the ground when protection of the tree is not given by insecticides. Five or six species of our ladybirds attack it, and at least one hymenopterous parasite has been bred from it in large numbers; two or three fungus diseases, too have been observed to affect it, but the combined influence of all the natural enemies is slight. What the colonial fruit growers desire is that efficient enemies be found and introduced; and it was thought that I might get such in America or gain information as to where they might be found. (Lounsbury, 1901.)

On a trip to the United States, Lounsbury talked with Howard and Marlatt of the U. S. Department of Agriculture in Washington, who gave him no encouragement to hope that an effective natural enemy for red scale could be found; and with Alexander Craw of the California State Board of Horticulture and other Californians, who were "quite hopeful in their views." He reported that the situation in California with respect to red scale and its parasites and predators was very similar to that in South Africa-many natural enemies attacked it, but none were able to hold it in check. His inquiries and observations led him to the conclusion "that no natural enemies of seale insects are known in America that would be likely to prove of much value against the Red Scale if introduced into the Colony; and further that no one is yet aware of the proper place in which to search for the much desired enemies" (Lounsbury, 1901). He was inclined to agree with the opinion of Maskell (1879) that the red scale originated in southern Europe, and expressed the hope that a search for effective enemies might be made there, despite the failure up to that time to discover any that were effective.

With respect to fungi attacking red scale, Lounsbury said:

In Natal the Red Scale suffers from the attacks of a parasitic fungus which I believe to be identical with Sphaerostilbe coccophila found in Florida on the San Jose Scale. The fungus has long been known in Europe as occurring on dead scale insects but investigations in Florida proved that it was a specific cause of death. The same fungus is said to attack the Red Scale in Queensland; and very recently in response to an enquiry the Ceylon Entomologist, Mr. E. E. Green, has written me that it or a closely allied form is an important check on the same scale there. During the last year the Natal Entomologist, Mr. Claude Fuller, favoured us with several sendings of orange twigs encrusted with scale affected by the disease and these twigs were tied to infested trees at Newlands with the object of infecting the scale thereon, but in no instance was the disease found to spread. It is surmised that the climate at the Cape is unfavourable for the propagation of the disease, the summers being too dry and the winters not warm enough. Since making the trials, the fungus has been discovered elsewhere in the suburbs on a lemon tree which is indicative that it occurs 
at the Cape already. That it occurs in the east of the Colony was learned three years ago; a species of native scale was found much diseased by it in the bush near Port Alfred in the Bathurst District, but no trace of it was seen in the Bathurst orange orchards. Some more trials at propagating it in the orchard will be made but success is not anticipated. (Lounsbury, 1901.)

In the 1933 letter to me mentioned earlier, Lounsbury gave much information concerning the topography, climate, citrus industry, and red scale in South Africa. An excerpt from this letter follows.

North, south, east, and west, the red scale occurs abundantly on citrus and nowhere in the whole country do I suspect it to have any parasites of importance. But I must add that in the Rustenburg and in the Warmbaths (60 miles north of Pretoria) it is outclassed as a pest by the circular purple scale (your Florida red) and that in most seasons it is very decidedly less a menace in these areas than it is practically every season on the Kat River and most other Cape Province places. I tentatively attribute the relative lack of virulence of the species in the Rustenburg and Warmbaths areas to ill defined environmental conditions of physical nature. Here in Pretoria, red scale in the generality of seasons does no material harm to a citrus tree that is left to itself and must depend on the rainfall for its entire water supply; but it will romp ahead and start killing twigs in the extra-wet seasons. Similarly, the scale is very apt to ravage a tree that is never short of water, say one standing near a leaking water tap, or one growing in a well-cared for rose garden, when trees of the same variety in dry ground nearby, even within 50 feet, fail to get much infested; but even well-kept trees appear to get heavier infested in the seasons of higher-thanaverage rainfall (incidentally the cooler) than in the seasons of sub-normal rainfall. To keep the scale from going ahead, I ought to add, it is not necessary to withhold irrigation water entirely, it seeming to be quite safe to give a tree enough during the long dry season to keep the foliage from wilting. ${ }^{43} .$.

In 1940 Lounsbury wrote, "In the early years due to Californian influences, there was an insistent public demand for the introduction of scale and aphisfeeding ladybirds, particularly from Australia." Orcus australasiae, $O$. chalybeus, Rhizobius ventralis, and Leis conformis were obtained from Australia, and three of the species were reared and liberated, but only $O$. australasiae survived for six months, and it apparently died out in another year. Rhizobius lophanthae [=Lindorus lophanthae] apparently became established from liberations made in 1900. Hippodamia convergens was introduced from California in the hope of controlling woolly aphids but "no descendants were found." "It was a great relief to me when the craze for the importation of ladybirds died down."

Rust (1915), who served as foreign collector for the State of California from 1919 to 1926 and was stationed in South Africa for the greater part of this time, was qualified by training to pass judgment on the red-scale situation in South Africa. Previous to going to Africa, he had studied the life history of Aphytis chrysomphali as a parasite of red scale in California. ${ }^{44}$ Rust commented on the work of $A$. chrysomphali on red scale in South Africa and shipped the coccinellids he found feeding on diaspid scales to California. He did not consider the insect enemies of red seale in South Africa as any more effective than those in California. Exochomus flavipes, which Rust sent to California at this time, was propagated and colonized extensively by D. W. Tubbs in Orange County, but failed to become established.

${ }^{43}$ Compare with Summerville's findings on the effect of climate in Australia, p. 256.

${ }^{44}$ The results of Rust's life-history studies are incorporated in Quayle's report (1911). 
The red scale was reported as the most injurious pest of citrus on the large Mazoe Estate, located in Southern Rhodesia, where it was studied comprehensively by E. P. Jones (1936). He was not favorably impressed with the importance of insects attacking red scale. Aphytis chrysomphali was present from October to April, but the percentage of parasitism averaged only between 1 and 2 per cent. He reported that fungi attacked only dead or dying scales, and only when humidity was high. Nine species of ladybird beetles were present, but all were general feeders; and while they were of more economic value than $A$. chrysomphali, their influence was small.

Stofberg (1937), Entomologist of the Subtropical Horticultural Research Station, Nelspruit, also reported that while Aphytis chrysomphali could often be observed on heavily infested trees, it was not able to reduce the infestation materially. He said further that the ladybird Lotis neglecta Muls. and a few others were predaceous enemies of red scale but their feeding habits were varied and they did not contribute much toward its control; and that the fungus Fusarium coccinellum was found parasitic upon red scale only under extremely humid conditions.

The parasites of red scale in South Africa were studied by A. J. Smith, Entomologist, Division of Entomology, Union of South Africa. In 1944, Smith ${ }^{45}$ reported that the infestation of citrus with red and purple scales appeared to be below normal in 1944, though some orchards were still heavily infested. In three orchards examined he found red seale from 5 to 14 per cent parasitized and from 9 to 15 per cent dead. In one of these orchards purple scale was 0.5 per cent parasitized with almost 16 per cent dead. He believed the parasite to be Aphytis chrysomphali. No entomogenous fungi were observed. Several species of coccinelids and one or more species of Chrysopa were feeding on both scale insects. Yet he said, "It is felt, however, that these natural enemies never occur in sufficient numbers to have any important effect on the scale population.... Climatic factors, especially sudden cold spells during the winter months, as was experienced during the past winter, may have had an appreciable effect in reducing the scale populations."

Prior to 1945, entomologists and most orchardists agreed that insect parasites and predators did not control red scale in Africa. But in 1946, Ullyett reported that in different parts of South Africa natural factors were effective in checking red scale in commercial citrus groves, provided that no chemical control was used..$^{46}$ Insect parasites and predators were said to be among the most important of the natural factors controlling red scale; parasites alone were unable to control it, but when the work of parasites was supplemented by that of predators, control was obtained; South Africa possessed a very efficient complex of natural enemies which had not been given a fair chance to prove their worth. Since the appearance of Ullyett's paper, OmerCooper and Whitehead (1950) and Steyn $(1954 a, b, 1955)$ have also reported that red scale is controlled in South Africa by insect parasites and predators. These claims merit careful consideration, for if correct, much money has been

${ }^{45}$ Smith, A. J., letter to T. J. Naudé, Chief, Division of Entomology, dated Rustenburg, February 9, 1944. The letter was shown to me by Naudé.

${ }^{46}$ See also the discussion of Ullyett's 1946 paper and the experiments on the Letaba Estates carried on under his guidance, pp. 242-45. 
spent unnecessarily on fumigating and spraying orchards for the control of red scale. Moreover, if red scale is controlled by insect parasites and predators in South Africa, there is reason to believe that it can be controlled by its insect enemies in California.

\section{REPORTS FROM AUSTRALIA}

A partial account of the red scale in Australia has been given in connection with the work of Albert Koebele and George Compere. According to information given Koebele, the red scale was known to orchardists as a pest of citrus in New South Wales as early as 1841. It was made a matter of entomological record by Maskell in 1879. Following its description as a new species, Maskell commented that it was found in immense numbers on oranges and lemons imported into New Zealand from Sydney, Australia; it was not indigenous to New Zealand although it occurred there on orange trees growing at Governor's Bay. As an example of the injuriousness of red scale in Australia, Comstock (1881b, pp. 293-95) told of a grove of 33 acres there which nine years earlier had rented for $£ 1,800$ and for which only $£ 150$ could be obtained six years later.

Walter W. Froggatt became interested in red scale soon after his appointment as Entomologist for New South Wales, and in 1897 he wrote:

This is our common scale on orange and lemon trees, chiefly upon the leaves and fruit, and is one of the most persistent species to destroy as it clings so closely to the food plant. In South Australia fruiterers are fined for selling oranges covered with this scale, but in Sydney shops one can hardly find an orange that is not more or less infested. (Froggatt, 1897.)

In 1905 the red scale was reported as the most important pest of citrus in the Orange River Colony (Dewar, 1905).

When Compere was appointed Entomologist for Western Australia in 1903, he started a crusade there to control insect pests by the introduction of parasites and predators. This had far-reaching consequences. The slogan "Restore the balance of nature and control pests by nature's method" made an irresistible appeal to orchardists in all the states of Australia. Cooper added fuel to the flame and brought matters to a head by proclaiming in speeches and articles that all the worst orchard pests had been or were about to be controlled by beneficial insects in California, and in letters to the heads of the Australian states offered to provide a parasite that would control codling moth. As one consequence, a conference of entomologists was held at Sydney in July 1906, with representatives from New South Wales, Victoria, Queensland, and South Australia. A decision was made to send their best qualified man to Hawaii, California, and other countries to observe the results obtained from introducing beneficial insects. Froggatt (fig. 32) was selected as the best qualified, and at a conference of the premiers of the Australian States held in June 1907, he was authorized to visit America and Europe to inquire into the best methods for controlling insect pests, and to obtain any parasites and predators that might be of value to Australia.

In the beginning Froggatt was not antagonistic to biological control and had attempted to control black scale, Saissetia oleae, in New South Wales by 
introducing parasites from South Africa in 1903. He was not favorably impressed by the results in California and reported that in his opinion nothing was seen to support the claims that had been made, and that scale insects and other orchard pests were as numerous and injurious in California as in Australia (Froggatt, 1909). With reference to red scale, Froggatt stated

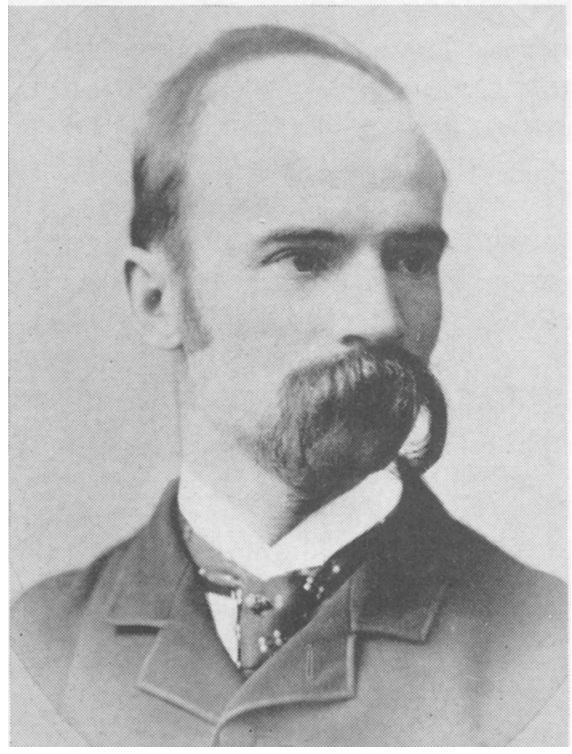

Fig. 32.-Walter W. Froggatt (1857$1937)$, an apostate with reference to biological corrtrol. (From a photograph taken about 1900 and obtained through the courtesy of S. L. Allman.) that it was a bad pest of citrus in California and Spain and that it was reported that citrus trees were being killed by it on the Island of Cyprus. ${ }^{47}$

In connection with the work of George Compere, an account was given of the introduction of a species of Aphytis into Western Australia from China in 1905. For almost 50 years the identity of this species has been a matter of speculation and contention. ${ }^{4}$ The species introduced into Western Australia in 1905 by George Compere was probably $A$. lingnanensis, but whether it is the species common there today is uncertain. Newman's later reports concerning the species of Aphytis on red scale in Western Australia indicate that the first sanguine hopes, voiced in 1906 (see pp. 202-03), were not realized. Thus in 1909:

Red Scale (Aspidiotus aurantii). This is without much doubt the most destructive scale insect in this State. It has a very wide range of food plants. It attacks all varieties of citrus, also quince, pear, apple, fig, loquat, mulberry, castor bean, roses, and many other garden plants and native shrubs. In the latter part of $1905 \mathrm{Mr}$. Compere brought from the Orient some red scale parasitized by a small yellow species of Chalcid fly, from which some fifteen issued. These were put in another cage containing two small trees infested with Red Scale. The trees were placed in a Perth garden badly infested with this scale, and it was soon noticed that the little parasite had become established. Many colonies of these insects have been distributed, and where they have become established, good work is reported. But it has been clearly demonstrated that a single species of parasite would not in itself be able to bring this scale into subjection. To this end $\mathrm{Mr}$. Compere again turned his attention to the matter, and upon his recent return to the State, brought with him no less than six new species of internal parasites of this scale. These are issuing in large numbers and can be seen ovipositing in fresh local scale. It is hoped that when these new arrivals have become established ... they will give as good an account of themselves as have those imported against the Black and Soft Brown Scales. (Newman, 1909.)

${ }^{47}$ Froggatt did not distinguish between Chrysomphalus dictyospermi Morg. and Aonidiella aurantii (Mask.). The red scale in Spain was probably C. dictyospermi and that in Cyprus, A. aurantii.

${ }^{48}$ In response to a recent request, C. F. H. Jenkins has promised to send specimens for identification. (C. F. H. Jenkins to H. Compere, Aug. 20, 1956.) 
A number of references to red scale and its enemies were made between 1922 and 1949 in the annual reports of the Department of Agriculture. These indicate that control by Aphelinus fuscipennis, A. diaspidis, and $A$. chrysomphali $^{: 9}$ was erratic (Newman, 1922, 1924, 1925, 1926, 1927, 1928). Of A. fuscipennis, Newman (1922) reported, "It is not a dependable parasite, being much influenced by weather conditions." And again (1925), "This insect is well established in our citrus areas, but cannot be relied upon to permanently control the scale. The past season has been very favorable to the parasite. It serves a very useful purpose." Colonies of $A$. diaspidis were forwarded to New South Wales, where it was reported to have become established. But in dry years these parasites were not effective enough to prevent the red scale from assuming "plague proportions." The ladybirds Rhizobius debelis, Orcus australasiae, and Chilomenes quadrapustulatus were mentioned in 1922 as being plentiful and doing "much good work"; but thereafter there is no mention of them. In 1948 Newman had obtained Comperiella bifasciata from the Waite Agricultural Research Institute and was breeding it for field distribution. ${ }^{50}$

C. F. H. Jenkins attributes the distribution of red scale as a pest of citrus in Western Australia to climate and a species of Aphytis. This entomologist wrote:

Red scale in Western Australia is by no means the all-important problem it is to citrus growers in the Eastern States. It is well established in the orange groves of Chittering, Harvey, and the Darling Range, but it is kept in check with nominal attention compared with the efforts of growers elsewhere. There are probably two reasons for this, one is that a parasite has been established locally on the pest, but the main factor is probably the climatic conditions.

As already stated, the red scale thrives mainly in the districts where citrus is grown under semi-arid conditions, as in the light rainfall but irrigated areas of South Australia, Victoria and New South Wales. When the rainfall of Kalamunda or Harvey, approximately 35-40 inches, is compared with that of the Murray Basin, approximately 11 inches, this climatic difference will be readily appreciated. Even in our own State, the incidence of the pest in the hill districts and Harvey is different from that found at Chittering and Gosnells, while the position at Carnavon, probably the most seriously infested district in Western Australia, has no counterpart in the southwestern portion of the state. (Jenkins, 1945.)

The following information supplied by the late W. B. Gurney and the accompanying report by N. S. Noble, concerning red scale and its enemies in New South Wales, are of sufficient value to be made a matter of published record.

Following your enquiry last year concerning the possible origin of red scale infestations in Australia, I have not neglected to make enquiries in numerous directions as to whether our red scale originated from Japan and China or other parts of the world. I regret we cannot get any satisfactory data to prove this one way or the other, and think on the whole it seems likely that infestations of red scale could have their source in many parts of the world.

I have personally visited various libraries and looked up newspaper and historical records without obtaining a definite lead on these points.

${ }^{40}$ These three species names apply in all likelihood to only one species.

${ }^{50}$ H. J. Katekar, a citrus grower of Australia, reported during a visit to California in May, 1959, that Comperiella bifasciata had controlled the red scale in some areas in Australia. 
E. H. Zeck and [N. S.] Noble have also enquired into the occurrence of the red and yellow strains of Chrysomphalus aurantii, and their reports, together with field observations by P. C. Hely, indicate that the two strains do occur here. ${ }^{51}$

Gurney arranged for Noble to check the earliest New South Wales historical records. The latter examined the first seven volumes of these data, from 1788 to 1811 . These show that the first fleet to sail for New South Wales arrived May 15, 1788, about a year after leaving England, over nine months after stopping in "Rio Janeiro" where "fruits and plants" were procured, and about six months after loading "grains and seeds" at the Cape of Good Hope. No mention is made of citrus. A footnote to a court case in 1880 reports that the first oranges grown in New South Wales were on a farm originally belonging to the Rev. Richard Johnson. This was on a grant of 100 acres of land made to Johnson by the Government in 1793. Other officers of Governnor Phillips's first fleet received similar grants of near-by lands. Except for land granted to the Church in Sydney, these were the first land grants made by the Government in Australia. By 1841, red scale was sufficiently abundant to attract the attention of orchardists, if the testimony of Scobie is reliable (p. 198). In view of the length of time required to make the early voyages and the lack of provision for transporting plants, Noble concluded that the first citrus grown in New South Wales was from imported seeds. He also noted that in 1807 Surgeon Luttrell wrote to Under Secretary Sullivan, "Oranges and lemons we have but not in abundance considering the length of time the colony has been settled." Noble thought it likely that either seed or plants of some fruit had been imported from China and Japan, for Surgeon Luttrell mentioned that "a fine Japan fruit called the loquat" was grown in New South Wales.

There is evidence which suggests that the red scale was introduced into Australia from China and that it may have made its first appearance as a pest of citrus in Australia at Parramatta.

The Pye Estate at Parramatta, noted for the many varieties of citrus grown and for the productiveness and quality of its oranges, was located close to the original grants of land made to Johnson and other officers of Governor Phillips' Fleet. As early as 1879 Pye had earned a reputation as the bestinformed orange grower of the time. In answer to a set of questions submitted by the editor of the Pacific Rural Press, Pye made a very significant statement in 1879 that could only have been made by a very discerning observer after a long experience with red scale as a pest of citrus. ${ }^{52}$ If the giant shaddocks and other citrus growing on the Pye Estate prior to 1888 (Bonavia, 1888) had been imported from China as nursery stock, this could very well have been the means by which red scale was introduced into Australia.

Noble also sent a detailed report of his investigations of parasitism in the red scale from June 1931 to October 1933. He obtained 49 batches of infested twigs, leaves, and fruit and recorded the parasites that emerged. He summarized the results as follows:

It has been found that a very large percentage of the parasites die within the scales, so that the actual number of parasites bred in any batch merely gives an indication and could not be used to indicate the percentage of parasitism.

${ }^{51}$ From a letter of W. B. Gurney to Harold Compere, June 19, 1934 ; see footnote 3.

${ }^{62}$ This significant statement concerns the unfavorability of the sour or Seville rootstock to red scale and is discussed under "Unfavorability of Citrus to Red Scale," p. 262. 
It will be seen that three species of parasites were present, viz. Aphelinus diaspidis [Aphytis chrysomphali], Aspidiotiphagus australiensis and Ablerus sp. ${ }^{53}$

Of the total of 49 batches, parasites were reared from 21 batches only.

A. diaspidis was present in 14 batches, A. australiensis in 7 batches and Ablerus $\mathrm{sp}$. in 3 batches and only in very limited numbers.

From general observations on emergence records and examination of scales it would appear that generally speaking the percentage parasitism was very low. No parasites were obtained from a batch of material from the North Coast and also from the Murrumbidge Irrigation area or from any batches from the western Districts. However, more extensive collections are necessary in order to state definitely whether the parasites are present or absent from these areas.

In any case parasites appear to be of little importance in the control of red scale in New South Wales and the parasites which are present do not appear to be uniformly distributed.

This was written before McKenzie (1937) clarified the identification of red scale and its near relatives, and when the identification of their parasites was even more confused than it is now. Of this situation Noble wrote:

The exact status of Ablerus sp. is not known. It has been found in association with Aphelinus diaspidis and in white louse scale with A. australiensis.

A. diaspidis is apparently the species which Mr. Compere refers to as Aphytis chrysomphali.

Newman in West Australia referring to the parasite of red scale, at different times refers to it as Aphelinus chrysomphali, Aphelinus diaspidis, and Aphelinus fuscipennis. Aspidiotiphagus australiensis Gir. has been bred by me from red scale, Chrysomphalus aurantii, purple scale, Lepidosaphes beckii, San Jose scale, Aspidiotus perniciosus, white louse scale, Chionapis citri, and very abundantly from Chrysomphalus aonidum, the red scale on aspidistra, from the Botanic Gardens, Sydney. In the latter scale 2, 3 and even 4 emergence holes are commonly seen in single scales. $^{54}$

As far as I can determine Aspidiotiphagus australiensis Gir. appears to be identical with Aspidiotiphagus citrinus Craw.

I note that Essig mentions that among other species of scales, Aspidiotiphagus citrinus parasitises yellow scale, California red and Florida red scale in California. However, according to H. Compere in his letter dated 10.8.33, Aphytis chrysomphali is the only parasite which attacks California red scale so that he apparently does not recognize Essig's record of Aspidiotiphagus citrinus.

In view of the confusion regarding the various scales, slide mounts were made of the red scale from which I bred $A$. australiensis abundantly. These were a very deep brownish red and the pygidium was typical of red scale.

If $A$. australiensis and $A$. citrinus prove to be identical, and $A$. australiensis attacks red scale in Australia, but $A$. citrinus does not attack the red scale of California, this would be evidence that the California red scale and the New South Wales scales are not quite the same..$^{55}$

It would certainly be of interest to know whether Comperiella bifasciata which apparently bred freely on Florida red scale, [Chrysomphalus] aonidum on aspidistra in California, would attack the Australian citrus red scale.

It would also be of interest to know whether species of parasites which successfully breed in yellow scale in California would breed in our yellow forms of citrus scale in Australia. ${ }^{58}$

${ }^{53}$ It is suspected that Aspidiotiphagus australiensis Girault may prove to be the same as the red-scale-inhabiting form of $A$. citrinus.

${ }_{54}$ The red scale on aspidistra, Botanic Gardens, Sydney, is Chrysomphalus bifasciculatus Ferris, and the parasite which makes multiple exit holes is Casca silvestri Comp. Unless the segments in the tarsi are counted, it is easy to mistake Casca for Aspidiotiphagus.

${ }_{55}$ Two different forms of Aspidiotiphagus are involved.

${ }^{56}$ This and the preceding quotation are from a report of N. S. Noble to W. B. Gurney. A copy of this report was enclosed in Gurney's letter of June 19, 1934; see footnote 3. 
Noble reported further attempts to straighten out the identification of the scales present on citrus in New South Wales. He communicated with P. G. Hely at Gosford, who sent specimens to Zeck. Noble concluded that both red and yellow scales were present.

A scientific approach to the study of red scale in Queensland was made by Summerville (1934), who attempted to evaluate in proper perspective all factors that might influence red scale, i.e., climate, entomophagous insects, diseases, topographical features, variety of citrus, and soils.

With respect to climate, Summerville confirmed the observations of others, previously noted, that red-scale infestations are worse in dryer and hotter climates and seasons. (But compare Lounsbury's views on the situation in Africa, p. 249!) He attributed this not only to the trees' being less able to withstand injury, but also to an increase in the scale population, mainly because of a lower mortality rate of the young under drier and hotter conditions. Decreased efficiency of natural enemies, particularly fungal parasites, under these conditions he believed to be a less important factor.

The effects of tree condition, variety, and exposure are discussed in the following paragraphs.

The state of the tree as regards health and vigor is also an important factor in determining the extent to which it will be attacked by this pest. Trees with impaired vigor are more susceptible to attack, not only in that they suffer more quickly, but in that they carry larger populations of the pest. The Emperor of Canton variety of mandarin is one which when healthy is rarely attacked to any extent by red scale, the pest in most instances, if present at all, being confined to immature fruit. When, however, it loses much vigor from disease or other cause an infestation of red scale frequently quickly follows. It appears that vigorous trees with a free flow of sap offer marked resistance to the pest, and, further, that on any tree the pest is less liable to become established on free growing parts than elsewhere, for when trees of supple habit of growth are attacked, it is usual to find the insect confined, at least in the first. instance and smaller infestations to the more woody or weaker parts, where there is no great flush of sap. [cf. p. 264.]

Varietal susceptibility is in conformity with what might be expected from the foregoing. Thus lemons which are more woody, are almost invariably infested, whilst the supple-growing mandarins are usually only troubled when other factors are operating strongly. Even in some very dry parts remote from the coast where the rainfall is very low, and where the available water cannot be used for irrigation, healthy mandarin trees quite free from red scale adjoin lemon trees which are persistently and heavily infested. Also in some of the wetter coastal districts small areas of lemons are sometimes included in an orchard, and though the red scale may be of no significance on the remainder of the trees, artificial control measures have to be applied against the red scale on lemons. Most varieties of oranges may be placed between lemons and mandarins in respect to habit of growth and also to the probability of attack by red scale, and the placement is roughly quantitative.

The foregoing remarks apply essentially to well-grown trees. Young trees of every variety appear to be susceptible to this pest, particularly trees planted out from the nursery.

Red scale will infest all aerial portions of a citrus tree. When the foliage is heavy by far the largest numbers are generally to be found on more exposed parts-leaves, fruit and twigs. On open and more scraggy trees, however, the limbs and main branches are commonly found to carry large colonies of the pest, and it appears that red scale prefers a position exposed to sunlight. It is probably mainly on account of this preference that young trees are so frequently attacked, for in such cases little if any of the tree is effectively shaded. (Summerville, 1934.) 
Summerville was convinced that soil had an effect independent of its nutritional properties, but said more work was needed before definite conclusions could be drawn. It seemed clear to him, however, that the moisture-holding capacity of the soil is an important and sometimes determining factor.

He listed the following parasites of red scale in Queensland: Aphytis chrysomphali (Mercet), Aspidiotiphagus australiensis Girault, Coccophagus iris Girault, Rhopalencyrtoidea dubia Girault, and Tomocera californica Howard. ${ }^{57}$ The steel-blue lady beetle, Orcus chalybeus (Bdv.), was rated as a common and very useful enemy of red scale in Queensland.

${ }^{57}$ The record of Tomocera californica as a parasite of red scale is questionable. In California the larvae feed on the eggs of Saissetia oleae. I do not have any first-hand knowledge of Coccophagus iris or Rhopalencyrtoidea dubia. 


\section{DISCUSSION \\ Biotic versus Abiotic Factors}

Howard and Fiske (1911), in discussing "Parasitism as a Factor in Insect Control" in connection with importation of parasites of the gypsy and browntail moths, distinguished between the mode of action of biotic factors as represented by parasites, predators, and diseases, and the abiotic factors as represented by climate. They theorized that for a balance to exist there must be a reciprocal action between one or more opposing factors. Diseases were ruled out as a balancing factor except under certain conditions. Howard and Fiske attached much greater importance to the role of parasites and predators than did Riley. Howard and Fiske wrote:

To put it dogmatically, each species of insect in a country where the conditions are settled is subjected to a certain fixed average percentage of parasitism, which, in the vast majority of instances and in connection with numerous other controlling agencies, results in the maintenance of a perfect balance. The insect neither increases to such abundance as to be affected by diseases or checked from further multiplication through lack of food, nor does it become extinct, but throughout maintains a degree of abundance in relation to other species existing in the same vicinity, which, when averaged for a long series of years, is constant.

Howard and Fiske were unable to recognize any factors that acted reciprocally with the plant-feeding insects other than diseases, parasites, and predators, and submitted for further discussion the hypothesis that:

... only through parasites and predators, the numerical increase of which is directly affected by the numerical increase of the insects upon which they prey, is that insect to be brought under complete natural control, except in the relatively rare instances in which destruction through disease is not dependent upon superabundance.

Here, in elementary form, is the beginning of an issue that has divided the most scholarly entomologists, the planners of biological projects, and the collectors of beneficial insects. Since 1911, numerous articles and entire books have been published on the subject without settling the contention. One school of thought contends that since there can be no reciprocal action between climate and insects-the climate affects the insects, but the insects cannot affect the climate-therefore, climate cannot act as a balancing force by destroying a greater proportionate number of individuals when the insects are abundant than when scarce. Some authorities have gone so far as to -contend that if the climate is tolerable, the individuals of a species will multiply indeterminately, and if the climate is intolerable, no individuals of the species can exist. The effects of climate are evaluated in black and white without any shades of grey. No allowance is made for grades of tolerability (Nicholson, 1947, p. 11).

Another school of thought, of which the late S. F. Bodenheimer was the leader, regards climate as all-important in limiting the excessive multiplication of insects (Bodenheimer, 1928). In 1930 Bodenheimer visited California and revived the ideological conflict over biological control, which had been quiescent since 1913. He expressed opinions somewhat similar to those held by Woodworth (see p. 184). At the time of Bodenheimer's visit, the citrophilus mealybug, Pseudococcus gahani, had just been brought under complete con- 
trol by parasites introduced from Australia in 1928. This control of the mealybug in 1929-30 was as much of an observable fact as was the control of the cottony-cushion scale in 1889-90, yet Bodenheimer demanded statistical proof of this accomplishment and insisted that a climatic factor was responsible for the subsidence of the mealybug.

Prior to $1930 \mathrm{H}$. S. Smith's concern with population studies was secondary to other interests. In the case of the citrophilus mealybug an assistant was employed for six months to dissect mealybugs and tabulate the percentages of parasitism under different conditions. Nothing was done with these data as it was then believed that a yardstick had not been perfected by which the value of parasites in the control of their hosts can be measured statistically under orchard conditions. Also, it was realized that if the statistical evidence did not accord with the observational evidence, the statistical evidence would be regarded as the less reliable. A percentage of parasitism alone has little meaning unless other factors can be measured statistically. Bodenheimer's disbelief in the control of the citrophilus mealybug by parasites, and insistence on the need for statistical proof, provided Smith with an incentive to make population dynamics a primary interest with special reference to the role of parasites and predators.

Smith (fig. 33) belonged to the school of thought that held that climate could not act as a balancing factor in insect populations. It is the teaching of experience that climate appears to do the very thing it is postulated that it cannot do. Smith attempted to explain this contradiction by a theory of "protective niches" which shelter certain individuals from the effects of climate. This is expressed in two separate sentences contained in one paragraph of his conclusions (Smith, 1935, p. 894). In one sentence Smith wrote: "It seems clear from what has preceded that density dependent factors can determine the average population density or equilibrium position of a species; that density independent factors operating alone can never do so...." And in a second sentence he wrote: "But climate so obviously limits geographical distribution and determines the average number of so many species, that even in the absence of proof, we must admit that under certain conditions it is capable of acting as a density dependent factor."

There are many subtleties in the literature on population dynamies and often the best authorities cannot understand each other. I have been advised that my brief interpretation of Nicholson's and Smith's concepts, partly on sentences out of context, presents a distortion of their meaning. Some authorities theorize that climate can act as a balancing force and determine population levels indirectly, but cannot explain how this is done.

Those who attribute the varying degrees of severity of red scale to climate may have opposing views on the direction of its effects. Compare, for example, Summerville's findings on the effects of climate in Australia (p. 256) with those of Lounsbury in South Africa (p. 249). Both these men are reliable observers.

Experiments show that in insectaries red scale develops and reproduces at a faster rate when the temperatures approximate $86^{\circ} \mathrm{F}$ and the humidities are high. Paradoxically, outdoors in the tropies, where temperature and humidities most closely approach those in the insectaries where red scale 


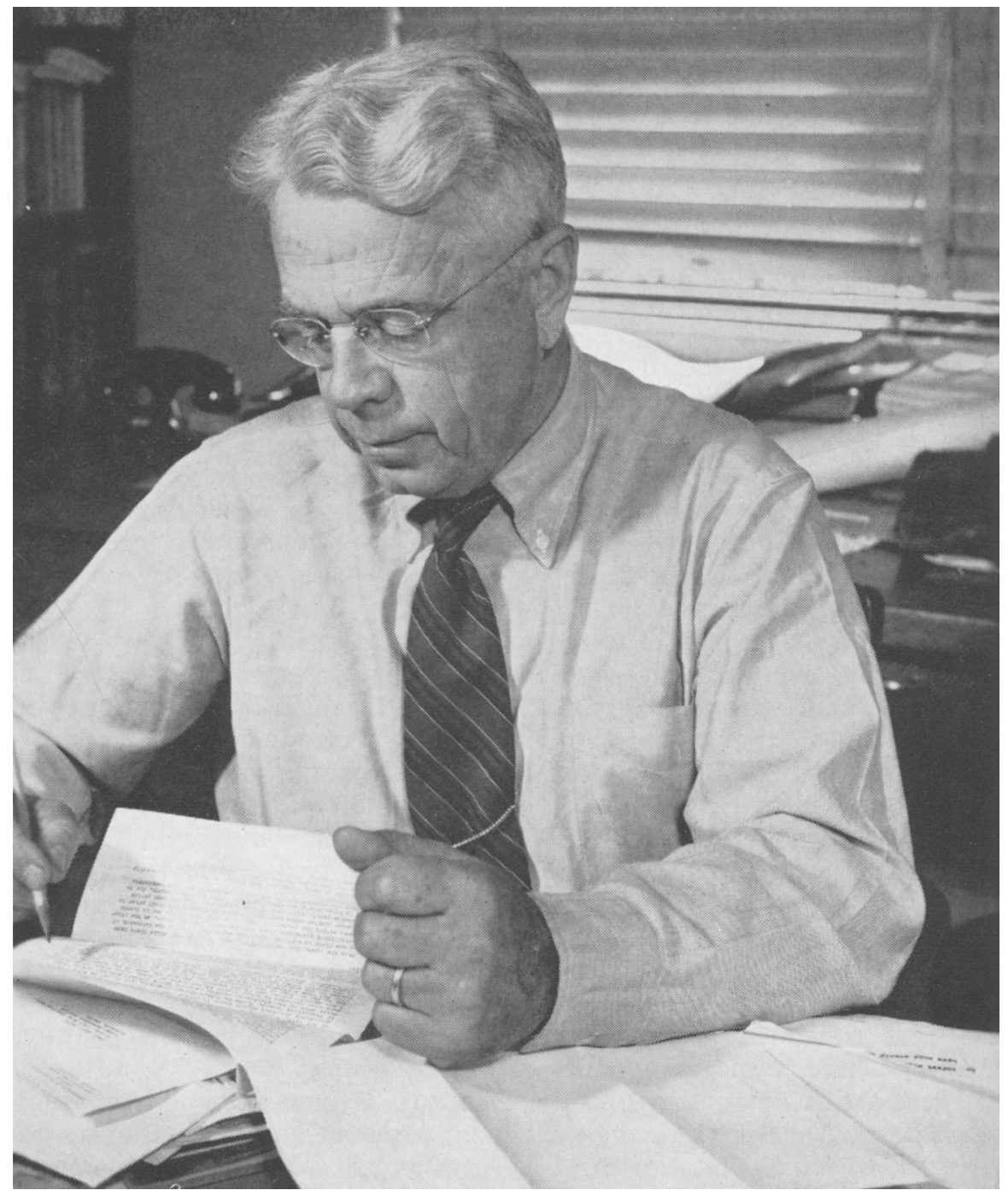

Fig. 33.- -Harry Scott Smith (1883-1957), a leader in biological control. Superintendent of California State Insectary 1913-1919; Chief, Bureau of Pest Control, California State Department of Agriculture, 1919-1923; Professor and Head of the Biological Control Department of the University of California from 1923 until retirement in 1951.

reproduces best, it rarely seriously infests citrus, with the exception of pummelo. Some regard this as evidence that diseases or parasites control red seale in the tropics. It seems strange that in the greater part of the tropics parasites or diseases of some kind control red scale on citrus, except pummelo, yet are not found attacking it on adjacent noncitrus host plants such as Rosa, Agave, and Fourcroya. The freedom of orange trees from red scale in the tropies is no more anomalous than the freedom of citrus from Florida red 
scale, Chrysomphalus aonidum, in California; or from black scale, Saissetia oleae, in northern California, South Africa, Mexico, Brazil, China, and parts of Australia. These are not unusual phenomena. More is involved than the effects of climate and natural enemies.

In Australia, South Africa, and South America where the climate corresponds most closely to that in southern California, the red scale is about as serious as in this state. The distribution of the red scale as a pest of citrus cannot be attributed to a direct effect of climate, for, as previously mentioned, under experimental conditions it does best when the temperatures and humidities are more similar to those of the climate of Florida than those of California.

Another abiotic factor that is sometimes suggested as having a role in redscale distribution is soil. Bodenheimer (1932), in his findings in Ceylon, was first to call attention to the possibility that the soil in which the plants grow may possibly affect the scales on the plants. In Ceylon the red scale had been recorded previously by Green (1896, p. 59) on Agave americana and Citrus decummana (shaddock or pummelo) but not on oranges; and Bodenheimer made a special search for it there to ascertain whether it appeared as red or yellow seale. (From a study made during his visit to California he had concluded that the yellow scale, Aonidiella citrina, was a phase of $A$. aurantii that had evolved here.) He reported finding it in one place only, a plot of twelve-year-old lime trees covering $31 / 2$ acres in the experimental garden at Anahradapura. According to him, only one tree in this plot was heavily infested-fruits, twigs, leaves, were encrusted with typical red scale. The scales were reddish brown; they did not show a pale zone around the margins, and were clearly convex. Surrounding the lone red-scale-infested tree were 10 or 15 trees lightly infested with a scale which Bodenheimer pronounced to be yellow. Bodenheimer stated that this situation induced him to believe that possibly the habitus character of Aonidiella aurantii as red or yellow scale is determined by nutritional factors. In previous papers and again in this report he stated that the available potassium in the soil may change red to yellow seale, or vice versa, and probably affects the number of red and yellow scale, a potassium-rich soil favoring their increase. He attributed the general absence of red and yellow scale in Ceylon to the character of the soil, which is rich in potassium but not in a form that plants can use.

Bodenheimer's opinion that Aonidiella citrina is a phase of $A$. aurantii is untenable, to say the least. It is generally conceded that the chemical composition of the soil affects the chemical composition of the fruit, and it may well be that the chemical composition of the soil affects red scale, but not, I think, in the way Bodenheimer suggested. A more comprehensive knowledge of red scale in relation to soil might contribute to a better understanding of some of the apparent anomalies in its distribution with reference to its host plants.

Summerville's suggestion that soil moisture may be a factor is reported on page 257 .

\section{Unfavorability of Citrus to Red Scale}

The unfavorability or resistance of citrus to red scale has received little attention. The possibility that a rootstock might transmit some of its own favorability or unfavorability to the varieties budded or grafted on to it has 
not been considered since 1879 , when S. W. Pye mentioned such a phenomenon in connection with the red scale. Pye reported this phenomenon in reply to a set of questions submitted by an editor of the Pacific Rural Press. This editor, probably E. J. Wickson, was attempting to solve some of the problems confronting orange growers in southern California, and Pye was considered as the man best qualified to solve the problems. The following appears in an editorial column under "Queries and Replies:"

Q. What stock is best on which to graft oranges?

A. The Seville or Bitter Navel; I believe one is as good as the other.

Q. For what reason is it the best?

A. Because it is the hardiest of all the tribe, free from disease (other than red scale, which affects it but little.)

Following this, Pye wrote under "Remarks on Queries:" "Although the red scale atacks the Seville orange, it does not seem to injure it as it does all other kinds.'

The possibility that a rootstock unfavorable to red scale might transmit a degree of its unfavorability to the variety budded on it may be a good subject for investigation. If the rootstock transmits resistance, this may explain why red scale is so much more serious in some orchards than in adjoining orchards of the same age and bearing the same kind of fruits but on different rootstocks.

The Rough lemon (Florida Rough, Mazoe, French, etc.) is noted for its extraordinary freedom from scale insects and diseases. Some attribute this freedom from scales to natural enemies. The Rough lemon was introduced into the Americas at an early date by the Spanish explorers, and at about the same time into Africa. It became feral in Florida, the West Indies, and in Southern Rhodesia, especially along the Mazoe River. The citrus observed by me growing "wild" in Paraguay and free of coccids may have been Rough lemon. In Peshawar, India, where the Rough lemon is grown rather extensively as a hedge plant, it was often attacked by yellow scale, Aonidiella citrina, and free of red scale. In California, Rough lemon has been used as a rootstock in only a few commercial groves. It seems logical to suspect that Rough lemon may be resistant to red scale, although the scale propagated readily on Rough lemon seedling trees in nutritional experiments conducted by Steyn at Letaba under laboratory conditions.

When studying the Argentine ant in relation to citrus pests in Louisiana, J. R. Horton recognized that some kinds of citrus were more resistant to scale insects than others, and wrote:

It is worth noting that the sweet seedling trees of Cameron Parish, which are apparently of Sicilian origin, are much more resistant to these scale [Lepidosaphes beckii, L. gloverii, Parlatoria pergandii, Unaspis citri] than the budded trees. Although the more important scales occur on this type of tree, the infestation is very light. (Horton, 1918.)

In my notes on the incidence of red scale on citrus in different parts of the world, repeated mention is made of seedling orange trees free of red scale. Unfortunately, I was not often able to obtain the names of the different varieties of citrus. Seville orange trees at the Mazoe Estate, Southern Rhodesia, were reported by Jones (1936) to be less severely injured by red 
scale than the commercial varieties in the near-by orchards. This difference in the seriousness of red scale was attributed by Jones to less thriftiness of the Seville, owing to lack of fertilizer and cultural care. In 1947 at the Letaba Estate, South Africa, there was much speculation concerning some old seedling orange trees that had never been treated for red scale and had never been seriously infested by it. At the time of my visit, only an occasional red scale could be found on these trees.

Ebeling (1950, p. 446) recognized that some kinds of citrus are more favorable hosts for red scale than others.

A most convincing exhibit of resistance or immunity of citrus to red scale was lost when trees in a small variety plot at the Citrus Experiment Station, Riverside, were destroyed recently. Unfortunately, the scientific names of the different species and varieties of citrus were not obtained An example was an "Otahite" orange next to a shaddock. The "Otahite" was free of red scale and apparently had never been infested, while the shaddock was heavily infested and had been so in previous years. In another example, the branches of two kinds of lime trees were in contact, and the branches of one were encrusted with red scale and those of the other free of it.

An occasional tree has been seen in the Riverside area bearing both navel and mandarin oranges. The branches bearing mandarins were free of red scale, or nearly so, while those bearing navels were heavily infested with it.

Evidence of the greater favorability of lemons to red scale than oranges was seen in an orchard in Riverside, since destroyed as unprofitable. Originally, the orchard was planted to lemons on orange rootstock and later topworked to the navel orange. When last seen, the lemon trunks were solidly matted with red scale, while the orange branches were moderately infested. The encrustations of red scale formed lines of almost knifelike sharpness defining the extent of the lemon trunks sandwiched between the orange roots below and the orange tops above.

Yellow scale was most serious at San Gabriel in the large orchard of A. B. Chapman, where in 1887 Coquillett discovered hymenopterous parasites killing it. It has been observed in southern California, in recent years, that the occasional seedling sweet orange trees which remain in cultivation are much more seriously infested with yellow scale than adjacent Valencia and navel orange trees. Commencing in 1887, or thereabouts, the old seedling sweet orange trees in the San Gabriel Valley were rapidly topworked to Valencia and navel oranges. May not the replacement of a food plant of high favorability by one of less favorability have been a factor, as well as parasites, in the subsidence of yellow scale in San Gabriel after 1890-1892? In central California today the yellow scale grows exuberantly on Valencia and navel orange trees, but these trees are on sour orange roots, which may possibly account for the difference.

The important fact that some kinds of citrus are more resistant to red scale than others has been generally overlooked or disregarded. Lelong commented that after 1880 the scale insects were more injurious to citrus than ever before in southern California. That year marks the approximate turning point when seedling orange trees were being topworked or replaced by budded varieties, and the latter are the preferred hosts of red scale. 
Today numbers of old sweet-orange trees on sour-orange stocks in southern California are being replaced by young trees owing to the destruction of the older trees by "quick decline," a virus disease. A large percentage of the young trees used for replanting are on Troyer roots. Plant pathologists have tested this rootstock for its resistance to disease and nematologists have tested it for its resistance to nematodes, but entomologists have not tested it for resistance to insects. Discerning nurserymen and some field entomologists have noticed that Troyer trees are particularly favorable to red scale. Nurserymen have also reported that when mites and aphids first appear in mixed plantings of nursery stock the most severely infested young trees are generally on Troyer roots. The vigor of the tops on Troyer roots may be one of the most valued characters from a horticulturist's or plant breeder's point of view, but in California this very character may make it one of the most favorable hosts of citrus-infesting insects. (Contrast this with Summerville's findings in Australia, p. 256.)

A critical study of the favorability of citrus to scale insects is needed in order to appraise accurately the exact value of parasites and predators in controlling their hosts, as well as to evaluate the comparative merits of treatments with chemicals.

\section{Systematics}

From 1877 to 1937 the red scale was repeatedly misidentified; other species of scales were mistaken for red scale, and red scale was mistaken for other species. Moreover, the generic classification was unsound and misleading. If evidence is needed to show the importance of sound systematics in applied biological control, the history of red scale and its parasites provides evidence in abundance.

Systematics has no popular appeal; many administrators, concerned more with applied than with abstract science, regard the study of systematics with disfavor; and even some biologists have little regard for it. It is in bad repute in some biological-control circles, largely owing to its failure to answer many questions that have arisen in connection with introduced chalcidoid parasites as living organisms. As one consequence, the Linnean or morphological concept of a species is now regarded by some as outmoded or obsolete, to be replaced by the biological concept of a species. Today, in applied biological control, more and more consideration is being given to units below the level of morphological distinctness. These lesser units-strains, races, varieties, subspécies, sibling species, or biological species-screened out as distinct in the work with living insects, cannot be disregarded, for in applied biological control the functional or biological characters may be more important than the morphological ones. With improved optical equipment, better techniques, increased knowledge, and opportunities to study insects as living organisms, systematists will be able to recognize species at lower and lower levels of distinctness, and future classifications will conform more and more to the facts of nature and less and less to the conventions of systematics.

But in the meantime the old morphological concept called a species and a nomenclature that conforms to the established conventions is something without which we cannot do. It provides names, organization, and a means of 
identification - the only way by which one's observations concerning a particular kind of insect can be communicated to others. It is impossible to talk or write about an insect without referring to it by a name or a symbol. When a meaningful scientific name is applied to a particular species of insect, and it is described adequately with distinguishing characters, then all qualified entomologists can determine exactly to what species the name applies. A scientific name is the key to finding what others have published.

Administrators of biological control projects generally recognize the great importance of identifying pest species correctly, but attach less importance to identifying the beneficial species correctly (Clausen, 1942, p. 744). Yet in applied biological control, the life blood of the greater number of projects is the importation and establishment of new species of beneficial insects, and only systematies provides the answer to what is new.

Systematics remains the basic biological science, without which there could be no organized planning or reporting. Rothschild and Clay (1952, p. 106) wrote, "... Sound systematics are the foundation upon which all biological theories, great or small, are built." To this it may be added that theories, plans, and practices are no sounder than the systematics on which they are based.

When red scale was classified under the genus Chrysomphalus, it was theorized that possibly it was not of Asiatic origin as generally believed, but that it might have originated in South America and been spread from there to other parts of the world in the transportation of nursery stock. This theory was suggested by the general rule that species usually originate where there is the greatest concentration of closely related species; and more species of Chrysomphalus were recorded from South America than from any other continent. This led to the decision to search South America for red-scale enemies in 1935. In 1937 Howard McKenzie published an improved classification in which aurantii and citrinus were transferred from Chrysomphalus to Aonidiella, and the species of the latter genus were defined at a lower level of morphological distinctness than before. McKenzie discovered the structural characters by which red and yellow seales can be separated when studied as museum specimens (see fig. 25, p. 225), and identified Aonidiella taxus correctly. (Previously, all the authorities on Coccidae had identified the Podocarpus-infesting $A$. taxus as $A$. aurantii.) Two species of Aonidiella that confused me when in India in 1932 were identified by McKenzie: one, designated as the "false yellow" in my original reports to Smith, was described by McKenzie as $A$. comperei; and the other, about which I was in doubt and occasionally collected by mistake for aurantii, was identified as $A$. orientalis (Newstead). This systematic paper brought a good measure of order out of chaos. If this information had been available some years earlier, it is unlikely that a search for enemies of red scale would have been made in South America; and many errors (noted in previous sections) that were due to inability to distinguish with certainty between red and yellow seales, or between red scale and $A$. taxus, would have been avoided.

The history of the red scale provides numerous examples of confusion and repetitious, unrewarding work, and of overlooked opportunities, all owing to incorrect identifications of the parasites. In preceding sections of this paper 
a considerable amount of evidence has been presented to show the importance of identifying the parasites correctly, and what follows is in part repetitious.

Two specimens reared from yellow scale, collected at San Gabriel by Coquillett in 1887, were determined as a new species of Coccophagus by Howard and given the manuscript name aurantii. In 1889 Coquillett, in a public address, reported on it as an undescribed species. Lelong (1890, p. 284) published on it under the heading, "Beneficial Insects, Red Scale Parasite, New Species (Unnamed)." He instructed Craw to investigate this parasite in the orchards at San Gabriel. Craw (1891b) was very favorably impressed with what he found there and promptly published a technical description of a parasite under the name Coccophagus citrinus $\mathrm{n}$. sp. and referred to another species as the "golden chalcid." With reference to the scale from which they came, Craw wrote: “... quite recently specific differences have been observed that prove it distinct, and it is now known as the 'yellow scale' (Aspidiotus citrinus Coquillett)." Unfortunately, the species Craw described under Coccophagus was not the same as that which Howard received from Coquillett and identified as a new species of Coccophagus, but represented a new genus now known as Aspidiotiphagus. The identity of the species described by Craw under Coccophagus citrinus became a matter of dispute which was discussed by me fully in an earlier paper (Compere, 1936a, pp. 296-99).

In Aspidiotiphagus I am unable to distinguish between the red- and yellowscale-inhabiting forms and a multitude of forms from other hosts. The name A. citrinus expresses a degree of morphological similarity only. Either many forms with different capacities are involved, or the same form has different capacities in different localities. It is certain that there are at least two biologically distinct forms, one on yellow and the other on red scale.

In 1894, Howard. published "The Hymenopterous Parasites of the California Red Scale." He was careful to distinguish between the red and yellow scales but, probably in deference to Riley, treated them as two varieties of the one species. The errors Howard made in 1894 have largely been corrected. Later, in connection with black scale, he made some of the same mistakes that he warned others against, or was an accessory to them. Coccophagus lunulatus How. [=C. scutellaris (Dalman)] is parasitic in lecanine scales and never on red or yellow scales; Thysanus occidentalis (How.) [=T. flavopalliata (Ashm.)] develops hyperparasitically in red and yellow scales; Aspidiotiphagus citrinus (Craw), or at least the form studied by Howard, reproduces in yellow scale and never in red scale; Coccophagus aurantii How. [= Prospaltella aurantii (How.) ] has not been reared from red scale in California or any other country to my knowledge with one possible exception. Silvestri's species, $P$. nupta, may prove to be the same as $P$. aurantii. The question of the identity of the species Howard described under Aphycus immaculatus remains unsolved. It seems safe to conclude that whatever it was, it was not a parasite of either red or yellow scale.

As mentioned earlier (pp. 193-95), at least two and perhaps three species of Aphytis were present in a sample sent to Riley by Coquillett in 1892 and identified at that time, presumably by Howard, as Aphelinus [=Aphytis] diaspidis Howard. Howard's subsequent mistakes concerning the identification of A. chrysomphali are, in part, traceable to this mixed sample. It largely 
explains his failure to distinguish between diaspidis and chrysomphali prior to 1912 , when Timberlake made it clear that two different species were involved in California under the name diaspidis (Compere, 1955). It is safe to assert that no parasites have been the cause of so much confusion in applied biological control as the species of Aphytis. The identifications of Aphytis made in connection with red and yellow scales have been discussed fully in a recent systematic paper. (Compere, 1955.)

In 1906, Howard described Comperiella bifasciata, and in 1907, Casca chinensis. I am unable to contribute anything new to the systematics of Casca.

A mistake may have been made by me in 1926 (Compere, 1926, pp. 44-48) in connection with the figure of Comperiella bifasciata Howard. With respect to the ocelli that are shown in an acute triangle and the longitudinal, median, black band on the frontovertex that is narrow, this figure is less suggestive of bifasciata Howard than of C. lemniscata on Aonidiella orientalis (Newstead) which was mentioned in the account of my search in India. Some time has been spent in an unsuccessful search for the particular specimen or specimens that served as the model for the drawing of the head. Another drawing made by me in 1922 but not published represents $C$. bifasciata more closely, with respect to the markings on the head and the position of the ocelli, than that published in 1926 . Conceivably specimens of $C$. lemniscata could have been sent to California by Silvestri in 1925 and have been mistaken for $C$. bifasciata and figured by me. A revision of the species of this genus is needed.

Silvestri (1930b, pp. 53-55) carefully described and beautifully illustrated some species discovered by him. With regard to the species of Prospaltella, Silvestri left to others the task of distinguishing between what he described as new and those described previously by others. In connection with red scale, Silvestri misidentified P. aurantii (How.) (fig. 34). The species described and illustrated by him under $P$. aurantii agrees exactly with $P$. elongata Dozier, and, as judged from the description and figures, $P$. nupta Silv. is very similar to if not the same as $P$. aurantii. He does not mention $P$. pernisiosi (fig. 35), the red-scale inhabiting form of which was introduced into California from Formosa in 1948 or 1949. In Prospaltella there is a turmoil of and an excess of scientific names. Species have been named indiscriminately and poorly and without consideration for previous work. This is not unusual in the systematics of the Aphelinidae, but more species have been confused under Prospaltella than under any other generic name in this family.

Ferris (1938) made an important advance when he described Chrysomphalus bifasciculatus as a new species distinct from $C$. ficus Ashm. [=C. aonidum Linn.].

Flanders $(1953 a)$ was unable to obtain scientific names for all the parasites he studied in connection with red scale and devised an unusual scheme of classification and nomenclature. The value placed on systematic characters by Flanders is in reverse order to that of the Linnean system. Flanders' system works backwards from biological characters to structural characters. Biological attributes are given for recognition characters, and letters of the alphabet substitute for species names. Flanders wrote: "In practice the lack of specific scientific names based on morphology is a handicap only from the 


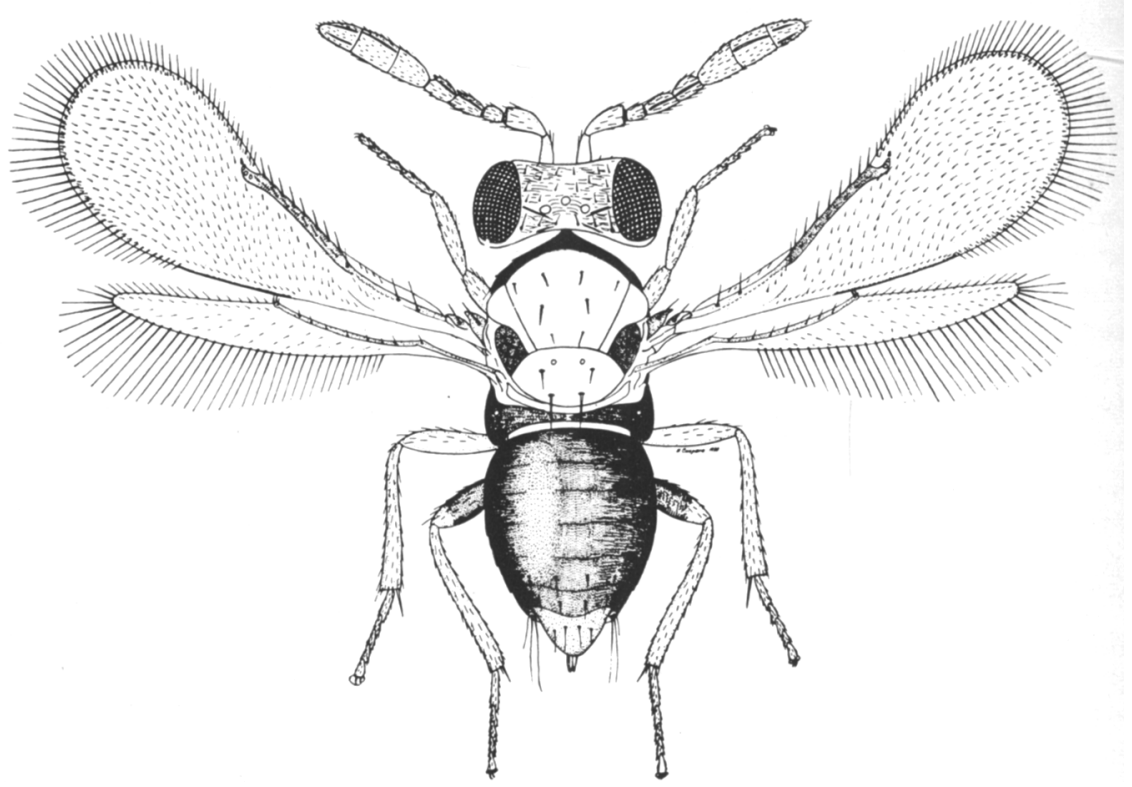

Fig. 34.-Prospaltella aurantii (Howard), a parasite of yellow scale that has been misidentified repeatedly.

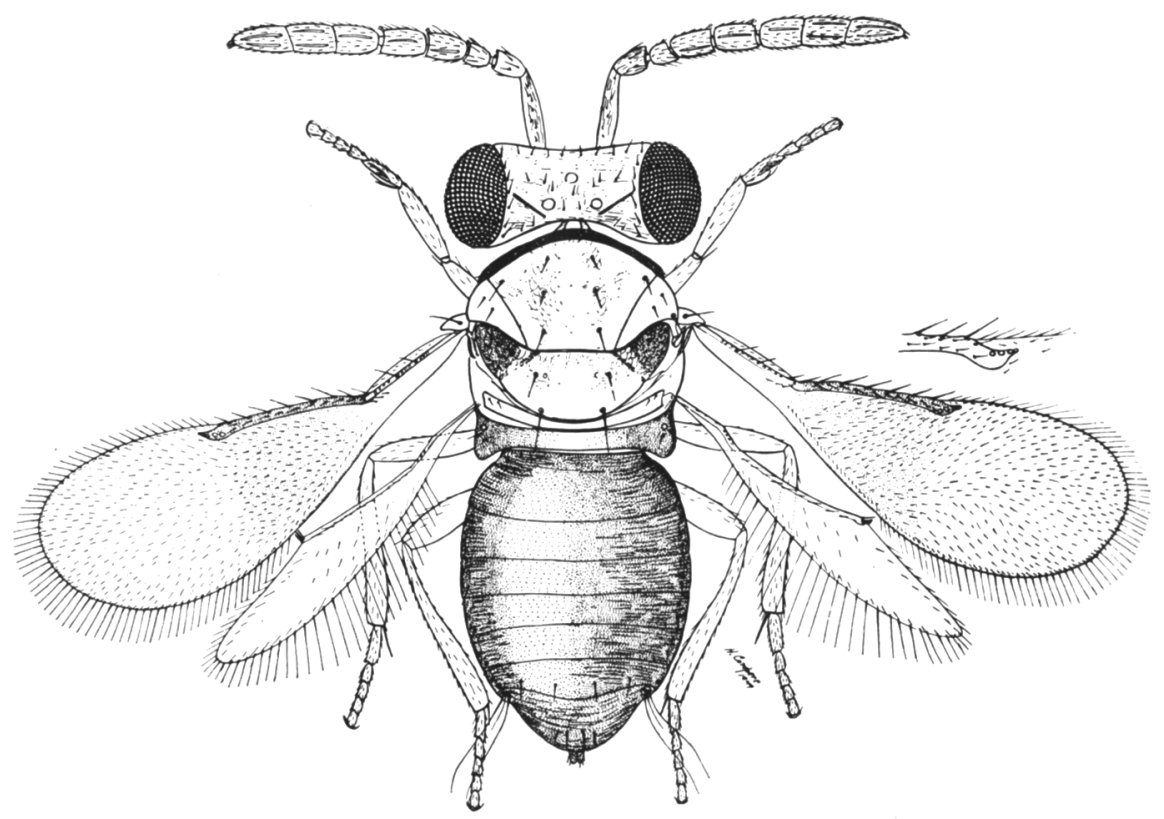

Fig. 35.-Prospaltella perniciosi Tower, the red-scale-inhabiting form introduced from China and established in California. This form is indistinguishable morphologically from that which commonly inhabits San Jose scale. 
standpoint of convenience and ready comparison. Since the biological characters of a species are the basic criteria for differentiation, classifications can be accomplished through the use of such characters. This is especially true where morphological characters are cryptic." If the species reported upon by Flanders are not identifiable by orthodox methods, it is extremely questionable whether others can ever know what he wrote about, nor can Flanders know what others may have written about them. "Aphytis sp. A" and "Aphytis sp. F" (Flanders, 1953b) appear indistinguishable morphologically and no new evidence has been obtained to distinguish between them. In 1955, "Aphytis sp. A" was described by me as lingnanensis on the basis of an obscure morphological character. "Aphytis sp. B" is recognized provisionally as hispanicus (Mercet). "Anabrolepis sp. A" is indistinguishable morphologically from $A$. extranea Timberlake, which in turn is indistinguishable from zetterstedtii (Westwood). A “Quaylea-like species" was described as a new genus and new species under the name Teleterebratus perversus Compere and Zinna (1955). "Prospaltella sp. K" may prove to be the same as inquirenda Silv. (1930b).

If some species exist in every grade of distinctness, as there is reasonable cause to assume, the matter of their identity will remain uncertain for a long time to come. In the meantime, there is a need for skilled systematists who can recognize morphologically distinct units. 


\section{SUMMARY AND CONCLUSIONS}

For almost 70 years entomologists specializing in biological control have claimed that the red scale is controlled, or had been controlled, or could be controlled by its insect enemies. It has been reported to be controlled by one or another of its parasites, or its predators, or a combination of parasites and predators, in parts of Australia, Asia, Africa, North America, South America, Mexico, and certain islands of the Pacific Ocean and Aegean Sea. Opinions are varied and sometimes conflicting as to which of its enemies control it not only in different countries but in the same country.

A. Koebele was the first to claim that red scale can be controlled by its insect enemies when reporting "Australia is in possession of more than enough natural enemies to keep this coccid in check with ease" (Koebele, 1893, p. 15). From about 1900 to 1909 George Compere repeatedly claimed in letters and interviews that parasites controlled red scale in China and rated a species of Aphytis [="the little yellow Chinese parasite"] as the most important of the parasites (see pp. 205-06 of this paper). Others who have reported the red scale as controlled by its insect enemies in one or another part of Asia are: Woglum (1913, p. 52), Silvestri (1930a, p. 902; see also p. 219 of this paper), Flanders (1954, pp. 130-31), Flanders and Gressitt (1957, p. $73)$, DeBach (1957, pp. 414, 424). It is almost certain that Woglum had insect parasites and predators in mind when reporting that red scale was under natural control in parts of India. Silvestri did not single out any particular enemy of red scale, or a complement of its enemies, when reporting that it was controlled in China. Flanders attributed the control of red scale in Hong Kong first to parasites, of which Casca chinensis was said to be the key species (Flanders, 1954, p. 131). Later, he and Gressitt credited predators rather than parasites with controlling red scale on citrus in South China (Flanders and Gressitt, 1957, p. 73; 1958). DeBach credited parasites with controlling red scale in different parts of Asia, as did George Compere in earlier years, and rated a species of Aphytis as the most important of the parasites.

The red scale was reported to be controlled by a parasite, or a combination of parasites and predators, in southern California by Bishop (1902, pp. 222-23), Rafferty (1906, pp. 291-92), George Compere (in 1909; see pp. 205-06 of this paper), Armitage (in 1922; see pp. 217-18 of this paper), Brock (in 1922; see p. 217 of this paper), and DeBach, Fleschner, and Dietrick (1948, p. 38). In 1908, a high percentage of parasitism of red scale in southern California was reported by Howard (1908).

The red scale was reported by Ullyet (1946) to be controlled in some orchards in South Africa by a very efficient complex of parasites and predators. He contended that parasites by themselves were unable to control red scale; that before a control could be established there must be a minor outbreak of the pest which, in some cases, would entail the loss of a large proportion of the exportable fruit over a period of two years, and that even then a control might not be attained. It is questionable whether those who grow oranges for profit in South Africa can afford such a loss of fruit, in addition to injury to the trees and the attendant risk. Omer-Cooper and Whitehead $(1950 a, b)$ 
regarded the so-called "golden chalcid," Aphytis chrysomphali, as the most important of the enemies of red scale in South Africa. In recent years the greater number of experts on the biological control of red scale have stressed the need to free the orchards of ants before attempting to control it with parasites. Yet Steyn (1955, p. 105) concluded from experiments at the Letaba Estate, South Africa, that the biological control of red scale there depended on having a mixed population of different species of ants in the control plots. A. F. Camp in 1956 (see footnote 38, p. 235) reported Coccidophilus citricola Brèthes as controlling red scale in Argentina. Only the more important of the affirmative testimonials have been summarized here.

I found nothing in Asia, Africa, Australia, or South America that I could consider good evidence to show that the red scale is controlled in these countries by its insect enemies. By good evidence I mean a background of general red-scale distribution and scarcity, and within this background, small, potentially explosive pockets of red scale of plaguelike intensity that are in the process of being killed by parasites or predators, or show tell-tale signs of having been killed by them. In addition to this is the finding of an appreciable percentage of parasitism or signs of predatism in the sparsely distributed scales. This kind of evidence can be seen in the case of scales and mealybugs that are generally acknowledged to be under control by their enemies. The possibility that under certain conditions the red scale would be more abundant and injurious if it were not for its enemies is not ruled out, as evidence has been presented to show that in some localities parasites and predators may prevent the red scale from becoming more abundant and injurious than it would otherwise be.

History shows that in some localities the populations of red scale have not always remained substantially the same year after year, and that the red-scale host relations may change. Some entomologists recognize that insect pest control presents an ever-changing problem, but they attribute this largely to pest-control practices, or other interferences by man. I submit for consideration the hypothesis that such changes take place in the red-scale populations where pest-control practices are not a factor. This may be why my testimony, based on observations in foreign countries from 1927 to 1948, is not always in agreement with what one may see today, or with what others have reported.

Collateral evidence shows that Riley had the red scale and Koebele's reports concerning it in mind when writing "Parasitic and Predaceous Insects in Applied Entomology" in 1893 (Riley, 1893a). Today, as in 1893, opinion is sharply divided regarding the possibilities of controlling red scale by its insect enemies in California. Almost 70 years of history supports Riley's opinion that only in a small percentage of cases can introduced pests be controlled by their insect enemies, and that little can be hoped for in the introduction of miscellaneous insect enemies, especially when these enemies do not control their hosts in the countries where they are found. Although it is the part of wisdom not to be dogmatic concerning red scale, in my opinion the evidence presented in this article warrants the following paraphrase of a sentence written in 1879 by Wickson. It is the teaching of almost ro years of history that where the climatic and nutritional factors are most favorable for its multiplication the red scale may be reduced by its insect enemies, but not 
to such an extent that its evil work is greatly restrained, much less arrested. This sentence reflects a personal opinion that is not accepted in biologicalcontrol circles.

Such slogans as George Compere's "Restore the balance of nature and control pests by nature's method" may make an irresistible appeal to orchardists; but they are scientifically unsound so far as red scale on citrus is concerned. The cultivated citrus sorts most susceptible to injury by red scale are improved or selected varieties greatly unlike the wild types. The arid regions where citrus is grown under irrigation and the red seale is most injurious are unlike the high-rainfall regions where citrus is native.

In Australia, South Africa, and South America, where temperatures and humidities are most comparable to those parts of southern California where red scale is most abundant, the red scale is also abundant and about equally important as a pest of citrus. In Florida, where the climate is tropical, the red scale is found on Ligustrum lucidum and Cocculus sp. and rarely, if ever, on citrus (Merrill, 1953, p. 13). Paradoxically, in cages or in an insectary, the red scale multiplies faster and thrives better when the temperatures and humidities correspond more closely to those of Florida than those of California. History does not provide an answer to this paradox or tell why navel orange trees are free of red scale in Baía when adjacent rosebushes are encrusted with it, why citrus is free of red scale in Natal when it occurs there in abundance on rosebushes and Fourcroya sp., or why rosebushes are free of red scale in Hong Kong when it is generally distributed there and occasionally abundant on host plants other than citrus. ${ }^{58} \mathrm{I}$ am unable to explain these anomalies in the geographical distribution of red scale as a pest with reference to its host relations.

Since 1948 more work has been done on the red scale and its enemies than in all the preceding years together. Speculations and theories have been proclaimed as principles of biological control. New rules have been promulgated on where and how to collect beneficial insects, and how to choose particular species for obtaining predictable results. It has been recommended that no foreign species be introduced until all the ascertainable basic data concerning the endemic species have been collected and evaluated. There is a difference of opinion as to whether collectors should first make a comprehensive ecological study and then ship only certain species with prescribed attributes, or ship all species obtainable. The student of this literature may find it difficult to distinguish between the sound and practical and the unsound and impractical. In some cases the technical vocabularies are so involved and specialized that one authority cannot understand another.

The enigma of red scale is far from solved. Observations point to an interaction between physical, chemical, and biological factors as determining the incidence of red scale. Observations, conjectures, and subjective experiments have not provided unequivocal answers. Carefully planned, objective experiments that take into account all the factors that affect the red scale as a living organism are needed.

${ }^{68}$ S. E. Flanders spent nine months in Hong Kong (1953-54) studying the red scale and its enemies. According to him, red scale was found on many kinds of plants but never on rosebushes. Occasional heavy infestations were found on Phyllanthus cochinchinensis, Euonymus chinensis, Heydotis acutangula, and Henslowia frutescens. 


\section{ACKNOWLEDGMENTS}

To the editor, Mrs. Mary Rubo, I express deepest appreciation for extended help in organizing, condensing, and clarifying the paper; and to Mrs. Ruth Tibbens for expert typing and making minor corrections in the original typescript.

\section{LITERATURE CITED}

Ashmead, W. H.

1880a. The red scale on the orange. Pacific Rural Press 19(1):8 (Jan. 3).

$1880 \mathrm{~b}$. Orange insects; a treatise on the injurious and beneficial insects found on orange trees of Florida. 78 pp., illus. Ashmead Bros., Jacksonville, Fla.

Bishop, A. D.

1902. Orange County. California State Board Hort., 8th Bien. Rept. (for 1901-02), pp. 222-23.

Blaisdell, F. E.

1892. A new species of Coleoptera from California. Ent. News 3:51.

BLANFORD, F.

1889. The climates and weather of India, Ceylon, and Burma. 369 pp. The Macmillan Company, London and New York.

BodenheIMER, F. S.

1928. Welche Faktoren regulieren die Individuenzahl einer Insektenart in der Natur Biol. Centralbl. 48:714-39. Cited by Smith (1935).

1931. Observations on citrus insects and their control in many parts of the world. The citrus insect problems in California. Hadar 4:251-54.

1932. Observations on citrus insects and their control in many parts of the world. Observations on citrus insects in Ceylon. Hadar 5:256-60.

Bonavia, E.

1888. The cultivated oranges and lemons of India and Ceylon. $384 \mathrm{pp}$. W. H. Allen \& Co., London.

Clausen, C. P.

1933. The citrus insects of tropical Asia. U. S. Dept. Agr. Cir. 226:27-28.

1942. The relation of taxonomy to biological control. Jour. Econ. Ent. 35:744-48.

COMPERE, $\mathrm{H}$.

1926. New coccid-inhabiting parasites (Encyrtidae, Hymenoptera) from Japan and California. California Univ. Pubs. Ent. 4(2):33-50. (See specifically p. 46.)

1935. Exploratory search for natural enemies of the red scale. California Citrog. $20: 371$, $382-86,388$.

1936a. Notes on the classification of the Aphelinidae. California Univ. Pubs. Ent. $6(12): 296-99$.

1936b. A new species of Habrolepis parasitic in Chrysomphalus aurantii Mask. Bul. Ent. Res. 27 (3) :493-96

1937. Collecting red and black scale parasites in Africa. California Citrog. 23:58, 88.

1953. An appraisal of Silvestri's work in the Orient for the University of California, some misidentifications corrected, and two forms of Casca described as new species. Extract. Naples Univ. Facolta di Sci. Agraria, Portici. Lab. Zool. Gen. e Agraria Boll. 33:35-45.

1955. A systematic study of the genus Aphytis Howard (Hymenoptera, Aphelinidae) with descriptions of new species. California Univ. Pubs. Ent. 10(4):271-320.

COMPERE, H., and H. S. SMith

1927. Notes on the life history of two Oriental chalcidoid parasites of Chrysomphalus. California Univ. Pubs. Ent. 4(4) :63-73.

1932. The control of the citrophilus mealybug, Pseudococcus gahani, by Australian parasites. Hilgardia 6(17):585-618.

COMPERE, H., and G. ZINNA

1955. Tre nuovi generi e cinque nuove specie di Encyrtidae. Extract. Naples Univ. Facolta di Sci. Agraria, Portici. Lab. Zool. Gen. e Agraria Boll. 14:94-116. 
Comstock, J. H.

1880. The red scale insect on the orange. Pacific Rural Press 19(1):8 (Jan. 3). -

1881a. Notes on Coccidae. Canad. Ent. 13(1):8-9.

1881b. Report on scale insects. U. S. Dept. Agr. Report of the Entomologist for 1880, Part II. pp. 276-349.

COOPER, E.

1913. Bug vs. bug. Parasitology. 23 pp. Printed privately at Santa Barbara, California, for Ellwood Cooper.

Coquillett, D. W.

1889. Injurious insects and remedies. Eleventh State Fruit Growers Convention, National City, California, A pril 16-19. pp. 17-18.

1890. Nature's methods for subduing insect pests. California State Board Hort. Ann. Rept. $1889: 394-400$.

1891. Report on various methods for destroying scale insects. U. S. Dept. Agr. Div. Ent. Bul. 23:19-36.

1892. Report on the scale insects of California. U. S. Dept. Agr. Div. Ent. Bul. 26:13-35.

1893a. Report on the Australian insects sent by Albert Koebele to Ellwood Cooper and B. M. Lelong. Insect Life $5: 253$.

1893b. The present status of the recent Australian importations. Insect Life 6:24-26. CRAW, A.

1890. Yellow scale parasite (genus Coccophagus, new sp.) California State Board Hort. Rept. $1890: 348-49$.

1891a. Yellow orange scale parasite. California Fruit Grower, February 28, 1891, pp. 132-33.

1891b. Internal parasites discovered in the San Gabriel Valley; recommendations and notes. California State Board. Hort. Bul. 57:1-7.

1891c. Destructive insects, their natural enemies, remedies and recommendations. $51 \mathrm{pp}$. California State Board of Horticulture, Division of Entomology, Sacramento, California.

1894. Reports of Horticultural Quarantine Officer and Entomologist. California State Board Hort. Bien. Rept. 1893-94:85-86.

1902. Reports of ... Horticultural Quarantine Officer. California State Board Hort. Bien. Rept. 1901-02:187-204.

Darwin, Charles

1859. On the origin of species. $x+502$ pp. John Murray, London.

DeBACH, P. H.

1957. New natural enemies of citrus pests imported. California Citrog. $42(12): 414,424$.

DeBach, P., C. A. Fleschner, and E. J. Dietrick

1948. Natural control of the California red scale on citrus. California Citrog. 34:6, 38-39.

DEWAR, W. R.

1905. First Annual Report Orange River Colony, Australia.

Ebeling, W.

1950. Subtropical entomology. 747 pp. Lithotype Process Co., San Francisco, California.

EHRHORN, E. M.

1905. Insects of the year. California State Comm. Hort. Bien. Rept. 1903-04:108-22.

Essig, E. O. (See especially pp. 112-13.)

1931. A history of entomology. 1029 pp. The MacMillan Co., New York, N.Y.

FERRIS, G. F.

1938. Chrysomphalus bifasciculatus, new species. S II-199. 2 p. In: Atlas of the scale Fitch, Asa insects of North America. Stanford Univ. Press, Stanford University, California.

1861. Sixth report on the noxious and other insects of the State of New York. N. Y. State Agr. Soc. Trans. 20 (for 1860):124-25, 745-868. (See specifically pp. 124$25,812-16$.

Flanders, S. E.

1930. Notes on the life history of Lindorus lophanthae. Ent. Soc. Amer. Ann. 23:594-96.

1934. The life histories of three newly imported predators of red scale. Jour. Econ. Ent. $27: 723-24$. 
1936. Coccidophilus citricola Brèthes, a predator enemy of red and purple scales. Jour. Econ. Ent. 29:1023-24.

1944a. The introduction and establishment of Habrolepis rouxi in California. Jour. Econ. Ent. 37:444-45.

1951. Mass culture of California red seale and its golden ehaleid parasites. Hilgardia $21(1): 1-42$.

1953a. Aphelinid biologies with implications for taxonomy. Ent. Soc. Amer. Ann. $46(1): 84-93$.

1953b. Hymenopterous parasites of three species of Oriental scale insects. Fxtract. Naples Univ. Facolta di Sci. Agraria, Portici. Lab. Zool. Gen. e Agraria Boll. $33: 10-28$.

1954. Report from Hong Kong. California Citrog. $39: 108,130-31$.

Flanders, S. E., and J. I. GressitT

1957. Natural control of California red scale in China. California Citrog. 43:73.

1958. The natural control of California red scale in China. California Dept. Agr. Bul. $47(1): 23-33$.

Freeborn, S. B.

1931. Citrus scale distribution in the Mediterranean basin. Jour. Econ. Ent. 24:1025-31. Froggatt, W.

1897. Coccids (scale insects) in Sydney gardens. Agr. Gaz. N. S. Wales 8(8):528-34.

1909. Report on parasitic and injurious insects. N. S. Wales Dept. Agr., Govt. Printer. GLover, $\mathrm{T}$.

1855. Report of the Commissioner of Patents for the year 1855:177. (Sce U. S. Dept. Green, E. E. Agr. Report of Entomologist for $1880: 344 ; 1881$.)

1896. The Coccidae of Ceylon, Part I, 103 pp. Dulau and Co., Ltd., London.

HAMILTON, H.

1890. Red scale (Aspidiotus aurantii). California State Board Hort. Rept. 1890:58-60.

HARNEY, G. W.

1891. The yellow scale-notes and recommendations. Yuba Co. Hort. Comm. Bul. 5.

HECKE, G. H.

1921. Pest control projects for the future. (Annual Report of I)irector of Agriculture.) California State Dept. Agr. Mo. Bul. 10:400-01.

HenRY, A. W.

1889. Pacific Coast work of the Division of Entomology. Insect Life 2(5):141-44.

Hout, L. M.

1877. Orange tree diseases. So. California Horticulturist 1:2.

1880. The red scale on citrus trees. Pacific Rural Press 19:67.

HORTON, J. R.

1918. The Argentine ant in relation to citrus groves. U. S. Dept. Agr. Bur. Ent. Bul. $647: 17$.

HOW ARD, L. O.

1881. Report on the parasites of the Coccidae in the collection of this Department. U. S. Dept. Agr. Rept. of the Entomologist for 1880:350-71. (See specifically p. 351.)

1894. The hymenopterous parasites of the California red seale. Insect Life 3:227-36.

1906. An interesting new genus and species of Encyrtidae. Ent. News 17(4):121-22.

1907. New genera and species of Aphelininae, with a revised table of genera. U. S. Bur. Ent. Tech. Ser. No. 12, part IV, pp. 83-84.

1908. Report of the Entomologist. U. S. Dept. Agr. Ann. Repts. 1907-08:527-69. Also published as a separate. 47 pp. (See p. 33.)

1909. Report of the Entomologist. U. S. 1)ept. Agr. Bur. Ent. pp. 491-531.

1930. A history of applied entomology. Smithsonian Misc. Coll. 84:1-564. (See specifically pp. 154-55.)

Howard, L. O., and W. F. Fiske

1911. The importation into the United States of the parasites of the gipsy moth and the brown-tail moth. U. S. Dept. Agr. Div. Ent. Bul. 91:1-312. (See specifically pp. 105-09.) 
IsAac, J.

1905. Bug vs. bug. California State Hort. Comm. Bien. Rept. 1903-04:79-107. Also printed as a separate, $26 \mathrm{pp}$. State Printing Office, Sacramento, Calif.

JENKINS, C. F. H.

1945. The citrus red scale. West. Australia Dept. Agr. Jour. 2d ser., 22(1):10-18.

JONES, E. P.

1936. The bionomics and ecology of red scale, Aonidiella aurantii Mask., in Southern Rhodesia. Mazoe Citrus Expt. Sta. Ann. Rept. for 1935. The British South African Company Pub. No. 5:15-52.

KLEE, W. G.

1887. Scale insects affecting citrus trees. California State Board Hort. Rept. 1885-86: $376-77$, illus.

1888. Red orange scale (Aspidiotus aurantii). California State Board Hort. Bien. Rept. $1887-88: 244-45$, illus.

KOEBELE, A.

1890. Report of a trip to Australia to investigate the natural enemies of the fluted scale. U. S. Dept. Agr., Div. Ent. Bul. 21:1-32.

1892. Expert's trip to foreign countries. pp. 7-12, In: Report on the importation of parasites and predaceous insects by the State Board of Horticulture. $15 \mathrm{pp}$.

1893. Studies of parasitic and predacious insects in New Zealand, Australia, and adjacent islands. Made by A. Koebele of the U. S. Dept. of Agric., by permission of the Secretary of Agriculture at the request of the California State Board of Horticulture. Published by permission of the Secretary of Agriculture, Washington, D.C. pp. 15-16.

LEBARON, W.

1870. The chalcideous parasite of the apple-tree bark louse (Chaleis) [Aphelinus] mytilaspidis n. sp. Amer. Ent. and Bot. 2:360-62.

LELONG, B. M.

1887. [Transcription of a public debate between C. V. Riley and B. M. Lelong at Seventh State Fruit Growers Convention.] California State Board Hort. Bien. Rept. 1885-86:468-70.

1890a. California State Board of Horticulture Ann. Rept. $1889: 1-536$.

1890b. California State Board of Horticulture Ann. Rept. 1890:1-521.

$1890 \mathrm{c}$. Fruit culture. 20 pp. Supt. State Printing, Sacramento.

LOUNSBURY, C. P.

1901. Report of the Government Entomologist for the year 1900. pp. 23-27. Cape of Good Hope Dept. Agr

1940. The pioneer period of economic entomology in South Africa. Ent. Soc. So. Africa Jour. 3:9-29.

Marlatt, C.

1906. The San Jose or Chinese scale. U. S. Bur. Ent. Bul. 62:63, 65-69.

MASKell, W. M.

1879. On some Coccidae in New Zealand. New Zealand Inst. Trans. 11:187-288.

MCKenzie, H. L.

1937. Morphological differences distinguishing California red scale, yellow scale, and related species. California Univ. Pubs. Ent. 6(13):323-36.

MerRIlL, C. B.

1953. A revision of the scale insects of Florida. Florida State Plant Board Bul. 1:1-143.

NEL, R. G.

1933. A comparison of Aonidiella aurantii and Aonidiella citrina, including a study of the internal anatomy of the latter. Hilgardia 7(11):417-66.

Newell, Wilmon, and T. C. BARBer

1913. The Argentine ant. U. S. Dept. Agr. Bur. Ent. Bul. 122:63-64, 92-93.

Newman, L. J.

1909. Beneficial insects. West. Australia Dept. Agr. Jour. 18 (5) : 377 .

1922. Report of Economic Entomologist. West. Australia Dept. Agr. Ann. Rept. p. 29.

1924. Report of Economic Entomologist. West. Australia Dept. Agr. Ann. Rept. p. 22.

1925. Report of Economic Entomologist. West. Australia Dept. Agr. Ann. Rept. p. 22.

1926. Report of Economic Entomologist. West. Australia Dept. Agr. Ann. Rept. p. 30. 
1927. Report of Economic Entomologist. West. Australia Dept. Agr. Ann. Rept. p. 27.

1928. Report of Economic Entomologist. West. Australia Dept. Agr. Ann. Rept. p. 29.

1945. Entomology. West. Australia Dept. Agr. Ann. Rept. p. 34.

1948. Entomology. West. Australia Dept. Agr. Ann. Rept. p. 29.

1949. Entomology. West. Australia Dept. Agr. Ann. Rept. p. 36

Nicholson, J. A.

1947. Fluctuation of animal populations. Australian and New Zealand Association for the Advancement of Science. Section D. Zoology. Perth meeting, August 1947. Presidential Address, $14 \mathrm{pp}$.

OMER-COOPER, J., and G. B. WhiteHEAD

1950. Studies on the biological control of red scale in the Eastern Cape Province. Introduction. The Citrus Grower [Union of So. Africa] 195:3, 12.

Pye, S. W.

1879. Orange growing in Australia. Pacific Rural Press 18:120.

QUAYLE, H. J.

1911. The red or orange scale. California Agr. Exp. Sta. Bul. 222:99-150. (See specifically pp. 142-44.)

RAFFERTY, FRED

1906. Orange County. California State Comm. Hort. Bien. Rept. 1905-06:291-92.

RILEY, C. V.

1869. First annual report on the noxious, beneficial and other insects of the State of Missouri (Jefferson City, Mo.).

1886. Report of the Commissioner of Agriculture, U. S. Dept. Agr. 1886:488-89.

1887. Address [at Seventh State Fruit Growers Convention]. California State Board Hort. Bien. Rept. 1885-86:450-62. Discussions pp. 462-71.

1889. The importation of parasites and predaceous insects. pp. 89-93. In: Report of the Entomologist, U. S. Dept. Agr. Rept. 1888:53-144. (See specifically p. 89.)

1890. General notes: Damage by red scale growing less. Insect Life 3(6):302.

1891. Remedies for the yellow scale. Insect Life 3(9-10):421.

1892. An Australian Scymnus established and described in California. Insect Life $5(2): 127-28$.

1893a. Parasitic and predaceous insects in applied entomology. Insect Life 6(2):130-41. $1893 b$. A new parasite of the red scale. Insect Life $5: 207-08$.

RothsCHILD, M., and T. ClaY

1952. Fleas, flukes, and cuckoos. 304 pp. Philosophical Library, New York, N.Y.

RUST, E. W.

1915. Three new species of Aphelinus (Hym.). Ent. News $26: 73-77$.

SHAw, B. C.

1920. Chalcid wasp parasites for scale efficacious in Australia. California Citrog. 6:56.

Silvestri, F.

1930a. Preliminary report on the citrus scale-insects of China. Fourth International Congress of Entomology, Ithaca, New York, Trans. 2:898-904.

1930b. Contributo alla conoscenza delle specie orientali del genere Prospaltella (Hym. Chalcididae). Estratto. Naples Univ. Facolta di Sci. Agraria, Portici. Lab. di Zool. Gen. e Agraria Boll. 25:49-68.

SмIтH, H. K.

1906. Riverside County. California State Comm. Hort. Bien. Rept. 1905-06:294.

SMITH, H. S.

1920. Report of the pest control service. California State Dept. Agr. Mo. Bul. 9(1011) :417-21. (See specifically p. 421.)

1923. Biological control work. California State Dept. Agr. Mo. Bul. 12(7-12):334-37.

1935. The role of biotic factors in the determination of population densities. Jour. Econ. Ent. $28: 873-98$.

SMITH, J. M.

1957. Effects of the food plant of California red scale, Aonidiella aurantii (Mask.) on reproduction of its hymenopterous parasites. Canad. Ent. $89(5): 219,230$.

Southern California Horticultural Society

1878. Report of committee. So. California Horticulturist 1(4). 
STEYN, J. J.

1954a. The pugnacious ant (Anoplolcpis custodicns Smith) and its relation to the control of eitrus seale insects at Letaba. Ent. Soc. So. Africa Mem. 3:1-196.

1954b. The effect of the cosmopolitan brown house ant (Pheidole megacephala F.) on citrus red scale at Letaba. Jour. Ent. Soc. So. Africa $17(2): 252-64$.

1955. The effect of mixed ant populations on red scale (Aonidirlla aurantii Mask.) on citrus at Letaba. Jour. Ent. Soc. So. Africa 18(1):93-105.

STOFBERG, F. S.

1937. The citrus red seale (Aonidiella aurantii Mask.). Union So. Africa Dept. Agr.

StRENTZeL. J. and Forestry (Plant Industry Ser. 24) Sci. Bul. 167:13.

1877. Wood ashes for scale and other insects. Pacific Rural Press 13:147.

SUMMERVILIE, W. A. T.

1934. Queensland citrus scale insects and their control. Queensland Agr. Jour. $41(5): 450-86 ; 41(6): 568-91 ; 42(2): 186-207$.

ULILYETT, G. C.

1946. Red scale on citrus and its control by natural factors. Farming in South Africa, May, 1946. Reissued as reprint No. 25, Dept. Agr., Pretoria. p. 3-5.

VOSLER, E. J.

1913. Recent importations of beneficial insects in California. California State Comm. Hort. Mo. Bul. 2(12):770.

Western Australia Minister of Agriculture

1906. Red scale parasite. West. Austral. Jour. Dept. Agr. 13(5):383; 14(1):5.

WICKSON, E. J.

1879. (Editor, Pacific Rural Press, anonymously.) Pacific Rural Press, Sept. 27, p. 200.

WOGLUM, R. S.

1913. Report of a trip to India and the Orient in search of the natural enemies of the citrus white fly. U. S. Bur. Ent. Bul. 120:1-58.

WoODWORTH, C. W.

1908. The theory of parasite control of insect pests. Science $28: 227-30$. 


$$
\text { . }
$$





\section{CONTENTS}

Early references to red scale, p. 173

Other early citrus scales, p. 177

Early advocates of biological control, p. 178

Policies, politics, and personalities, p. 181

The controversy over the distinction between red and yellow scales, p. 186

Parasites of the yellow scale, p. 189

Early reports of red-scale predators in California, p. 191

Early reports of red-scale parasites in California, p. 193

Koebele's reports on his second trip to Australia, and Rhizobius, p. 197

George Compere's work, p. 199

Australia, p. 200

Hong Kong, p. 201

Cooperative project between Western Australia and California, p. 202 The dispute over Apbytis species, p. 204

Changes of policy and personnel, p. 207

Importation of parasites from Japan, p. 213

Trials with local predators, p. 215

Observations on Aphytis chrysomphali, p. 217

Silvestri's mission to the Orient, p. 218

Harold Compere's reports, p. 222

New South Wales, p. 222

Preparations for the Asian trip, p. 224

Japan, p. 226

Bombay, p. 227

Poona, p. 229

Nagpur, p. 230

Other Indian districts, p. 231

China ports, p. 233

Predators, p. 234

South America, p. 234

Africa, $1936-37$, p. 238

Africa, $1946-47$, p. 241

Reports from Africa, p. 246

Reports from Australia, p. 251

Discussion, p. 258

Biotic versus abiotic factors, p. 258

Unfavorability of citrus to red scale, p. 261

Systematics, p. 264

Summary and conclusions, p. 270

Acknowledgments, p. 273

Literature cited, p. 273 
The journal Hilgardia is published at irregular intervals, in volumes of about 600 pages. The number of issues per volume varies.

Subscriptions are not sold. The periodical is sent as published only to libraries, or to institutions in foreign countries having publications to offer in exchange.

You may obtain a single copy of any issue free, as long as the supply lasts; please request by volume and issue number from:

\author{
Agricultural Publications \\ 207 University Hall \\ 2200 University A venue \\ Berkeley 4, California
}

The limit to nonresidents of California is 10 separate issues on a single order. A list of the issues still available will be sent on request. 